\title{
Diversidad y distribución de los endemismos de Asteraceae (Compositae) en la Flora del Ecuador
}

\author{
A. O. RIVERO-GUERRA \\ Universidad Estatal Amazónica, Programa de Ecosistemas, Biodiversidad y Conservación de Especies, Paso Lateral \\ Km 2 1/2, v. Puyo-Tena, EC-160150 Puyo, Ecuador
}

ORCID iD. A. O. RIVERO-GUERRA: https://orcid.org/0000-0001-6908-8061

E-mail: rivero-guerra@hotmail.com; arivero@uea.edu.ec

Editor: N. Garcia-Jacas

Recibido 30 noviembre 2017; aceptado 16 julio 2019; publicado on line 12 marzo 2020

\begin{abstract}
Diversity of ENDEMIC SPECIES of AsteraceAe (Compositae) In THE Flora of EcuAdor.- The family Asteraceae is represented in the Flora of Ecuador by a total of 310 endemic taxa. There are grouped into 4 subfamilies (Asteroideae, Barnadesioideae, Cichorioideae and Mutisioideae), 16 tribes, and 89 genera. The habitat of two hundred and seventy-two taxa $(87.74 \%)$ is restricted to the Andean Region. The highest levels of endemism are associated with the Andes, and are to be found in a great majority in the high Andean forest up to the moorlands, and in the Galapagos Islands. The genera that show the greatest extent of endemism are: Mikania (26), Pentacalia (23), and Gynoxys (20). Three monotypic genera are endemic: Cyathomone, Idiopappus and Trigonopterum. The genera Darwiniothamnus, Kingianthus, Lecocarpus, and Scalesia are also endemic. The diversity of the family increases from $2000 \mathrm{~m}$ to $3000 \mathrm{~m}$ above sea level, achieving its maximum between 2900-3000 m, with a dominance of shrubby (195 species, 1 subspecies, 2 varieties) and herbaceous (97 species) plants. One hundred and twenty-six species are considered vulnerable, 90 are in danger of extinction, and 24 are critically threatened. Mean annual temperature and precipitation show significant statistical variation between biogeographical sectors.
\end{abstract}

Key words: altitudinal gradient; eco-regions; Ecuador, endemism; geographical distribution; risk of extinction.

\section{Resumen}

Diversidad de endemismos de ASTERACEAE (COMPOSITAE) EN LA Flora Del ECUAdor. - La familia Asteraceae está representada en la Flora de Ecuador por un total de 310 táxones endémicos. Están agrupadas en 4 subfamilias (Asteroideae, Barnadesioideae, Cichorioideae y Mutisioideae), 16 tribus y 89 géneros. Doscientas setenta y dos táxones $(87,74 \%)$ restringen su hábitat a la región andina. Los niveles más altos de endemismos están asociados a los Andes, mayoritariamente desde el bosque andino alto hasta el páramo, y a las Islas Galápagos. Los géneros con mayor riqueza de endemismos son Mikania (26), Pentacalia (23), y Gynoxys (20). Tres géneros monotípicos son endémicos: Cyathomone, Idiopappus y Trigonopterum. Los géneros Darwiniothamnus, Kingianthus, Lecocarpus, y Scalesia también son endémicos. La diversidad de la familia se incrementa desde los $2000 \mathrm{~m}$ a $3000 \mathrm{~m}$, alcanzando su mayor riqueza entre los 2900-3000 m, con dominancia de las plantas arbustivas (195 especies, 1 subespecie, 2 variedades) y herbáceas (97 especies). Ciento veinteseis especies tienen categoría de vulnerable, 90 están en peligro de extinción y 24 están en estado crítico de amenaza. Las temperaturas y precipitaciones medias anuales varían significativamente entre los sectores biogeográficos.

Palabras clave: distribución geográfica; ecorregiones; Ecuador; endemismos; gradiente altitudinal; riesgo de extinción.

Cómo citar este artículo / Citation

Rivero-Guerra, A. O. 2020. Diversidad y distribución de los endemismos de Asteraceae (Compositae) en la Flora del Ecuador. Collectanea Botanica 39: e001. https://doi.org/10.3989/collectbot.2020.v39.001

Copyright

(C) 2020 CSIC. This is an open-access article distributed under the terms of the Creative Commons Attribution 4.0 International (CC BY 4.0) License. 


\section{INTRODUCCIÓN}

La biogeografía permite estudiar los patrones de distribución de las especies de un ecosistema o región (Aranguren et al., 2008). La biodiversidad no se distribuye de forma homogénea (Suárez-Mota \& Villaseñor, 2011) al estar influenciada por su perfil ecológico, bioclimático (Cilia-López et al., 2014), edáfico y geológico (Kruckeberg, 2002). La misma se concentra en áreas megadiversas, que destaca especial interés su protección y conservación por la alta riqueza de especies que alberga y por ser el centro de origen y diversificación de gran parte de su diversidad, particularmente de endemismos (Pressey et al., 1993; Mittermeier, 1988; Akeroyd \& Synge, 1992; Suárez-Mota \& Villaseñor, 2011).

Las principales causas de la pérdida de la biodiversidad de plantas a escala mundial son: el aumento de la población humana, el cambio de uso de suelo, la deforestación, el sobrepastoreo, la extracción y comercio ilegal, la introducción de especies exóticas y el cambio climático (Royo-Márquez et al., 2013).

El Neotrópico (entre el Trópico de Cáncer y el de Capricornio) es la región biogeográfica con la mayor biodiversidad del planeta (Prance, 1994; Myers et al., 2000). Los ecosistemas andinos son los más complejos de la región con un porcentaje estimado del $25 \%$ de la diversidad biológica a nivel mundial; variabilidad ecológica y florística que se muestra en todo su gradiente altitudinal (Jørgensen et al., 2006).

\section{Origen geológico de la Coordillera de los Andes}

La Cordillera de los Andes ocupa una extensión aproximada de $8000 \mathrm{~km}$ (Clapperton, 1993) y atraviesa el continente sudamericano de norte a sur. Está subdividida en tres secciones según su período de origen geológico y complejidad tectónica: norte, centro y sur (Cuesta et al., 2012). Verticalmente presenta cuatro zonas: subandina, andina, altoandina y nieve perenne (Morillo \& Briceño, 2000). Su origen comenzó a fines del Cretácico (Mesozoico) (Antonelli \& Sanmartín, 2011), debido al intenso vulcanismo submarino y terrestre que se inició en el Jurásico (201-145 Ma) y alcanzó su máxima actividad en el Cretácico (López Ramos, 2001). Los Andes Australes (Argentina y Chile) son los más antiguos (Neill, 1999a). Los Andes Centrales conforman una gran meseta (altiplano) compartida por el Norte de Argentina y Chile, occidente de Bolivia y el sur de Perú (Morillo \& Briceño, 2000), muestran dos períodos de levantamiento: el primero hace $20 \mathrm{Ma}$ y el segundo hace $10 \mathrm{Ma}$ en el Mioceno-Plioceno (Gregory-Wodzicki, 2000; Pennington \& Lavin, 2017). En cambio, los Andes del Norte (Ecuador, Colombia y Venezuela) reflejan tres períodos de levantamiento, el primero hace $25 \mathrm{Ma}$ (Oligoceno-Mioceno) y los otros dos hace 5 a 1,5 Ma (Plioceno-Holoceno) (Van der Hammen, 1974; Neill, 1999a; Antonelli \& Sanmartín, 2011; Cuesta et al., 2012). Esta sección de la cordillera es fragmentada en valles y sierras que genera heterogeniedad de hábitats y climas (Richter \& MoreiraMuñoz, 2005).

La flora y vegetación andina probablemente se diferenciaron a mitad del Mioceno (Neógeno) y se adaptaron a las distintas altitudes (Van der Hammen, 1974; Morillo \& Briceño, 2000), lo que favorece la migración de especies de la flora templada $\mathrm{y}$ austral hacia las cumbres y origina especiación in situ (Morillo \& Briceño, 2000).

Los Andes Tropicales (Andes del Norte y Centro, $4000 \mathrm{~km}$ ) (Myers et al., 2000) están formados por dos cadenas montañosas paralelas (Occidental y Oriental) de pendientes fuertes que se extienden de norte a sur y están separadas por menos de 200 $\mathrm{km}$ de valles interandinos que se caracterizan por presentar una vegetación de bosque seco y semiárida (Neill, 1999a, b; García et al., 2014), además, de las Cordilleras de Galeras, Cutucú y Cóndor de plegamiento tectónico que se localizan hacia el este (Neill, 1999a, b). Biogeográficamente, es un área anisotrópica variable (Zunino \& Zullini, 2003) con una triple función en correspondencia con los requerimientos ecológicos y la historia evolutiva de las especies (Jørgensen et al., 2006; Jiménez et al., 2017; Pennington \& Lavin, 2017).

Los cimientos de la Cordillera Oriental o Real son del Paleozoico, 541-252 Ma (Jaillard et al., 2008) sobre rocas metamórficas (pizarras, esquistos, gneis) del Precámbrico que están plegadas, comprimidas y orientadas de NNE-SSO (Nieto, 1991; INIGEMM, 2017). El inició de su levantamiento data del Cretácico, $145 \mathrm{Ma}$ (López Ramos, 2001; Rodríguez-Peces \& Gordón-Pérez, 2015). Aparentemente su actividad volcánica ha sido superior a la Cordillera Occidental. Litológicamente está formada por lutitas y areniscas cuarcíticas 
(Devónico); calizas (Carbonífero); esquistos (Devónico-Jurásico); tobas, andesitas y lavas (EocenoOligoceno); granidioritas (Paleoceno-Mioceno); turbiditas (Pre-cretácicas) y arcillas (Paleógeno; Nieto, 1991; Pilatasig et al., 2005; INIGEMM, 2017).

La Cordillera Occidental de los Andes es más joven geológicamente que la Cordillera Oriental (INIGEMM, 2017), problamente con una actividad volcánica inferior a la Cordillera Oriental y al sector interandino. Tienen su origen en la meseta oceánica y en el arco volcánico del Cretácico-Paleógeno, formación Macuchi (145-66 Ma, Jaillard et al., 2008). Está formada por rocas volcano-clásticas, andesitas y lava en forma de almohadilla que se depositaron hasta el Eoceno y que se emplazaron tectónicamente, además de los depósitos marinos y volcánicos del Eoceno al Holoceno (Nieto, 1991). Se resaltan los aportes de materiales detríticos de la Cordillera Oriental que intervinieron en su formación, principalmente en la provincia de Cuenca (Vallejo et al., 2009). Más del 50\% de la cordillera está formada por rocas ígneas (dacitas, andesitas, granitoides) del Cretásico superior con bajo contenido en sílice y alto contenido de hierro y magnesio, además de cenizas, rocas sedimentarias (arenisca, lititas, turbiditas), entre otros; los depósitos de rocas volcánicas del Cuaternario ocupan el 10\% de su superficie (INIGEMM, 2017).

El sector interandino es una depresión de 2500$3000 \mathrm{~m}$ de altitud que pertenece al arco continental Paleógeno-Cuaternario, 66-0,01 Ma (Jaillard et al., 2008) con cuencas o fosas formadas por la actividad tectónica y provistas de sedimentos fluviolacustres, localmente fluvio-glaciares cuaternarios (areniscas, arenas, conglomerados, arcillas), además de los depósitos provenientes de las emisiones volcánicas (coladas, lahares, proyecciones, cineritas, cenizas cementadas o cangahua; García Cruzatty \& Schlatter Vollmann, 2012). Estas cuencas son prominentes y contínuas hacia el norte, lo inverso se produce hacia el sur del país (Nieto, 1991).

\section{Diversidad de suelos en Ecuador continental}

Desde el norte de la Cordillera Oriental hasta los límites provinciales de Morona Santiago con Cuenca dominan los suelos andisoles, con presencia de ultisoles en la zona fronteriza con Colombia, además de parches de inceptisoles. La Cordillera Oriental presenta un cambio en los tipos de suelo cerca de los límites entre Cuenca-Cañar-Morona Santiago, con predominio de los suelos del tipo inceptisol, seguidos en relevancia por los alfisoles, entisoles, ultisoles y molisoles. Se hace énfasis en relación al mosaico de suelos existente al este en la provincia de Cuenca de inceptisoles, molisoles, entisoles y alfisoles (Mapa 1:25000/SIG Tierras-IEECGSIN/2009-2015, http://www.sigtierras.gob.ec/ mapa-de-ordenes-de-suelos). Los suelos de la zona occidental del Parque Nacional Podocarpus son franco y franco arenosos, ricos en materia orgánica y nitrógeno que favorece la retención de la humedad en el suelo (Lozano et al., 2007).

En la Cordillera Occidental y en los valles interandinos predominan los andisoles y molisoles, con escasa representación de entisoles, aridisoles y alfisoles, concentrados en la provincia de Cuenca (Mapa 1:25000/SIG Tierras-IEE-CGSIN/2009-2015; García Cruzatty \& Schlatter Vollmann, 2012).

Los procesos geotectónicos acaecidos millones de años atrás en el norte de América del Sur configuraron su geografía y sentaron las bases para un proceso de diversificación de especies a gran escala en el continente cuya diversidad se fundamenta en múltiples procesos evolutivos que pudieron haber interactuado a escala espacial y temporal, mientras que otros procesos evolutivos, climáticos y biogeográficos intervienen en su estabilidad, expansión, contracción o extinción (Antonelli \& Sanmartín, 2011; Rull, 2011). Estas evidencias han quedado sustentadas a través de filogenias moleculares y el registro fósil (Hoorn et al., 2010).

\section{EI clima}

Ecuador se localiza en la Zona de Convergencia Intertropical (ZCIT) y recibe la influencia del patrón climático "El Niño-Oscilación del Sur, ENOS", la Vaguada del Perú, las Perturbaciones de la Amazonía, el Alta Semipermanente del Pacífico Suroriental, la Alta del Caribe (Urdiales \& Célleri, 2018), y la Oscilación Decadal del Pacífico (Serrano Vincenti et al., 2012). Las corrientes cálidas ecuatoriales de norte y sur, la contracorriente ecuatorial del norte y la corriente fría de Humboldt influyen marcadamente sobre el clima de Ecuador continental e insular (Pourrut et al., 1995; Samaniego-Rojas et al., 2015). Las Islas Galápagos reciben, además, 
el efecto de la Corriente de Cronwell (Cromwell et al., 1954); y los Frentes Intertropical y Ecuatorial hacen posible la existencia de dos estaciones lluviosas en el archipiélago (Pourrut, 1986).

La convergencia de los vientos Alisios del noreste y del sureste produce un marcado gradiente vertical y asimétrico de termperaturas en Ecuador, además de ocasionar intensa niebla y precipitaciones extremas durante casi todo el año en la región Amazónica ecuatoriana (llanuras aluviales, vertiente oriental de los Andes y Cordilleras Amazónicas), y de elevar las masas de aire de la tropósfera inferior (Richter \& Moreira-Muñoz, 2005).

Los vientos Alisios del Pacífico viajan de Sur a Norte en el litoral ecuatoriano. Esta región recibe la influencia del Anticiclón del Pacífico y ocasionalmente de la Vaguada del Sur (Peralta et al., 2016), con un incremento de las precipitaciones hacia la Cordillera Occidental condicionadas a su orografía. El fenómeno de "El Niño" produce intensas lluvias en ambas regiones, mientras que el evento "La Niña" produce sequía en las llanuras costeras (Luna-Romero et al., 2018).

En la Cordillera Occidental los vientos Alisios del Pacífico se superponen con los que provienen del este y generan fuertes corrientes de chorro en la zona de transición entre la tropósfera y la estratósfera que producen intensa nubosidad y niebla, incluso, por debajo de las crestas (Richter \& Moreira-Muñoz, 2005), además de una disminución de la pluviosidad a cotas altitudinales elevadas (LunaRomero et al., 2018).

En el sur de Ecuador se pierde la individualidad de la Cordillera Occidental y predomina la Cordillera Oriental, con un patrón heterogéneo de precipitaciones hacía el occidente y es una zona menos seca que el sector interandino (Richter \& MoreiraMuñoz, 2005), con altas precipitaciones de carácter permanente en la vertiente oriental de la cordillera. Los vientos Alisios soplan en distintas direcciones de Sur a Norte en invierno (julio) y de Norte a Sur en verano (febrero) formando nubes de turbulencia en las cumbres de ambas cordilleras, que generan vientos catabáticos secos, calientes y permanentes que descienden hacia el sector interandino con marcada influencia al sur de Ecuador (Richter \& Moreira-Muñoz, 2005).

En el sector interandino, las zonas de mayor altitud son extremadamente húmedas durante todo el año ("efecto Merriam") con un gradiente vertical de precipitaciones marcado y altas tasas de evaporación, principalmente en la vertiente de sotavento; en este sector el ascenso o descenso de las temperaturas a escala altitudional está directamente correlacionado con la aridez o la intensidad pluvial, respectivamente (Richter \& Moreira-Muñoz, 2005).

Los Andes despliegan una topografía compleja que favorece las condiciones físicas variadas para la formación de diversos hábitats y constituye una fuerte barrera a la dispersión de las especies (Anderson et al., 2011; Jost, 2011; Martínez et al., 2011), a la formación de corredores y a la vicarianza. La elevación de los Andes es la causa de los regímenes de precipitación altamente diferenciados en los flancos oriental y occidental de la cordillera. Interviene en la formación, ocurrencia y distribución espacial y temporal de las precipitaciones, con doble efecto barrera a las corrientes húmedas procedentes del Atlántico y del Pacífico (Urdiales \& Célleri, 2018). En la medida que se avanza en el gradiente altitudinal se produce una reducción de la evapotranspiración, se incrementa de nubosidad y la niebla, se produce un descenso en la temperatura, se acentúan las fluctuaciones de la temperatura entre el día y la noche, se modifica la composición florística y sube la tasa de endemismos (Larsen et al., 2011; Young, 2011).

\section{Diversidad de plantas en Ecuador}

Ecuador ocupa una superficie de $256.370 \mathrm{~km}^{2}$ (Ulloa Ulloa et al., 2017), no más del $0,02 \%$ de la superficie terrestre a escala mundial y está incluido en la lista de los 17 países "megadiversos" (Mittermeier et al., 1997 citado por Neill, 2012). El país consta hasta el 2012 con 17.748 especies nativas de plantas vasculares, 1422 del total corresponden a pteridófitos, 18 a gimnospermas y 16.308 a angiospermas, con unas 5500 especies endémicas aproximadamente (Neill, 2012); estas cifras son superiores a las reportadas por Ulloa Ulloa et al. (2017: 17.548 especies de plantas vasculares, 5480 del total son endémicas). El paisaje muestra una marcada heterogeneidad como consecuencia de factores orográficos, climatológicos y fitogeográficos (Jørgensen et al., 2006). Desde el punto de vista biogeográfico se divide en cuatro regiones naturales: Andes, Amazonía, Litoral e Insular (Neill, 1999b; Jørgensen et al., 2006; García et al., 2014). 
La región Amazónica ecuatoriana representa el $30 \%$ del territorio nacional y el $1,6 \%$ del total del área amazónica de América del Sur, que se extiende al este de las estribaciones orientales de los Andes desde la frontera con Colombia hasta la frontera con Perú (Muriel, 2008). Los bosques de tierra firme y los inundados o inundables dominan la región Amazónica (250-3100 m, García et al., 2014), que se caracterizan por la dominancia de árboles, bejucos y epífitas.

El Litoral ocupa la región entre el Océano Pacífico y el piedemonte de los Andes, que incluye la cuenca del río Guayas, el río Esmeraldas y las cordilleras paralelas a la costa desde Esmeraldas hasta Guayaquil (Neill, 1999b; García et al., 2014). Se subdivide en tres subregiones (norte, centro y sur) que muestran un marcado gradiente desde el bosque húmedo o muy húmedo hasta formaciones muy áridas al sur de Ecuador, que influye en su alto nivel de endemismos (Muriel, 2008). La subregión norte ocupa desde la frontera con Colombia hasta la provincia de Manabí, le sigue la subregión centro que se extiende hasta el sur de la provincia de El Oro y por último la subregión sur hasta el límite fronterizo con Perú (Muriel, 2008). La región insular contempla las 121 islas del archipiélago de Galápagos de origen volcánico (Snell et al., 1995), que ocupa una superficie terrestre de $8010 \mathrm{~km}^{2}$ (García et al., 2014).

\section{Asteraceae: riqueza \& diversidad}

Los patrones de riqueza-diversidad y endemismos varían según el grupo taxonómico estudiado (Pennington \& Lavin, 2017). Asteraceae, es la mayor familia de plantas vasculares (Panero \& Funk, 2008) con 25.037 especies (Panero \& Crozier, 2016) que representa el $8 \%$ de toda la flora mundial (Panero \& Funk, 2008; Funk et al., 2009) y la segunda en importancia en América (12.043 especies; Ulloa Ulloa et al., 2017). A escala global, la diversidad de $A s$ teraceae queda repartida de la siguiente manera en orden descendente (Panero \& Crozier, 2016): América del Sur (6316 especies), Asia (6016 especies), América del Norte (5404 especies), África (4631 especies), Europa (2283 especies), Oceanía (1444 especies), y las Islas del Pacífico (174 especies).

Los datos publicados por Ulloa Ulloa et al. (2017) para América reflejan que México es el país con mayor diversidad de Asteraceae (3045 especies) y en orden descendente le siguen los países que conforman América del Norte (2173 especies), el Cono Sur (2008 especies), Brasil (1996 especies), Colombia (1202 especies), Bolivia (1184 especies), Ecuador (995 especies), América Central (896 especies), Venezuela (718 especies), Indias Occidentales (644 especies) y las Guayanas (142 especies). La diversidad se concentra en la supertribu Helianthodae con 3159 especies en América del Norte y 2535 especies en América del Sur (Panero \& Crozier, 2016). La mayor diversidad de la supertribu Senecionodae ocurre en América del Sur (1214 especies), mientras que la máxima representatividad de la supertribu Asterodae está en África (1900 especies) y Asia (1650 especies); en Oceanía es el grupo con mayor representatividad (1127 especies, Panero \& Crozier, 2016). A nivel global la supertribu Asterodae presenta 7109 especies (Panero \& Crozier, 2016), que representa el 28,39\% del total de la familia. Se destaca que la diversidad de Cichorioideae se produce en América del Sur, África, Asia y Europa. Asia, es el continente con mayor riqueza de especies de Carduoideae (Panero \& Crozier, 2016).

Su distribución es cosmopolita, excepto en la región Antártica (Funk et al., 2005; Aranguren et al., 2008) y muestra un amplio espectro altitudinal, con un predominio en las regiones templadas (Beltrán, 2016) y en las regiones cálidas y semiáridas de los trópicos y subtrópicos (Roque et al., 2016); su diversidad decrece en los bosques tropicales (Beltrán, 2016). Concentran su diversidad en los Andes de Sudamérica (Funk et al., 1995, 2005; Aranguren et al., 2008), particularmente en los páramos (Aranguren et al., 2008) que son uno de los ecosistemas más recientes de los Andes (2,5-3,0 Ma; cf. Van der Hammen, 1974; Morillo \& Briceño, 2000) localizados a altitudes por encima de los $3200 \mathrm{~m}$.

La Cordillera Andina es muy diversa en representantes de esta familia (303 géneros y 3424 especies, Funk et al., 1995). Los datos filogenéticos y paleontológicos sugieren que la familia se originó en la región andina (Katinas et al., 1999, 2007), aunque Stuessy et al. (1996) ubica su centro de origen en la Patagonia, con centros secundarios de diversificación importantes en las regiones Mediterránea, del Cabo, Australia, México y los Andes (Funk et al., 2005). Los estudios de Panero \& Funk (2008) confirman el origen de la familia Asteraceae en América del Sur y que su dispersión ocurrió previo a la separación de este continente de América 
del Norte y África; después tuvo lugar una radiación explosiva desde el continente africano al resto del mundo, lo que enfatiza su gran capacidad de dispersión a grandes distancias y su habilidad para establecerse y adaptarse con éxito a nuevos hábitats.

Los datos palinológicos sugieren que al final del Oligoceno (20-25 Ma) muchas tribus ya existían y que durante el Mioceno se produjo una explosión evolutiva, acompañada de procesos de diversificación (Germeraad et al., 1968; Muller, 1970; Salgado-Labouriau, 1982; Morillo \& Briceño, 2000). Los resultados publicados por Panero \& Crozier (2016) indican lo siguiente: (1) la divergencia de Goodeniaceae del clado Calyceraceae-Asteraceae se produjo hace aproximadamente $75,2 \mathrm{Ma}$; (2) la divergencia de Asteraceae de Calyceraceae ocurrió hace 69,5 Ma, a fines del Cretácico, cerca del límite Cretácico-Paleoceno; (3) se estima que el origen de las familias Calyceraceae y Asteraceae ocurrió hace 39,2 Ma (Eoceno tardío) para la primera y 64,75 Ma (Paleoceno temprano) para la segunda, difiriendo en $25 \mathrm{Ma}$; (4) las 13 subfamilias de $\mathrm{As}$ teraceae se originaron en el Paleoceno y Eoceno entre 64,75 y 43,2 Ma.

Es importante destacar que la diversidad de Asteraceae ha sido empleada como modelo para estimar la riqueza total de plantas y como indicador de áreas prioritarias a conservar (Rzedowski, 1991; Villaseñor \& Ortiz, 2007, 2012). Presentan una amplia variación o plasticidad en el hábito de crecimiento, las características del vilano, el desarrollo de inflorescencias especializadas provistas de estructuras florales con presentación secundaria del polen que han coevolucionado directamente con sus diversos sistemas de cruzamiento y con sus mecanismos de polinización y dispersión (Panero \& Funk, 2008; Panero et al., 2014), así como la producción de gran cantidad de metabolitos secundarios (Panero \& Funk, 2008). Su radiación evolutiva fue impulsada por la arquitectura compleja del capítulo y sus transiciones adaptativas, en especial por la expansión y evolución de los genes de tipo CYC2 que contribuyen a su complejidad (Chen et al., 2018). Se destacan los procesos de poliploidización y diploidización que promueven el incremento de la tasa de especiación (Rivero-Guerra, 2008, 2009; Rivero-Guerra \& Laurin, 2012; Panero \& Crozier, 2016). Su diversidad, origen y distribución ofrece una excelente oportunidad para comprender la reciente radiación y adaptación de este grupo de plantas a escala global (Panero \& Funk, 2008).

Esta familia es relevante en la agricultura (para el consumo humano y animal, como malezas, y por sus propiedades tóxicas e insecticida), en jardinería (uso ornamental), en apicultura (donadoras de néctar y polen), en la industria alimentaria (aceites comestibles, especias), en la industria farmacéutica y cosmética (metabolitos secundarios con actividad biológica y aceites esenciales) y en la industria maderera (madera, leña y celulosa, Del Vitto \& Petenatti, 2009; Oliveira Amorim \& Pousada Bautista, 2016).

La familia Asteraceae está escasamente estudiada en Ecuador a pesar de constituir la segunda familia en importancia en cuanto a número de especies (217 géneros, 7 de ellos endémicos, y 918 especies, de las cuales 370 son endémicas; cf. Jørgensen \& León-Yánez, 1999; Katinas et al., 2007). León Yánez (2011) determinó 361 especies endémicas de Asteraceae para Ecuador, que representan el $8 \%$ del total de endemismos de la flora nacional, que alberga 746 especies nativas en el bosque andino. El primer suplemento de la Flora de Ecuador (Ulloa Ulloa \& Neill, 2005) adiciona 33 nuevos táxones a esta familia, 17 de los cuales en el género Mikania Willd.; el segundo suplemento (Neill \& Ulloa Ulloa, 2011) incluye 13 nuevas especies, 13 registros nuevos y 2 cambios taxonómicos, para un total de 28 adiciones y cambios.

Se ha avanzado en el conocimiento taxonómico de escasos géneros de Asteraceae representados en la Flora de Ecuador. Los géneros estudiados son: Acmella Pers. (Jansen, 1985), Aldama La Llave (Schilling \& Panero, 2011), Barnadesia Mutis (Urtubey, 1999), Clibadium F. Allam. (Arriagada, 2003; Pruski, 2005), Critoniopsis Sch. Bip. (HaroCarrión \& Robinson, 2008), Crysanthellum Pers. (Turner, 1988), Cuatrecasanthus H. Rob. (Robinson \& Funk, 2012), Delilia Spreng. (Delprete, 1995), Diplostephium Kunth (Vargas, 2011, 2018), Espeletia Mutis ex Humb. \& Bonpl. (Diazgranados, 2012), Jaegeria Kunth (Torres, 1968), Lecocarpus Decne. (Adersen, 1980), Liabum Adans. (Gutiérrez \& Katinas, 2015), los géneros que integran el grupo Lucilia Cass. (Freire et al., 2015), Pseudognaphalium Kirp. (Freire et al., 2018), Sampera V. A. Funk \& H. Rob. (Funk \& Robinson, 2009), Scalesia Arn. (Shilling et al., 1994; Blaschke \& Sanders, 2009), Senecio L. (Calvo \& Freire, 2016; 
Calvo, 2017; Calvo et al., 2019; Salomón et al., 2018), Tagetes L. (Schiavinato et al., 2017; Pruski \& Robinson, 2018). Además de los estudios filogenéticos efectuados en las tribus Ecliptinae (Panero et al., 1999); Heliantheae, subtribu Helianthinae (Schilling \& Panero, 2002, 2011) y subtribu Espeletiinae (Diazgranados \& Barber, 2017); Liabeae (Funk et al., 2012), subtribu Munnoziinae (Kim et al., 2003); Senecioneae (Pelser et al., 2007; Pelser et al., 2010); Tageteae (Loockerman et al., 2003); Vernonieae (Robinson, 1999) y en los géneros Dahlia Cav. e Hidalgoa La Llave (Sánchez-Chávez et al., 2019), Darwiniothamnus Harling (Andrus et al., 2009), Diplostephium (Vargas et al., 2017), Gamochaeta Wedd. (Urtubey et al., 2016), complejo Gerbera L. (Pasini et al., 2016), Lasiocephalus Willd. ex Schltdl (Duškova et al., 2010), Pectis L. (Hansen et al., 2016) y Scalesia (Blaschke \& Sanders, 2009). Se hace referencia, además, al estudio taxonómico en la subfamilia Mutisioideae (Katinas et al., 2008).

El presente trabajo pretende estudiar los siguientes aspectos relacionados con los endemismos de la familia Asteraceae en la Flora de Ecuador: (1) evaluar su distribución geográfica actual mediante el uso de datos de colecciones biológicas; (2) determinar la variación a nivel de subfamilia, tribu, género y especie respecto a la región, provincia y sector biogeográfico en la que habitan; (3) evaluar su espectro de variación en relación a la altitud, fisonomía y fenología de la vegetación, bioclima, ombrotipo, termotipo y piso florístico o bioclimático en el que se desarrollan; (4) determinar la correlación existente entre la superficie y la edad geológica de las Islas Galápagos respecto al número de endemismos de esta familia; y (5) determinar la variación de las temperaturas y precipitaciones en los sectores biogeográficos y en el gradiente altitudinal.

\section{MATERIAL Y MÉTODOS}

\section{Bases de datos}

Se consultaron 2868 registros de Asteraceae de la Base de Datos TROPICOS (https://www.tropicos. org), la información provista por Bioweb (https:// bioweb.bio) y El Catálogo de la Vida (https:// www.catalogueoflife.org) para Ecuador, además del Catálogo de Plantas y Líquenes de Colombia (http://catalogoplantasdecolombia.unal.edu.co/en), así como la información provista por los materiales de los 85 herbarios registrados en las referidas bases de datos TROPICOS. También se consultaron los 361 registros para esta familia que aparecen en el Libro Rojo de Plantas Endémicas del Ecuador (Barriga et al., 2011) y las bases de datos de la IUCN (https://www.iucnredlist.org), The Plant List (http://www.theplantlist.org) y Global Compositae (https://compositae.landcareresearch.co.nz/ Default.aspx). El último escrutinio taxonómico se efectuó el 10 de junio de 2019.

\section{Datos meteorológicos}

Los datos de las temperaturas (88 estaciones meteorológicas) y precipitaciones (160 estaciones meteorológicas) medias anuales (Apéndice 1) fueron provistos por el INAMHI de Ecuador (http://www.forosecuador.ec/forum/ecuador/ educaci $\% \mathrm{C} 3 \% \mathrm{~B} 3 n-y-c i e n c i a / 35393$-inamhi-anuarios-metereol $\% \mathrm{C} 3 \% \mathrm{~B} 3$ gicos-en-pdf), además de datos extraidos de otras estaciones meteorológicas que aparecen referidos en Nouvelot et al. (1993), Richter \& Moreira-Muñoz (2005), MAE (2013), Andrade \& Ríos (2014), Samaniego-Rojas et al. (2015) y Luna-Romero et al. (2018).

\section{Variables estudiadas}

Se estudiaron las siguientes variables cualitativas: hábito de crecimiento; región, provincia y sector biogeográfico en el que habitan los endemismos; fisonomía y fenología de la vegetación en la que crecen; bioclima, ombrotipo, termotipo y piso florístico o bioclimático en el que se desarrollan; además de la provincia ecuatoriana donde habitan y la calificación del riesgo de extinción de cada endemismo. Las variables cuantitativas que se evalúan son: altitud, latitud, longitud, temperatura y pluviosidad. Para bioclima, ombrotipo, termotipo y piso florístico o bioclimático se siguió la metodología propuesta en MAE (2013).

\section{Análisis estadístico}

Se aplica el análisis de regresión para determinar: (1) la ecuación que describe la distribución de los endemismos de Asteraceae en la flora de Ecuador 
continental en relación a la altitud, (2) el grado de correlación entre la superficie y la edad geológica de las Islas Galápagos respecto al número de especies endémicas de la familia Asteraceae que la habitan, y (3) el nivel de interrelación entre la variación de la temperatura y precipitaciones en el gradiente altitudinal. El análisis de conglomerados se efectuó para evaluar el grado de similaridad en la composición de especies y en la distribución de las tribus respecto a los sectores biogeográficos de Ecuador continental. También se empleó el análisis de MANOVA anidado para estimar la variación de las termperaturas y las precipitaciones entre los sectores biogeográficos y en las zonas dentro de cada sector para las estaciones metorológicas con ambos datos; para las estaciones meteorológicas con datos de precipitaciones exclusivamente se aplicó el ANOVA anidado.

Las técnicas se aplicaron después de asegurar los requisitos en cuanto a la distribución normal multivarante (MANOVA) o univariante (ANOVA) de datos (prueba de Kolmogorov-Smirnov y Shapiro-Wilk) y homogeneidad de la varianza (contraste Barlett-Box y prueba de Levene) (Dytham, 2003; Grafen \& Hails, 2002). Se emplean los paquetes estadísticos STATISTICA v7.0 (StatSoft, Tulsa, Oklahoma) y SPSS v20.0 (SPSS, Chicago, Illinois). El coeficiente de correlación se consideró alto para $r \geq 0,75$, moderado cuando $0,50 \leq r$ $<0,75$, y bajo cuando $r<0,50$. Los resultados se consideraron significativos si la probabilidad de la hipótesis nula fue menor que 0,05 .

\section{RESULTADOS}

En el Apéndice 2 se muestra que la familia Asteraceae está representada en la flora de Ecuador continental por 310 endemismos (307 especies, 1 subespecies y 2 variedad) que pertenecen a 80 géneros y 15 tribus (Apéndices 2 y 3 ), y corresponden a las subfamilias Asteroideae (245 especies y 1 subespecie, 79,35\%), Barnadesioideae (5 especies y 1 variedad, 1,94\%), Cichorioideae (43 especies y 1 variedad, 14,19\%), y Mutisioideae (14 especies, $4,55 \%)$. Las tribus Senecioneae (26,13\%), Eupatorieae $(21,61 \%)$, Heliantheae $(15,81 \%)$, Astereae $(9,35 \%)$ y Vernonieae $(6,77 \%)$ son las que presentan el mayor número de especies en orden decreciente (Apéndice 3).
Se excluyen del listado un total de 159 nombres científicos cuya causa radica en la pérdida de la condición de especie endémica por extender su área de distribución a otros países del continente, principalmente a Colombia y Perú, y/o por ser sinónimo de otras especies de la misma familia (Apéndice 4).

Un total de 272 endemismos habitan exclusivamente en la región Andina (87,74\%), 12 (3,87\%) en el Litoral (1 [0,32\%] Chocó-Pacífico Ecuatorial; 2 [0,65\%] Chocó; 9 [2,90\%] Pacífico Ecuatorial), 5 (1,61\%) en la Amazonía y 9 (2,90\%) son compartidos en cada caso por las regiones AndesAmazonía y Andes-Litoral (1 [0,32\%] Andes-Chocó; 2 [0,65\%] Andes-Chocó-Pacífico Ecuatorial; 6 [1,94\%] Andes-Pacífico Ecuatorial). Además, 3 $(0,97 \%)$ de los endemismos son de sector y provincia biogeográfica desconocidas (Apéndice 2).

En el Apéndice 3 se indica que en la región Litoral (provincias biogeográficas Chocó y Pacífico Ecuatorial) se localizan endemismos de las tribus Astereae, Barnadesieae, Coreopsideae, Eupatorieae, Heliantheae y Senecioneae. La provincia Andes del Norte evidencia todas las tribus de la familia Asteraceae de la Flora de Ecuador con la aparente excepción de las tribus Coreopsideae y Neurolaeneae en los páramos, Onoserideae en la Cordillera Oriental de los Andes, en los páramos y en los valles interandinos y las tribus Gnaphalieae, Liabeae y Millerieae en los valles interandinos. En la provincia biogeográfica Amazonía Noroccidental habitan endemismos de las tribus Eupatorieae, Heliantheae, Liabeae, Millerieae y Senecioneae.

La Fig. 1 refleja similitud en la distribución de las tribus Astereae y Barnadesieae, Cichorieae y Millerieae, Gnaphalieae y Mutisieae, Coreopsideae y Onoserideae, Nassauvieae y Neurolaeneae, Liabeae y Vernonieae, Eupatorieae, Heliantheae y Senecioneae respecto a los sectores biogeográficos en los que habitan en Ecuador continental.

El Apéndice 5 muestra el número de especies endémicas de los géneros Elaphandra Strother, Hebeclinium DC., Mikania, Pentacalia Cass. y Verbesina L. representadas en las provincias biogeográficas Chocó y Pacífico Ecuatorial, además de los géneros Acmella, Baccharis L., Barnadesia, Bidens L., Clibadium, Egletes Cass., Ophryosporus Meyen, Stevia Cav. y Wedelia Jacq. en el Pacífico Ecuatorial. La Cordillera Occidental de los Andes exhibe endemismos de todos los géneros de la familia Asteraceae de la Flora de Ecuador 


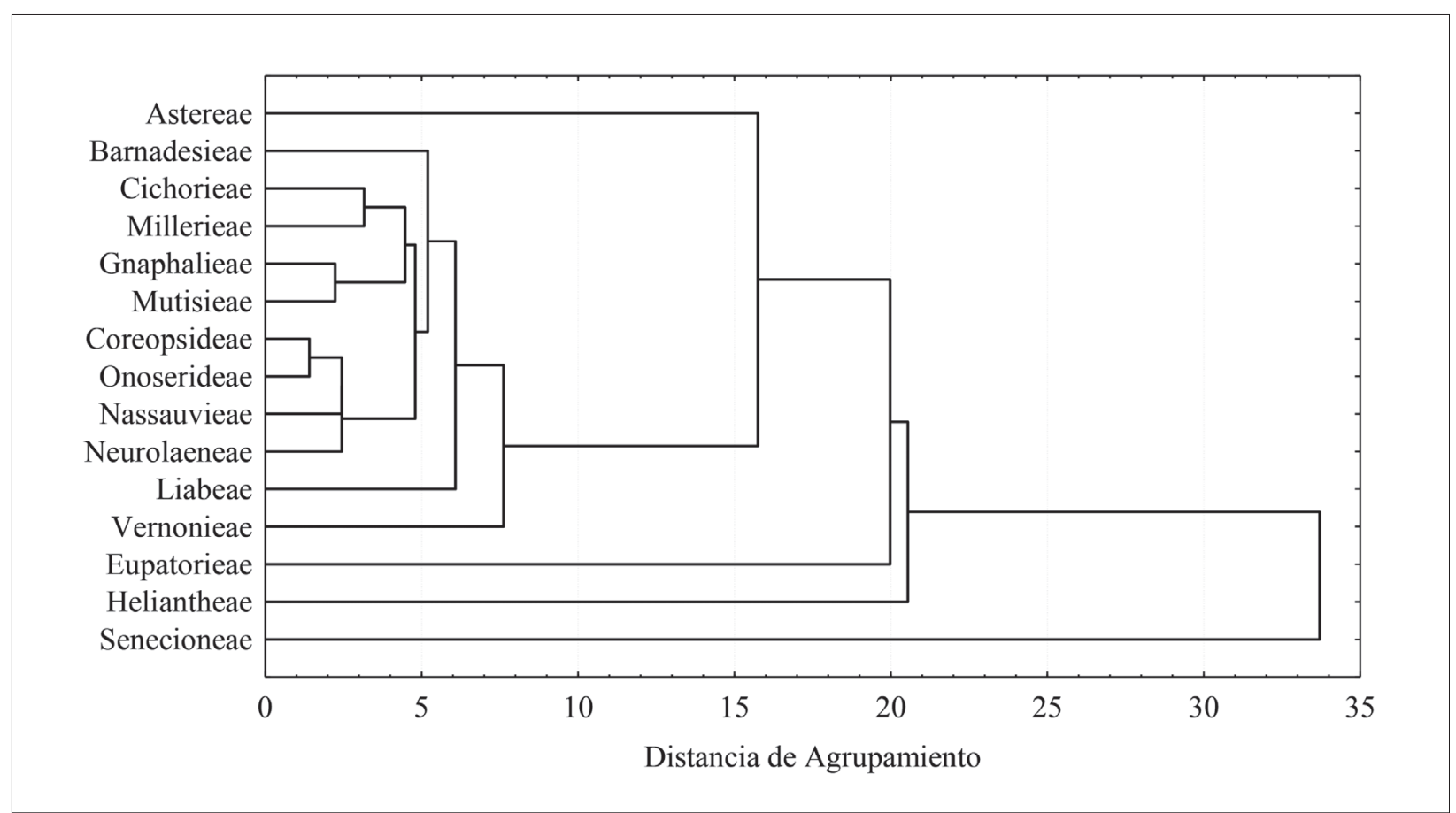

Figura 1. Similaridad en el patrón de distribución de las tribus de Asteraceae representadas en la Flora de Ecuador continental respecto a los sectores biogeográficos que ocupan en correspondencia con los resultados de la Tabla 2.

sin registro poblacional aparente para los géneros Arnaldoa Cabrera, Ayapanopsis R. M. King \& H. Rob., Barnadesia, Bartlettina R. M. King \& H. Rob., Bidens, Cuatrecasanthus H. Rob., Egletes Cass., Espeletia, Guevaria R. M. King \& H. Rob., Ichthyothere Mart., Ophryosporus, Oritrophium (Kunth) Cuatrec., Paragynoxys (Cuatrec.) Cuatrec., Perymenium Schrad., Sciadocephala Mattf. y Stachycephalum Sch. Bip. ex Benth. Resultados análogos se obtienen para la Cordillera Oriental de los Andes con posible ausencia de registros de endemismos para los géneros Acmella, Ageratina Spach, Arnaldoa, Aster L., Bidens, Cacosmia Kunth, Chuquiraga Juss., Crepis L., Cronquistianthus R. M. King \& H. Rob., Cyathomone S. F. Blake, Egletes Cass., Elaphandra, Erato DC., Fleischmannia Sch. Bip., Haplopappus Cass., Hebeclinium, Ichthyothere, Idiopappus $\mathrm{H}$. Rob. \& Panero, Liabum Adans, Llerasia Triana, Lomanthus B. Nord. \& Pelser, Onoseris Willd., Pilosella Hill, Stachycephalum, Stevia, y Wedelia. Endemismos de los siguientes géneros habitan en los páramos de los Andes del Norte: Achyrocline (Less) DC., Aequatorium B. Nord., Ageratina, Aphanactis Wedd., Aristeguietia R. M. King \& H. Rob., Asplundianthus R. M. King \& H. Rob., Baccharis L., Barnadesia, Chuquiraga, Clibadium, Critoniopsis,
Cronquistianthus, Dendrophorbium (Cuatrec.) C. Jeffrey, Diplostephium, Erigeron L., Espeletia, Fleischmannia, Floscaldasia Cuatrec., Gnaphalium L., Grosvenoria R. M. King \& H. Rob., Gynoxys Cass., Hieracium L., Idiopappus, Joseanthus H. Rob., Jungia L., Kingianthus H. Rob., Llerasia, Loricaria Wedd., Mikania, Monticalia C. Jeffrey, Munnozia Ruiz \& Pav., Mutisia L., Oritrophium, Pappobolus S. F. Blake, Paragynoxy, Pentacalia, Pilosella, Sampera, Senecio, Verbesina, Werneria Kunth y Xenophyllum V. A. Funk. El sector biogeográfico Catamayo-Alamor presenta endemismos de los géneros Badilloa R. M. King \& H. Rob., Barnadesia, Cacosmia, Calea L., Critoniopsis, Cronquistianthus, Diplostephium, Elaphandra, Fleischmannia, Jungia, Lomanthus, Mikania, Monactis Kunth, Munnozia, Onoseris, Pappobolus, Senecio, Stevia, Verbesina y Wedelia. Los endemismos del sector Interandino pertenecen a los géneros Acmella, Aldama, Aristeguietia, Arnaldoa, Baccharis, Barnadesia, Calea, Critoniopsis, Cronquistianthus, Dasyphyllum Kunth, Dendrophorbium, Diplostephium, Fleischmannia, Gynoxys, Jungia, Kaunia R. M. King \& H. Rob., Kingianthus, Monactis, Monticalia, Mutisia, Pappobolus, Paragynoxys, Pentacalia, Verbesina y Xenophyllum. La provincia biogeográfica Amazonía Noroccidental se distingue 
por presentar endemismos de los géneros Elaphandra, Hebeclinium, Ichthyothere, Mikania, Pentacalia, Sampera, y Stachycephalum. Se añade que los géneros Cyathomone, Idiopappus y Kingianthus son endémicos de la flora de Ecuador Continental.

El análisis de agrupamiento sugiere similitud en la composición de especies entre las regiones Litoral (excepto Jama-Zapotillo), Amazonía y las especies que se distribuyen de norte a sur en la Cordillera Oriental; y entre los sectores biogeográficos Jama-Zapotillo, Catamayo-Alamor, norte y centro de la Cordillera Occidental y norte de la Cordillera Oriental; valles interandinos y centro de la Cordillera Occidental; y entre los páramos y el norte de la Cordillera Occidental (Fig. 2).

Las provincias con mayor frecuencia de endemismos son Pichincha (95 especies), Loja (91 especies), Azuay ( 85 especies) y Chimborazo (83 especies; Fig. 3 y Apéndice 2). Treinta y tres especies de la familia Asteraceae, subfamilia Asteroideae son endémicas de Islas Galápagos agrupadas en 11 géneros y 5 tribus (Apéndice 6). Endemismos de la tribu Tageteae están representados en las Islas Galápagos exclusivamente, sin aparente presencia de endemismos de esta tribu en Ecuador continental. Los géneros Darwiniothamnus (3 especies), Lecocarpus (4 especies), Scalesia (15 especies) y Trigonopterum Steetz ex N. J. Andersson
(1 especie) son endémicos de las Islas Galápagos. Los géneros Baccharis y Acmella están representados en las Islas Galápagos y en Ecuador continental. Los datos indican que la tribu Heliantheae (20 especies, 60,60\%) es la más rica en especies, seguidas en orden descendente por las tribus $\mathrm{Mi}$ llerieae (5 especies, 15,15\%), Astereae (4 especies, 12,12\%), Coreopsideae (2 especies, 6,06\%) y Tageteae (2 especies, 6,06\%, Apéndice 6). Los endemismos se distribuyen en 18 islas e islotes, con destacada representatividad en las islas Isabela, San Cristobal, Santa Cruz, Floreana, Santiago, y Fernandina (Tabla 1). El análisis de regresión múltiple indica que existe una correlación baja y significativa entre la superficie y la edad geológica de las Islas Galápagos respecto al número de especies endémicas de la familia Asteraceae que la habitan $\left(R^{2}\right.$ corregida $=0,39 ; F_{1,17}=11,73 ; p$ $<0,05)$. Además, a mayor elevación se produce un incremento del número de endemismos de esta familia en la zona húmeda.

Un total de 24 táxones (5 especies en Islas Galápagos; 19 en Ecuador continental) están en peligro crítico, aunque en su mayoría son vulnerables y en peligro de extinción (Fig. 4). E1 57,72\% de los táxones son arbustos, prosiguen en representatividad las hierbas $(28,28 \%)$, los bejucos $(6,99 \%)$, y los árboles (6,41\%, Fig. 5).

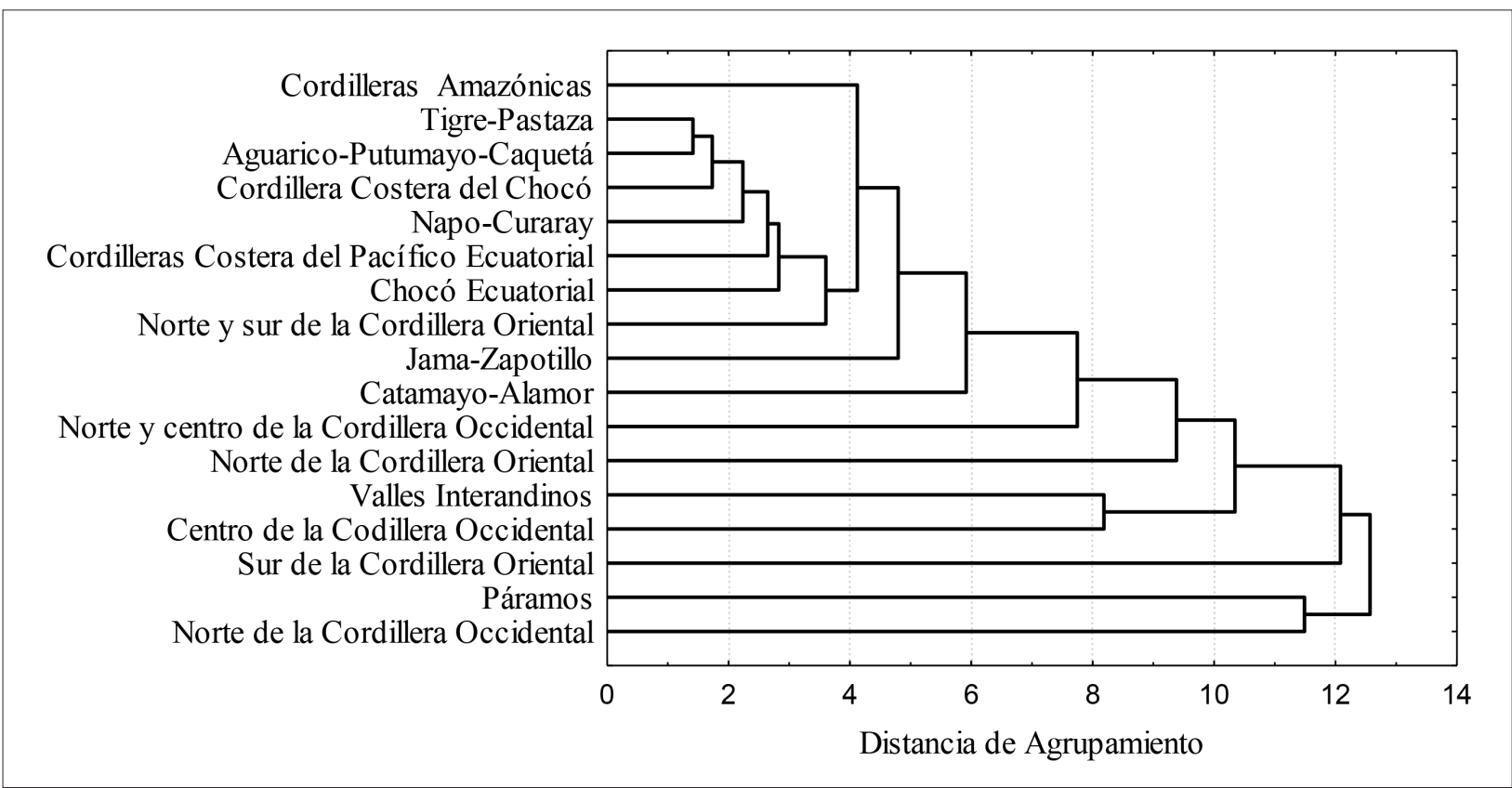

Figura 2. Similaridad en el patrón de distribución de los endemismos de Asteraceae representadas en la Flora de Ecuador continental respecto a los sectores biogeográficos que ocupan en correspondencia con los resultados de las Tabla 2 y 4. 


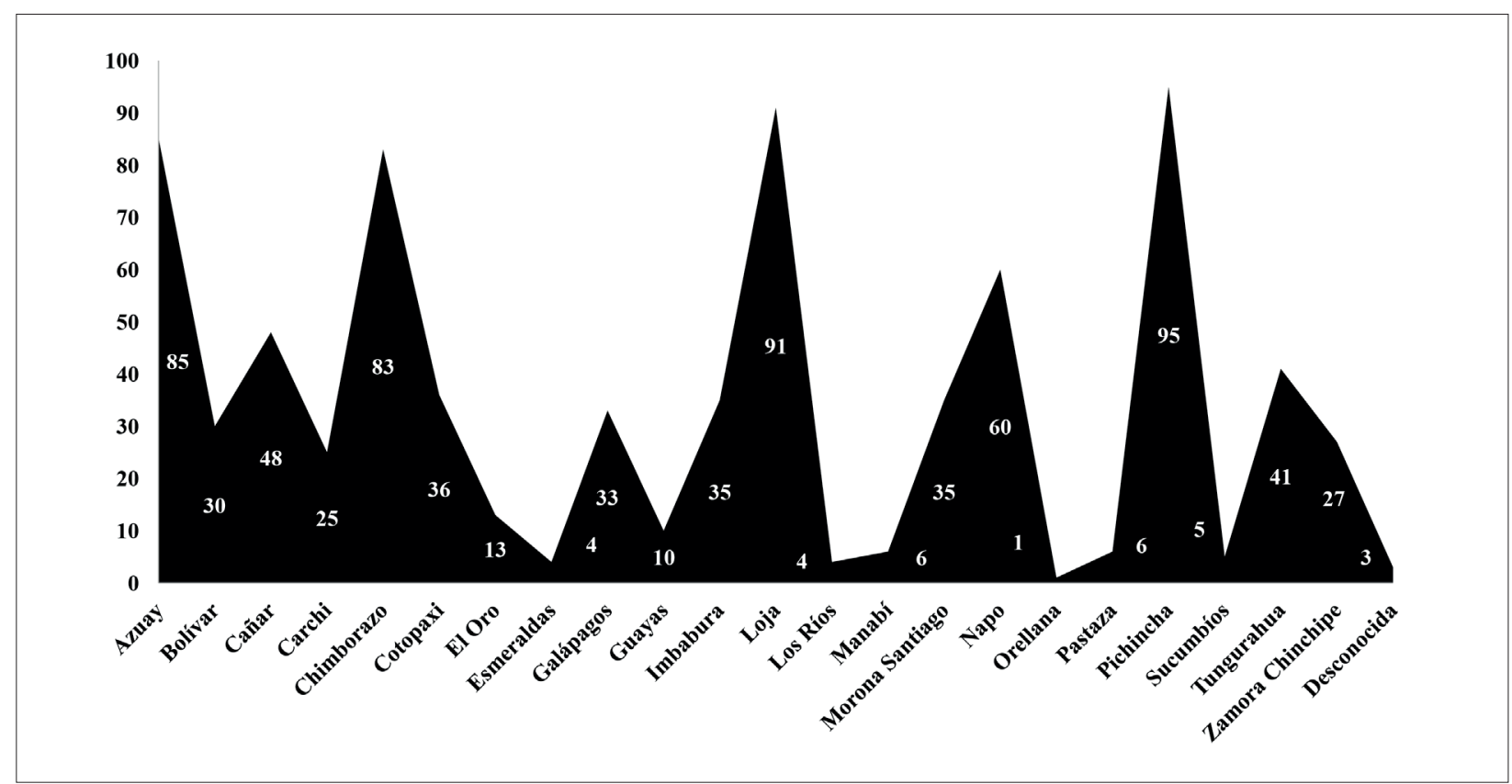

Figura 3. Frecuencia de endemismos de la familia Asteraceae por provincia política de Ecuador.

Tabla 1. Relación entre la superficie y la edad geológica de las Islas Galápagos respecto al número de especies endémicas de la familia Asteraceae que habitan $\left(R^{2}\right.$ corregida $\left.=0,39 ; F_{1,17}=11,73 ; p<0,05\right)$.

\begin{tabular}{|l|c|c|l|}
\hline \multicolumn{1}{|c|}{ Isla } & Número de especies & $\begin{array}{c}\text { Superficie aproximada } \\
\left(\mathbf{k m}^{2}\right)\end{array}$ & $\begin{array}{c}\text { Rango aproximado de edad } \\
\text { (años) }\end{array}$ \\
\hline Baltra & 1 & 26,19 & $\leq 1.000 .000$ \\
\hline Española & 4 & 60,48 & $2.800 .000-5.600 .000$ \\
\hline Islotes de Española & 1 & 0,6 & $\leq 1.000 .000$ \\
\hline Fernandina & 10 & 642,48 & $60.000-300.000$ \\
\hline Floreana & 12 & 172,53 & $1.500 .000-3.300 .000$ \\
\hline Islotes de Floreana & 1 & 1,38 & $\leq 1.000 .000$ \\
\hline Islote Edén & 1 & 0,23 & $\leq 1.000 .000$ \\
\hline Islote la Fe & 1 & 0,2 & $\leq 1.000 .000$ \\
\hline Isabela & 16 & 4588,12 & $70.000-700.000$ \\
\hline Pinta & 7 & 59,4 & $\leq 1.000 .000$ \\
\hline Pinzón & 2 & 18,15 & $1.400 .000-2.700 .000$ \\
\hline San Bartolomé & 1 & 1,24 & $\leq 1.000 .000$ \\
\hline San Cristobal & 14 & 558,08 & $2.300 .000-6.300 .000$ \\
\hline Santa Cruz & 14 & 985,55 & $2.200 .000-3.600 .000$ \\
\hline Santa Fe & 4 & 24,13 & $2.800 .000-4.600 .000$ \\
\hline Santiago & 12 & 584,65 & $77.000-2.400 .000$ \\
\hline Seymour Norte & 1 & 1,84 & $\leq 1.000 .000$ \\
\hline Wolf & 14 & 1,34 & $90.000-1.600 .000$ \\
\hline
\end{tabular}




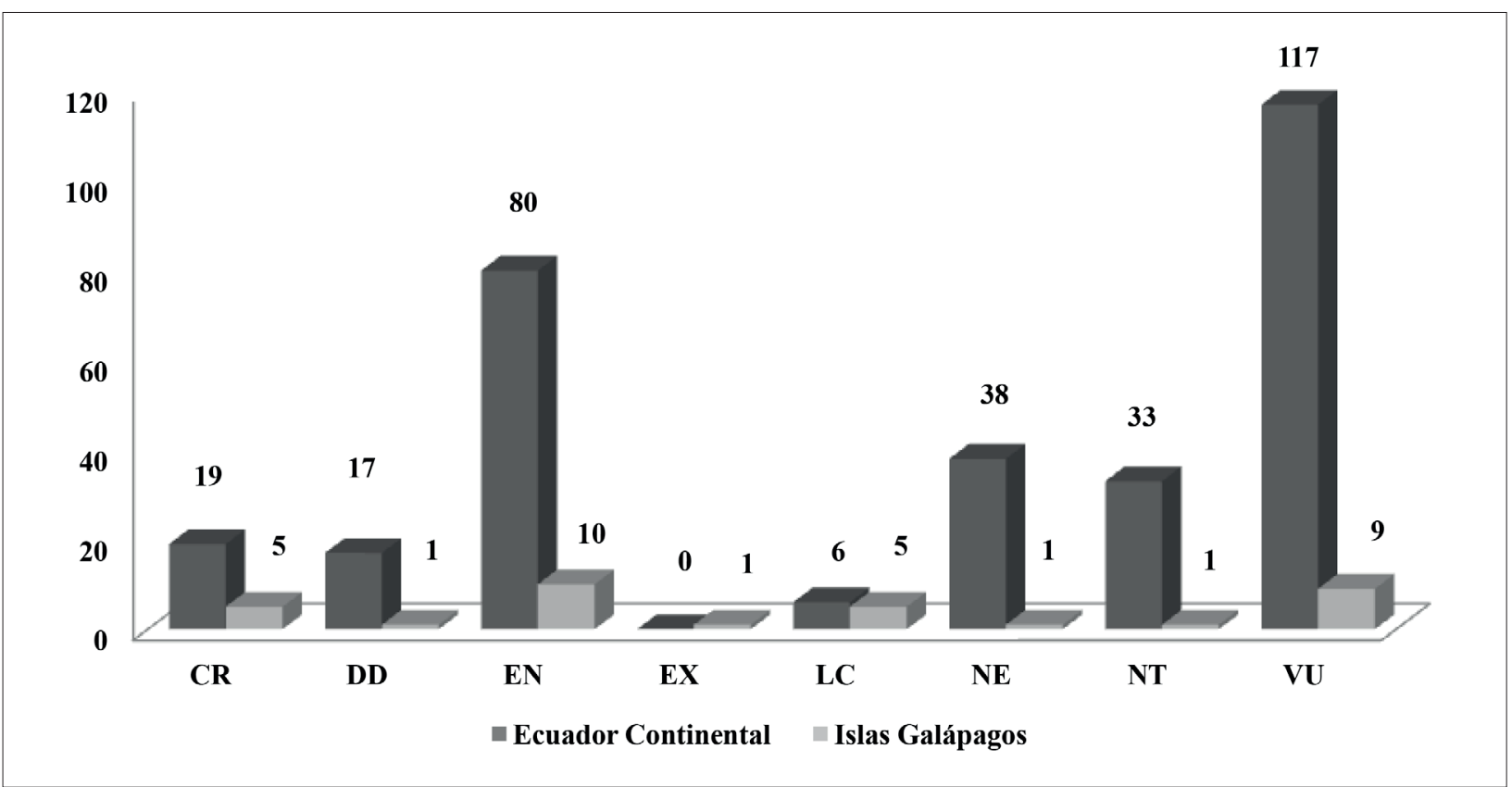

Figura 4. Calificación del riesgo de extinción de los endemismos de la familia Asteraceae representadas en la Flora de Ecuador.

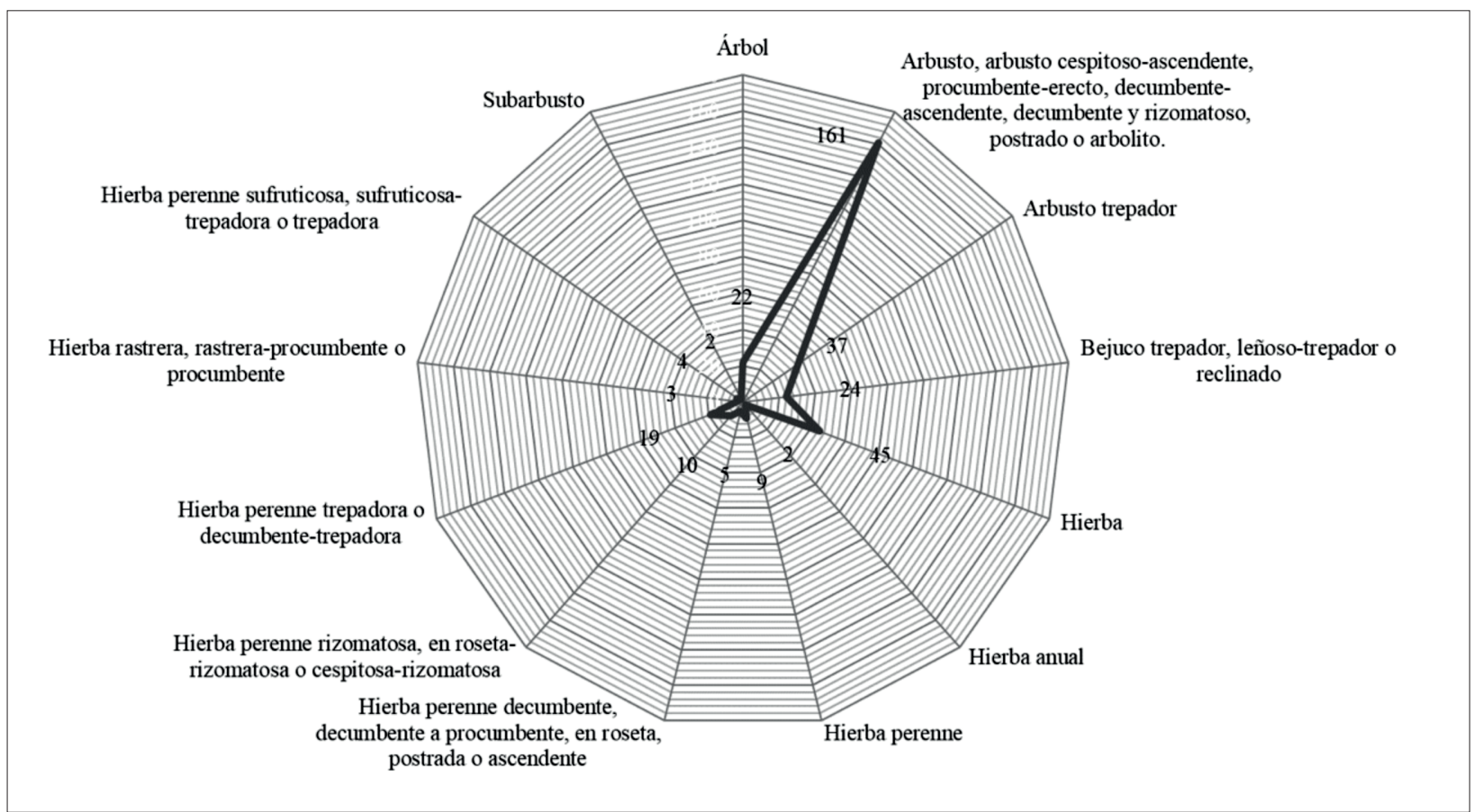

Figura 5. Calificación del riesgo de extinción de los endemismos de la familia Asteraceae representadas en la Flora de Ecuador.

Los endemismos de esta familia se distribuyen desde los $0^{\circ} \mathrm{N}$ hasta los $4^{\circ} \mathrm{S}$ y de $\operatorname{los} 75^{\circ} \mathrm{W}$ hasta los $91^{\circ} \mathrm{W}$ en Ecuador, con especial ocurrencia a $0^{\circ} \mathrm{S}$ entre $77^{\circ} \mathrm{W}$ y $79^{\circ} \mathrm{W}$ (Figs. 6 y 7). Las especies exhiben un amplio espectro altitudinal desde cercano al nivel del mar hasta cotas superiores a los 5000 metros de altitud que describe una regresión polinómica de orden 6 de ajuste al 84,04\% (Figs. 8 y 9), y alcanza su máximo en el rango de $2900 \mathrm{~m}$ a $3000 \mathrm{~m}$ (Fig. 8). 


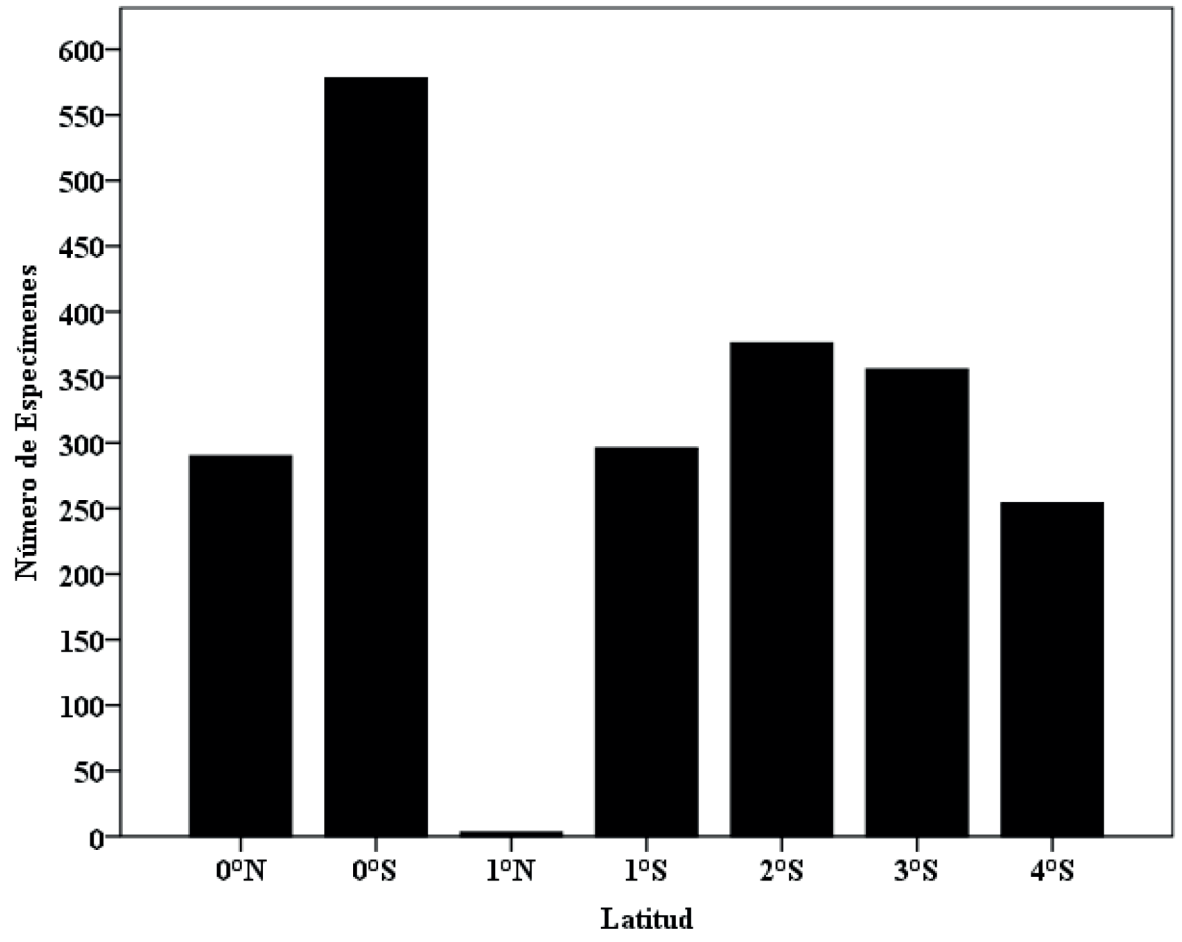

Figura 6. Variación latitudinal de los endemismos de la familia Asteraceae en la Flora de Ecuador.

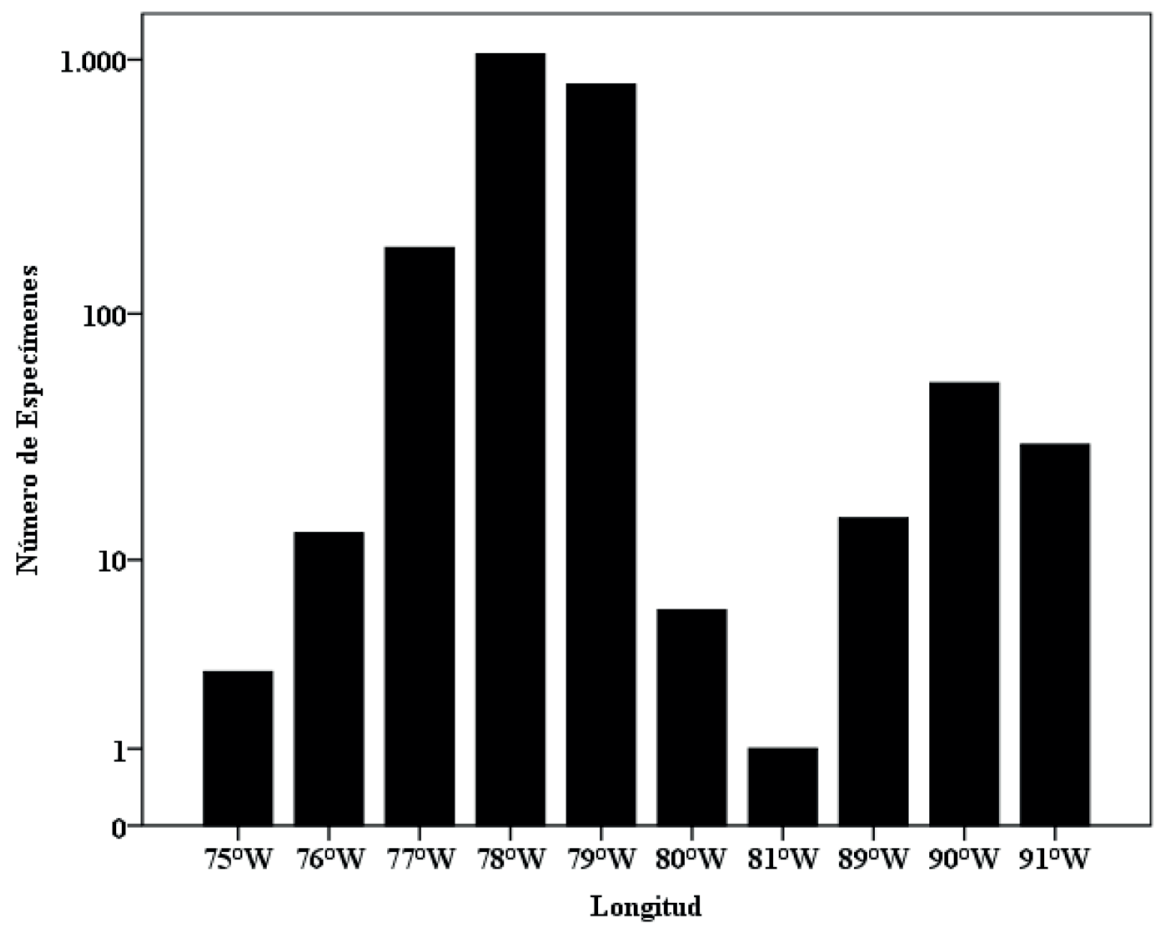

Figura 7. Variación longitudinal de los endemismos de la familia Asteraceae en la Flora de Ecuador. 


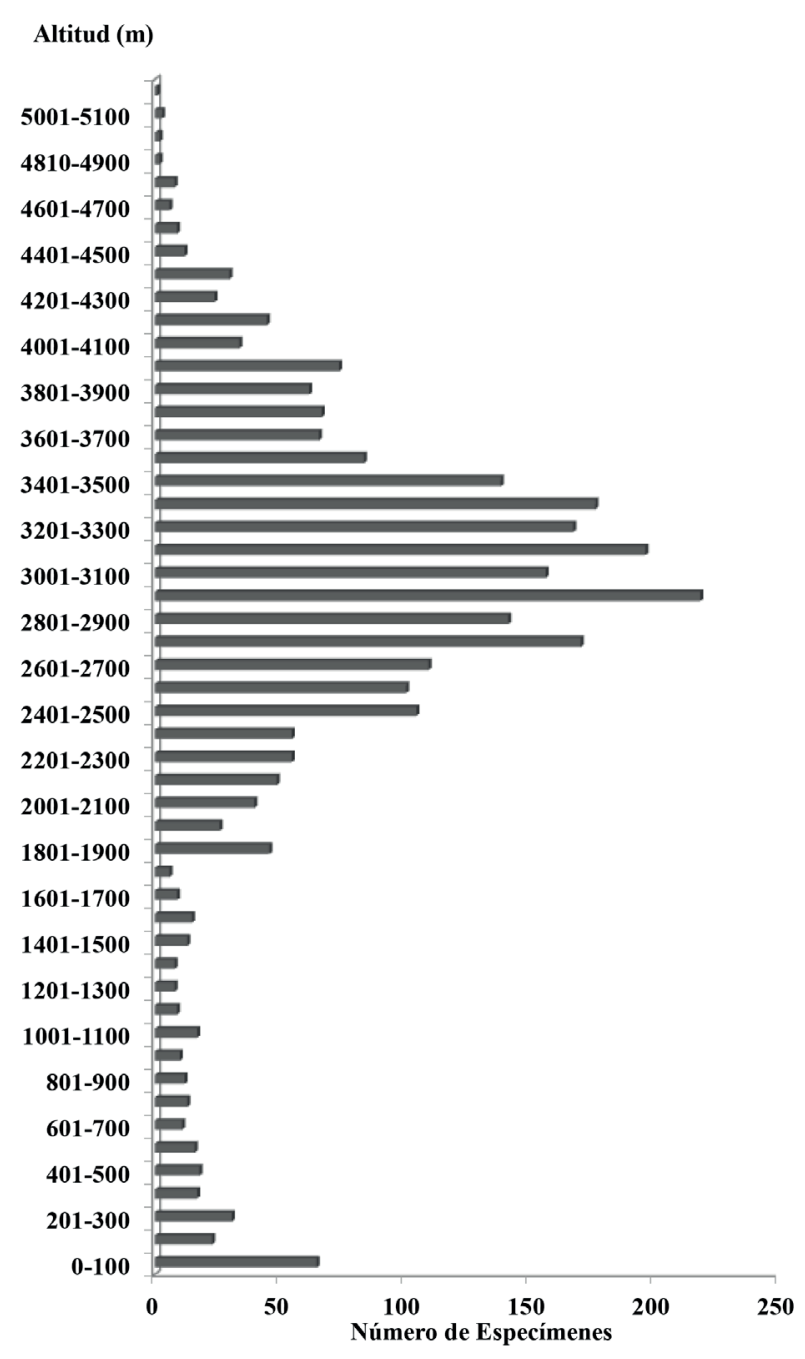

Figura 8. Variación altitudinal de los endemismos de la familia Asteraceae en la Flora de Ecuador.

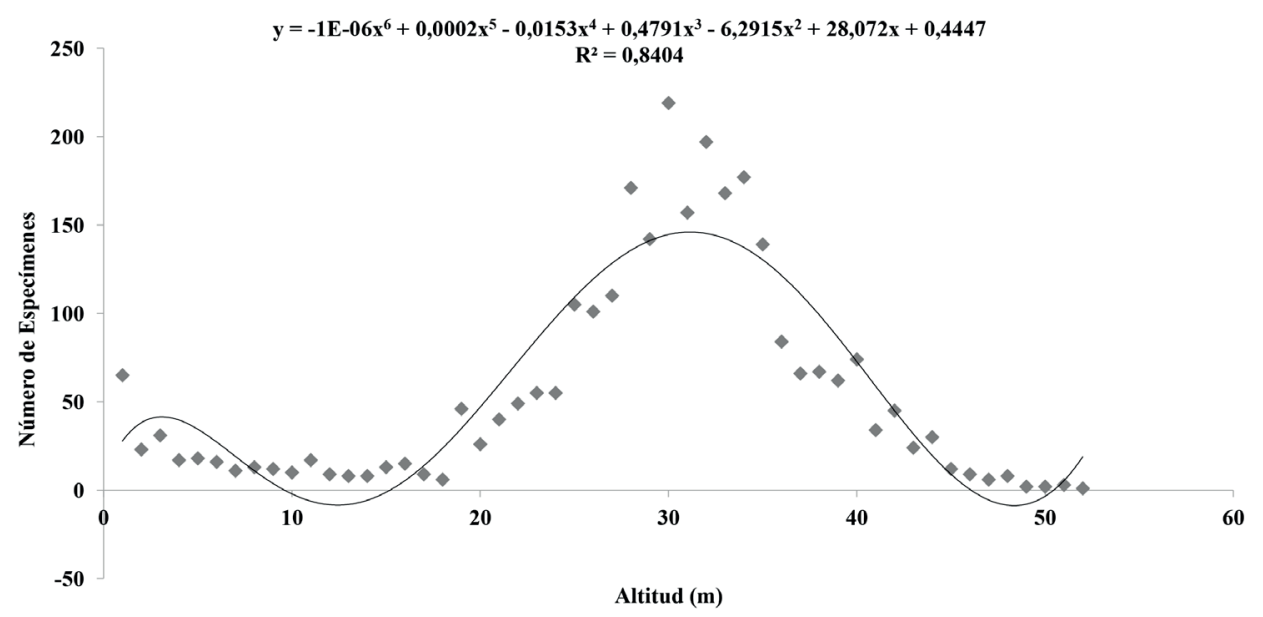

Figura 9. Regresión polinómica de orden 6 que describe la frecuencia de especímenes endémicos de la familia Asteraceae en la Flora de Ecuador según el rango altitudinal que se muestra en la Figura 8. 
Tabla 2. Frecuencia de endemismos de la familia Asteraceae representados en la Flora de Ecuador en relación a la fisonomía y fenología de la vegetación en la que habitan.

\begin{tabular}{|c|c|}
\hline Fisonomía y fenología de la vegetación & Número de táxones \\
\hline Arbustal semideciduo y siempreverde & $2(0,65 \%)$ \\
\hline Arbustal siempreverde & $4(1,29 \%)$ \\
\hline Arbustal, rosetal caulescente siempreverde & $1(0,32 \%)$ \\
\hline Bosque deciduo & $3(0,97 \%)$ \\
\hline Bosque deciduo y siempreverde & $2(0,65 \%)$ \\
\hline Bosque semideciduo & $3(0,97 \%)$ \\
\hline Bosque semideciduo y siempreverde & $6(1,94 \%)$ \\
\hline Bosque siempreverde & $108(34,84 \%)$ \\
\hline Bosque siempreverde estacional & $2(0,65 \%)$ \\
\hline Bosque siempreverde y siempreverde estacional & $3(0,97 \%)$ \\
\hline Bosque y arbustal semideciduo & $14(4,52 \%)$ \\
\hline Bosque y arbustal semideciduo y siempreverde & $37(11,94 \%)$ \\
\hline Bosque y arbustal siempreverde & $51(16,45 \%)$ \\
\hline Bosque y arbustal siempreverde, siempreverde estacional y deciduo & $1(0,32 \%)$ \\
\hline Bosque y herbazal siempreverde & $5(1,61 \%)$ \\
\hline Bosque, herbazal y arbustal semideciduo y siempreverde & $11(3,55 \%)$ \\
\hline Bosque, herbazal y arbustal siempreverde & $16(5,16 \%)$ \\
\hline Herbazal siempreverde & $15(4,84 \%)$ \\
\hline Herbazal y arbustal semideciduo y siempreverde & $2(0,65 \%)$ \\
\hline Herbazal y arbustal siempreverde & $13(4,19 \%)$ \\
\hline Desconocidas & $11(3,55 \%)$ \\
\hline Total & 310 \\
\hline
\end{tabular}

Los endemismos de Asteraceae en Ecuador continental crecen principalmente en una vegetación de bosque siempreverde o de bosque y arbustal siempreverde o semideciduo y siempreverde, con una frecuencia inferior al $20 \%$ en herbazales y arbustales (Tabla 2).

El 67,42\% de los endemismos (209) soportan un bioclima pluvial, mientras que el 16,45\% (50) habitan bajo un bioclima pluvioestacional a pluvial. Se enfatiza que el 6,13\% (19) y el 3,87\% (12) de los endemismos se desarrollan en bioclimas publioestacionales y xéricos respectivamente (Tabla 3). En general, el 61,29\% de los endemismos (190) ocupan un ombrotipo húmedo a hiperhúmedo seguido por los que se establecen en un ombrotipo de seco a húmedo (41, 13,23\%, Tabla 4).
Tabla 3. Frecuencia de endemismos de la familia Asteraceae representados en la Flora de Ecuador en relación a la variación bioclimática de donde habitan.

\begin{tabular}{|l|c|}
\hline Bioclima & Número de táxones \\
\hline Pluvial & $209(67,42 \%)$ \\
\hline Pluvioestacional & $19(6,13 \%)$ \\
\hline Pluvioestacional a pluvial & $50(16,45 \%)$ \\
\hline Xérico & $12(3,87 \%)$ \\
\hline Xérico a pluvial & $5(1,61 \%)$ \\
\hline Xérico a pluvioestacional & $3(0,97 \%)$ \\
\hline Desconocida & $11(3,55 \%)$ \\
\hline Total & $\mathbf{3 1 0}$ \\
\hline
\end{tabular}


Tabla 4. Frecuencia de endemismos de la familia Asteraceae representados en la Flora de Ecuador en relación a la variación del ombrotipo de donde habitan.

\begin{tabular}{|l|c|}
\hline Ombrotipo & Número de táxones \\
\hline Húmedo & $11(3,55 \%)$ \\
\hline Húmedo a hiperhúmedo & $190(61,29 \%)$ \\
\hline Húmedo a ultrahúmedo & $2(0,65 \%)$ \\
\hline Hiperhúmedo & $7(2,26 \%)$ \\
\hline Subhúmedo & $3(0,97 \%)$ \\
\hline Subhúmedo a húmedo & $1(0,32 \%)$ \\
\hline Subhúmedo a hiperhúmedo & $3(0,97 \%)$ \\
\hline Seco & $19(6,13 \%)$ \\
\hline Seco a subhúmedo & $5(1,61 \%)$ \\
\hline Seco a húmedo & $41(13,23 \%)$ \\
\hline Seco a hiperhúmedo & $17(5,48 \%)$ \\
\hline Desconocida & $11(3,55 \%)$ \\
\hline Total & $\mathbf{3 1 0}$ \\
\hline
\end{tabular}

La dispersión de los endemismos de la familia Asteraceae en Ecuador continental en relación a las oscilaciones térmicas es extensa, al demostrar que su variación se enmarca desde el termotipo infratropical inferior hasta el criorotropical atérmico (Tabla 5). El espectro de pisos florísticos o bioclimáticos que ocupan varía desde las tierras bajas hasta el nivel nival, todos ellos con una frecuencia de endemismos inferior al 20\%. La mayor frecuencia se observa en el piso montano con un termotipo mesotropical inferior y superior $(59,19,03 \%)$ y de montano al montano alto con un termotipo de mesotropical inferior y superior a supratropical inferior $(56,18,06 \%$; Tabla 5).

Encelia hispida Andersson, Scalesia atractyloides Arn., S. helleri B. L. Rob., S. stewartii L. Riley, S. villosa Stewart, Lecocarpus darwinii Andersen, L. lecocarpoides (B. L. Rob. \& Greenm.) Cronquist \& Stuessy, Pectis subsquarrosa (Hook. f.) Sch. Bip., y P. tenuifolia (DC.) Sch. Bip. habitan en las zonas litoral y árida, que representan el 27,27\% de los endemismos de Asteraceae de las Islas Galápagos (Apéndice 6). En las zonas litoral, árida y de transición crecen Scalesia aspera Andersson, S. gordilloi O. Hamann \& Wium-And.,
Trigonopterum laricifolium (Hook. f.) W. L. Wagner \& H. Rob. y Lecocarpus pinnatifidus DC. que constituyen el 12,12\% del total. En la zona húmeda (Darwiniothamnus alternifolius Lawesson \& Adsersen, Scalesia cordata Stewart y S. microcephala B. L. Rob.) y en las zonas árida, transición y húmeda [Darwiniothamnus lancifolius (Hook. f.) Harling, Chrysanthellum pusillum Hook. f. y Scalesia baurii B. L. Rob. \& Greenm.] se desarrollan el $9,09 \%$ de los endemismos insulares de esta familia. En las zonas litoral (Scalesia crockeri Howell y S. retroflexa Hemsl.); árida [Scalesia incisa Hook. f. y Lecocarpus leptolobus (S. F. Blake) Cronquist \& Stuessy]; transición y húmeda [Acmella darwinii (D. M. Porter) R. K. Jansen y Delilia repens (Hook. f.) Kuntze]; litoral, árida, transición y húmeda [Darwiniothamnus tenuifolius (Hook. f.) Harling y Scalesia affinis Hook. f.] habitan el 6,06\% de los endemismos de Asteraceae representados en estas islas. Mientras que el 3,03\% de los endemismos crecen en las zonas áridas y de transición (Scalesia divisa Andersson); húmeda y de transición (Scalesia pedunculata Hook. f.) y en la de transición exclusivamente (Baccharis steetzii Andersson, Apéndice 6). En relación al ecosistema en el que habitan, los endemismos galapaguenses de esta familia crecen en bosque y arbustal húmedo (zona litoral), en vegetación de bosque y arbustal deciduo (zona árida), en bosque siempreverde estacional y en vegetación arbustiva (zona de transición), en bosque y arbustal siempreverde, y en herbazal húmedo (zona húmeda, Apéndice 6).

\section{Variación de la temperatura y la pluvisidad en los sectores biogeográficos y en el gradiente alti- tudinal}

La temperatura media anual es más elevada en el Litoral y en la Amazonía, lo inverso ocurre en los páramos (Fig. 10). Los sectores Catamayo-Alamor, Cordillera Oriental de los Andes y Cordilleras Amazónicas presentan una baja oscilación térmica de las temperaturas medias anuales.

La Cordillera Oriental de los Andes, Chocó Ecuatorial y todos los sectores de la región Amazónica muestran los más altos niveles de pluviosidad anual (Fig. 11). Los sectores más secos son los valles interandinos, Jama-Zapotillo, Catamayo-Alamor y los páramos de la Cordillera Occidental de los Andes (Fig. 11). La intensidad pluviométrica es 
Tabla 5. Frecuencia de endemismos de la familia Asteraceae representados en la Flora de Ecuador en relación a la variación de termotipo y del piso florístico/bioclimático de la vegetación en la que habitan.

\begin{tabular}{|c|c|c|}
\hline Termotipo & Piso florístico/bioclimático & $\begin{array}{l}\text { Número de } \\
\text { táxones }\end{array}$ \\
\hline Infratropical superior & Tierras bajas & $9(2,90 \%)$ \\
\hline Infratropical superior a termotropical inferior & Tierras bajas a piemontano & $4(1,29 \%)$ \\
\hline Infratropical superior a termotropical superior & Tierras bajas a montano bajo & $3(0,97 \%)$ \\
\hline Infratropical superior a mesotropical inferior y superior & Tierras bajas a montano & $2(0,65 \%)$ \\
\hline Termotropical inferior & Piemontano & $7(2,26 \%)$ \\
\hline Termotropical inferior y superior & Piemontano a montano bajo & $5(1,61 \%)$ \\
\hline Termotropical inferior a mesotropical inferior y superior & Piemontano a montano & $6(1,94 \%)$ \\
\hline Termotropical inferior a supratropical inferior & Piemontano a montano alto & $3(0,97 \%)$ \\
\hline Termotropical inferior a supratropical superior & Piemontano a montano alto superior & $1(0,32 \%)$ \\
\hline Termotropical superior & Montano bajo & $14(4,52 \%)$ \\
\hline Termotropical superior a mesotropical inferior y superior & Montano bajo a montano & $13(4,19 \%)$ \\
\hline Termotropical superior a supratropical inferior & Montano bajo a montano alto & $11(3,55 \%)$ \\
\hline Termotropical superior a supratropical superior & Montano bajo a montano alto superior & $1(0,32 \%)$ \\
\hline Termotropical superior a orotropical inferior y superior & Montano bajo a subnival & $1(0,32 \%)$ \\
\hline Mesotropical inferior y superior & Montano & $59(19,03 \%)$ \\
\hline Mesotropical inferior y superior a supratropical inferior & Montano a montano alto & $56(18,06 \%)$ \\
\hline Mesotropical inferior y superior a supratropical superior & Montano a montano alto superior & $18(5,81 \%)$ \\
\hline Mesotropical inferior y superior a orotropical inferior y superior & Montano a subnival & $16(5,16 \%)$ \\
\hline Supratropical inferior & Montano alto & $24(7,74 \%)$ \\
\hline Supratropical inferior y superior & Montano alto a montano alto superior & $10(3,23 \%)$ \\
\hline Supratropical inferior a orotropical inferior y superior & Montano alto a subnival & $11(3,55 \%)$ \\
\hline Supratropical superior & Montano alto superior & $7(2,26 \%)$ \\
\hline Supratropical superior a orotropical inferior y superior & Montano alto superior a subnival & $8(2,58 \%)$ \\
\hline Supratropical superior a criorotropical atérmico & Montano alto superior a nival & $1(0,32 \%)$ \\
\hline Orotropical inferior y superior & Subnival & $7(2,26 \%)$ \\
\hline Orotropical inferior y superior a criorotropical atérmico & Subnival a nival & $2(0,65 \%)$ \\
\hline Desconocida & Desconocida & $11(3,58 \%)$ \\
\hline Total & & 310 \\
\hline
\end{tabular}




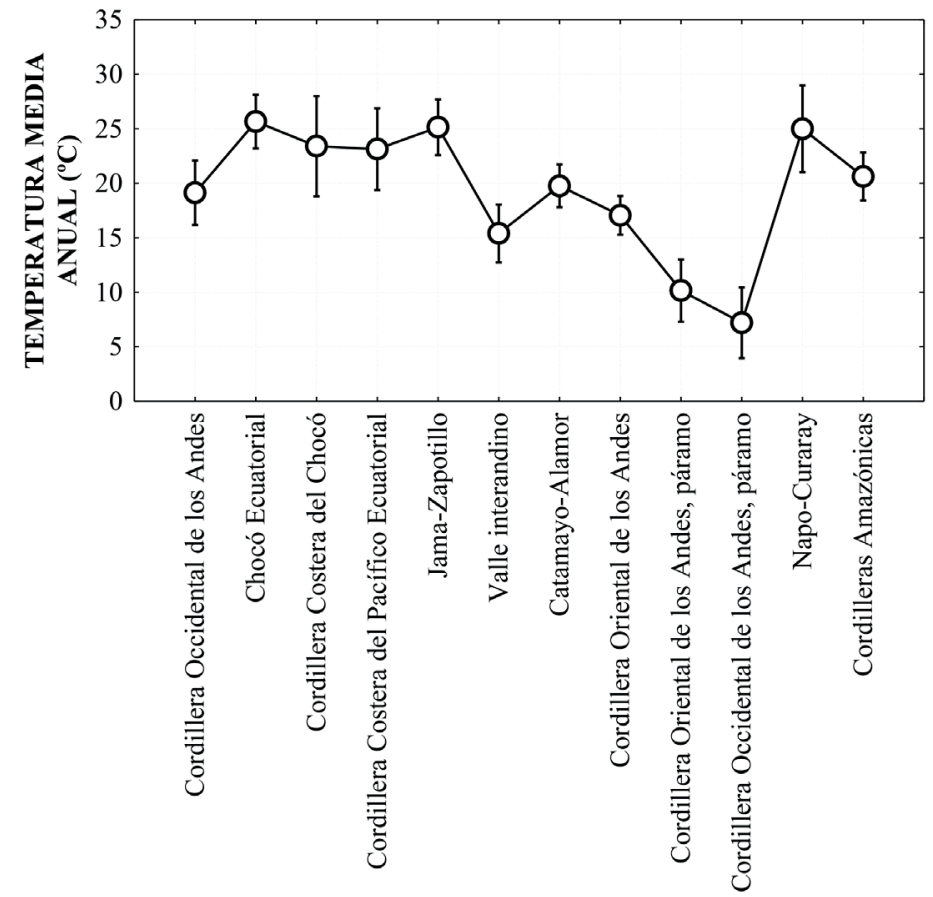

SECTOR BIOGEOGRÁFICO

Figura 10. Variación significativa de la temperatura media anual por sector biogeográfico en Ecuador con un intervalo de confianza de 0,$95 ; \mathrm{F}_{22,126}=9,26 ; p<0,0001$. Los sectores Tigre-Pastaza y Aguarico-Putumayo-Caquetá se fusionan con el de Napo-Curaray al constar con datos de una única estación meteorológica en cada caso.

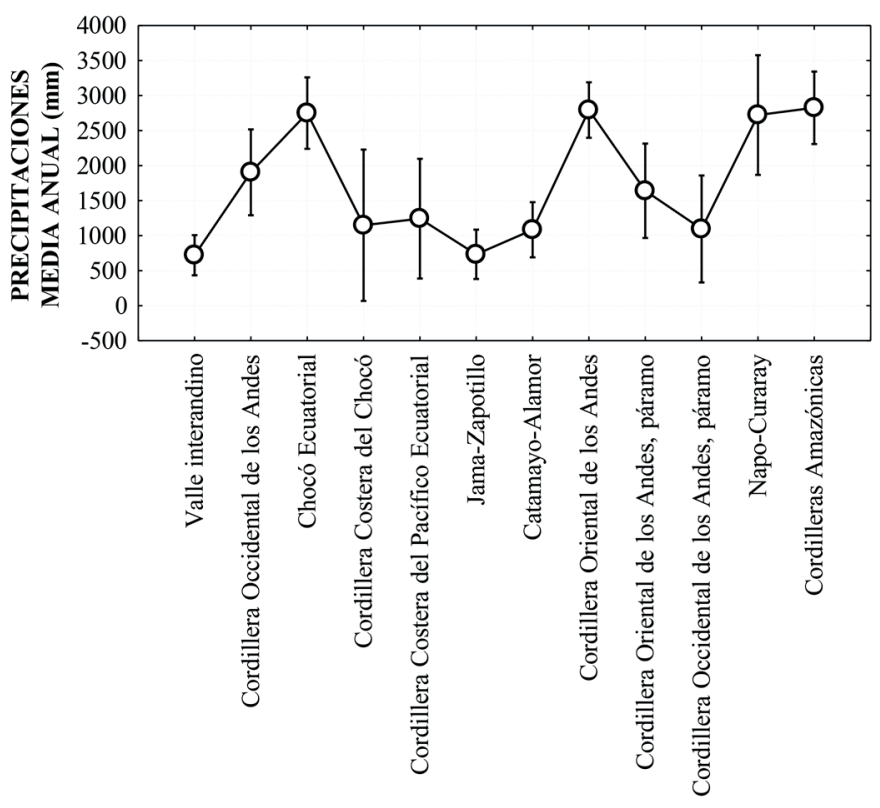

SECTOR BIOGEOGRÁFICO

Figura 11. Variación significativa de las precipitaciones media anual por sector biogeográfico en Ecuador con un intervalo de confianza de 0,$95 ; \mathrm{F}_{11,121}=14,06 ; p<0,0001$. Los sectores Tigre-Pastaza y Aguarico-Putumayo-Caquetá se fusionan con el de Napo-Curaray al constar con datos de una única estación meteorológica en cada caso. 
inferior en los páramos de la Cordillera Occidental en relación a los páramos de la Cordillera Oriental (Fig. 11). El ANOVA anidado muestra variación significativa en relación a las precipitaciones medias anuales de todas las estaciones meteorológicas entre los sectores biogeográficos $\left(F_{11,121}=14,06 ; p\right.$ $<0,0001$ ), no así entre las zonas (norte-centro-sur) anidado dentro de cada sector $\left(F_{13,121}=0,98 ; p>\right.$ $0,05)$.

El MANOVA anidado de la variación de los valores de temperatura y precipitaciones para las estaciones meteorológicas con ambos datos indica significación estadística a escala multivariante entre las regiones biogeográficas ( $\lambda$ de Wilks $=0,14$; $\left.F_{22,126}=9,26 ; p<0,0001\right)$, no así entre las zonas (norte-centro-sur) anidadas dentro de cada sector $(\lambda$ de Wilks $\left.=0,65 ; F_{24,126}=1,24 ; p>0,05\right)$. El análisis univariante indica que las temperaturas $\left(F_{11,64}=\right.$ $15,96 ; p<0,0001)$ y precipitaciones $\left(F_{11,64}=4,93 ; p\right.$ $<0,0001)$ medias anuales varían significativamente entre los sectores biogeográficos.

El ajuste de la disminución de la temperatura en función del incremento de la altitud es significativo y asciende al 94,12\% (Fig. 12), no existiendo una correlación significativa entre la pluviosidad y la altitud.

\section{DISCUSIÓN}

Los análisis efectuados en la familia Asteraceae están en correspondencia con los propuestos por Jørgensen \& León-Yánez (1999) a escala global para la Flora de Ecuador e indican que: (1) la región andina es la que alberga la mayor riqueza de especies, (2) los más altos niveles de endemismo están asociados a los Andes y a las Islas Galápagos, (3) la mayoría de las especies tienen una distribución altitudinal restringida, y (4) los hábitos de crecimiento más frecuentes son el arbustivo y el herbáceo.

\section{Diversidad de especies de Asteraceae en los An- des y en los valles interandinos de Ecuador}

\section{Páramos de Ecuador}

El límite natural de crecimiento del estrato arbóreo en el bosque andino está entre $3300 \mathrm{~m}$ y 3500 m (Cuesta et al., 2012), lo que sitúa el límite de crecimiento de las plantas vasculares entre $4600 \mathrm{~m}$ y $5000 \mathrm{~m}$ de altitud (Smith \& Young, 1987). Entre ambos se localizan los pastizales altoandinos amacollados y arbustos siempreverdes, algunos de ellos micrófilos con hojas coriáceas y pubescentes

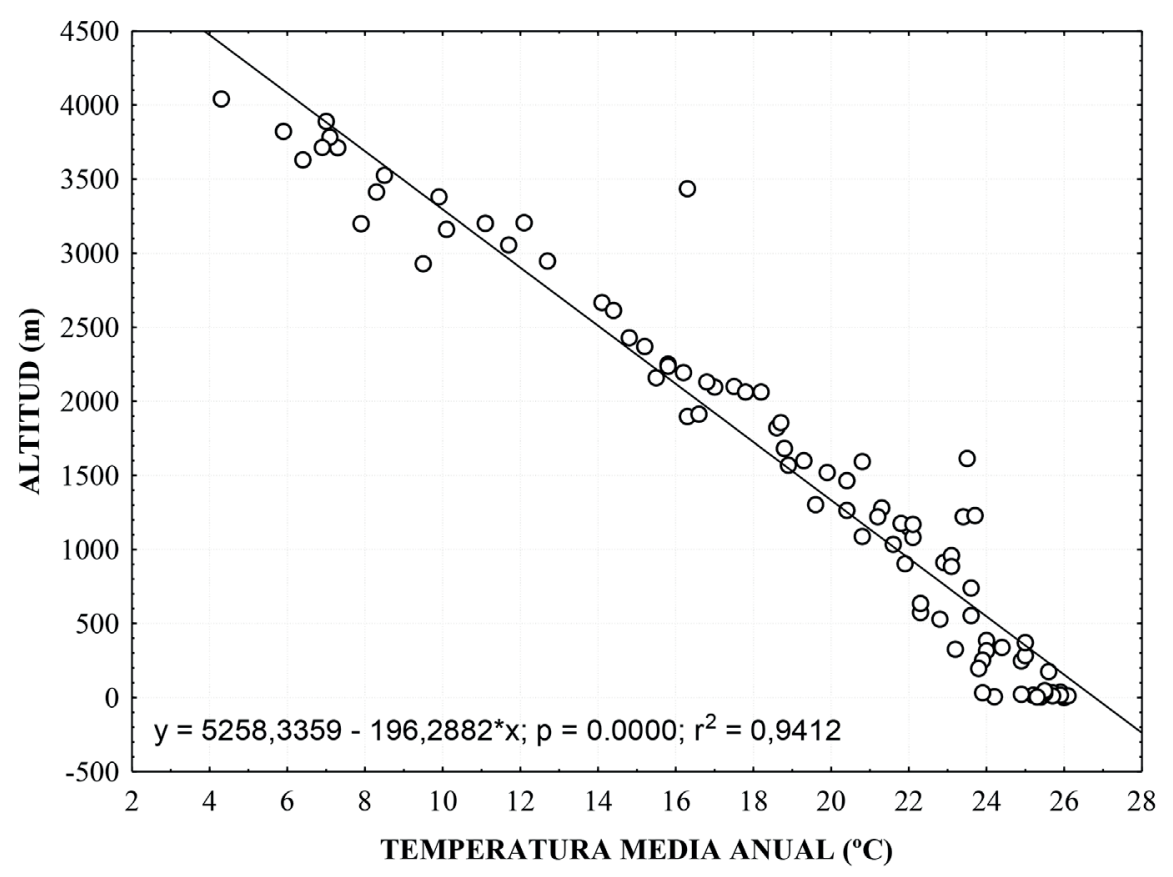

Figura 12. Variación de la temperatura en relación a la altitud con una ajuste del 94,12\%. 
(Luteyn, 1999; Muriel, 2008), que son reemplazados por plantas almohadilladas, rosetas acaulescentes, hierbas de bajo porte y arbustos postrados en la medida que se incrementa el gradiente altitudinal (Ramsay \& Oxley, 1997; Muriel, 2008).

Los páramos son ecosistemas mixtos tropicales áridos de alta montaña que conquistan la zona intermedia entre los límites superiores de la extensión de los bosques y el hielo perenne de los glaciares andinos desde Venezuela hasta el norte de Perú. En el que dominan pajonales, rosetales, arbustales, árboles enanos, humedales y bosquetes (Mena Vásconez \& Hofstede, 2006). Las especies de plantas parameras exhiben adaptaciones evolutivas a la congelación, a la alta irradiación solar y a la sequedad fisiológica como la disminución del metabolismo en las horas más frías, alta tasa de rebrote, porte bajo, microfilia (Oritrophium), desarrollo de hojas en rosetas (Espeletia, Floscaldasia, Oritrophium), suculentas o carnosas (Senecio), coriáceas (Chuquiraga) y con gran producción foliar; pigmentos oscuros, diversidad de elementos epidérmicos como pelos o tricomas (Ageratina, Cronquistianthus, Diplostephium, Erigeron, Grosvenoria, Mikania, Oritrophium, Verbesina), ceras (Senecio), glándulas (Ageratina, Diplostephium, Grosvenoria, Oritrophium), emergencias (Chuquiraga), zarcillos (Mutisia); tallos subterráneo (Erigeron, Floscaldasia, Oritrophium), formación de estolones (Pilosella); así como un período de crecimiento, floración $\mathrm{y}$ fructificación corto.

En Ecuador los páramos ocupan el 5\% del territorio nacional y se extienden desde los $2800 \mathrm{~m}$ hasta los $4200 \mathrm{~m}$ (Beltrán et al., 2009). Están ligados a los glaciares, que han perdido entre el $30 \%$ al $37 \%$ de su masa de hielo entre 1956 y el año 2000 (Serrano Giné \& Galárraga Sánchez, 2015), proceso que se ha visto acelerado desde comienzo de los ochenta en el glaciar del volcán Antisana y los glaciares con una superficie inferior a $1 \mathrm{~km}^{2}$ presentan gran probabilidad de desaparecer en un período inferior a 10 años (Cáceres et al., 2006). Los páramos están interconectados de norte a sur lo que facilita el flujo de genes y las migraciones (Aguirre \& Torres, 2013); aunque el número de especies y su cobertura disminuye con la altitud (MECN-INB, 2015).

Las especies de la familia Asteraceae son dominantes en este ecosistema (Izco et al., 2007; Pacurucu Reyes et al., 2015; Aguirre-Mendoza et al.,
2015; Caranqui et al., 2016) y en todas las zonas seleccionadas de estudio de la Red Andina de Monitoreo (GLORIA, Cuesta et al., 2012); con 313 especies en territorio ecuatoriano, que alcanza su máxima diversidad entre 2500-3000 m (Jørgensen \& León-Yánez, 1999). Kessler et al. (2011) argumentan que Asteraceae - junto a Melastomataceae y Myrsinaceae son las familias dominantes por encima de los $3000 \mathrm{~m}$ de altitud. Izco et al. (2007) y Eguiguren et al. $(2015 a, b)$ señalan que la mayor riqueza florística se extiende entre $3200-3500 \mathrm{~m}$ en Ecuador. Las evidencias actuales sugieren que la diversidad de los endemismos de esta familia se incrementa en el gradiente altitudinal desde los 1800 $\mathrm{m}$ hasta $3400 \mathrm{~m}$, logrando su mayor riqueza entre los 2900-3000 m, lo cual se desfasa de estudios previos para la región.

Morillo \& Briceño (2000), en un estudio de la diversidad de Asteraceae en los páramos venezolanos, encontraron que las Heliantheae presentan la mayor diversidad genérica, específica y el mayor número de endemismos, seguida de las Senecioneae, Astereae, Eupatorieae y Gnaphalieae; con escasa representación de las tribus Anthemideae, Liabeae, Mutisieae y Vernonieae. Los autores muestran que el mayor número de especies de Heliantheae se extiende desde Venezuela hasta Colombia y disminuye drásticamente al sur de Sudamérica, con valores análogos de especies de Eupatorieae, Senecioneae, Astereae y Gnaphalieae para Venezuela y Colombia; en cambio, para el resto del continente Astereae y Gnaphalieae exhiben una mayor diversidad. Los resultados obtenidos para Ecuador se desfasan ligeramente de los anteriores al ser las tribus Senecioneae, Eupatorieae, Heliantheae, y Astereae las que presentan el mayor número de endemismos en orden decreciente.

Este ecosistema es frágil, con gran diversidad de especies endémicas distribuidas en un hábitat fragmentado y adaptadas a grandes fluctuaciones diarias de las temperaturas entre el día y la noche, que contrasta con su gran estabilidad anual (Serrano Giné \& Galárraga Sánchez, 2015). Además, tienen que soportar fuertes y prolongadas heladas, recibir una elevada radiación ultravioleta e insolación perpendicular, crecer bajo un alto régimen de humedad con valores variables de precipitación tanto estacionales como espaciales, estar expuesta a fuertes vientos desecantes y tolerar una baja presión atmosférica (Beltrán et al., 2009; Lozano et 
al., 2013, 2015; Anhalzer \& Lozano, 2015; Serrano Giné \& Galárraga Sánchez, 2015). También debe amortiguar el impacto del fuego, el pastoreo, la deforestación, y la agricultura (Muriel, 2008; Lozano et al., 2013, 2015; Anhalzer \& Lozano, 2015; Lozano et al., 2016) que provocan la liberación del dióxido de carbono a la atmósfera, cuestión crítica para la regulación del ciclo del carbono en la Tierra (Suárez Duque et al., 2016). Las plantaciones de especies exóticas como Pinus L. spp. y Eucalyptus L'Hér spp. merman la disponibilidad de agua hasta el 70\% (Serrano Giné \& Galárraga Sánchez, 2015), incrementan la evapotranspiración (Crespo et al., 2014) e influyen de forma negativa en los cambios en la estructura y distribución de las comunidades (Aguirre \& Torres, 2013).

Los páramos reservan gran cantidad de carbono y pueden contribuir a la mitigación de los gases efecto invernadero por deforestación y degradación (Suárez Duque et al., 2016). En el Parque Nacional Podocarpus el contenido de carbono en el páramo varió de $2,9 \mathrm{t} / \mathrm{h}$ a $14,4 \mathrm{t} / \mathrm{ha}$ en la fitomasa $\mathrm{y}$ de $37,4 \mathrm{t} / \mathrm{ha}$ a $164,6 \mathrm{t} / \mathrm{ha}$ en el suelo (Eguiguren et al., 2015b). Resultados análogos se obtuvieron en los páramos del Parque Nacional Sangay (Cargua et al., 2014: $6,55 \mathrm{MgC} / \mathrm{ha}$ en el sotobosque a $215,0 \mathrm{MgC} / \mathrm{ha}$ en el suelo) y en el páramo de Igualata (Carrasco et al., 2016: 36,6 tC/ha a 92,27 tC/ ha en la biomasa y de $197,68 \mathrm{tC} / \mathrm{ha}$ a $610,39 \mathrm{tC} / \mathrm{ha}$ en el suelo en una amplitud altitudinal de $4090 \mathrm{~m}$ a $4130 \mathrm{~m}$ ). Además, los suelos del páramo tienen un alto contenido de materia orgánica en los primeros estratos del suelo que tiende a incrementarse con la altitud, principalmente en los suelos no intervenidos (Cunalata et al., 2013; Carrasco et al., 2016).

Las bajas temperatura del páramo y la formación de complejos órgano-metálicos en el suelo, particularmente el aluminio contenido en la ceniza volcánica y la materia orgánica se combinan formando una estructura resistente a la actividad de los descomponedores que inducen a una reducción drástica de la tasa de descomposición de la materia orgánica con una reducida reserva de hojarasca y biomasa aérea (Cunalata et al., 2013; Hofstede et al., 2014; Suárez Duque et al., 2016). Esto contribuye a tres de sus principales servicios ecosistémicos que son el almacenamiento y la regulación del agua (incluyendo la potable, de riego, y la que genera electricidad), además de ser fuentes de los principales ríos (Mena Vásconez \& Hofstede,
2006; Cunalata et al., 2013; Lozano et al., 2013).

En este ecosistema destacan los bofedales que son humedales en el que dominan las plantas almohadilladas de alta productividad; se desarrollan en zonas inundadas o seminundadas sobre suelos impermeables, con alto contenido de materia orgánica muerta que se transforma en turba y favorece el almacenamiento del carbono en el suelo (Suárez Duque et al., 2016). Los depósitos de turba se producen cuando la producción primaria de la cobertura vegetal excede a las pérdidas por lixiviado y descomposición, lo que provoca que la materia orgánica se concentre de forma vertical o lateral (Turetsky et al., 2004).

La vegetación, principalmente del centro y norte de Ecuador, crece sobre suelos generalmente de origen volcánico (Mena Vásconez \& Hofstede, 2006; Serrano Giné \& Galárraga Sánchez, 2015), derivados de cenizas volcánicas y de otros depósitos piroclásticos resultantes de las erupciones volcánicas (Podwojewski, 1999) o de rocas metamórficas e ígneas (Vera, 2004).

Los suelos de los páramos del norte y centro son jóvenes (andosoles), compuesto por depósitos volcánicos con gran parte de vidrios, no diferenciados, de color negro, y con alto contenido de materia orgánica; presentan complejos aluminio-orgánicos y/o minerales poco cristalizados, sin arcilla y con limo; de elevada capacidad de retención de agua $\mathrm{y}$ de aniones, en particular de fosfatos y sulfatos; altamente permeables con microagregación y resistentes a la erosión; con la pérdida de sus propiedades físicas llegan a repeler el agua (Podwojewski \& Poulenard, 2000; Vera, 2004; Borja Ramón et al., 2008b; Cisneros et al., 2010; Serrano Giné \& Galárraga Sánchez, 2015). También encontramos histosoles que presentan un mayor contenido de arcilla y una concentración superior de fósforo, potasio, calcio, magnesio, hierro, manganeso, zinc y amonio que los andosoles (Borja Ramón et al., 2008b; Cisneros et al., 2010). Ambos suelos son ácidos y el pH varía de 4,5 a 4,9 (Borja Ramón et al., 2008b). En los páramos del sur los suelos son más antiguos, muestran ausencia de cobertura piroclástica y derivan de rocas metamórficas, con una menor fertilidad y capacidad para movilizar el fósforo (Vera, 2004). Se caracterizan por ser delgados y pobres, de color oscuro hasta rojizo, anaranjado o amarillo por su contenido en óxido reducido de hierro y pueden contener cuarzo; presentan una alta tasa de 
retención de agua, de aluminio intercambiable y de arcilla mineralógica, además de una alta densidad aparente (Podwojewski \& Poulenard, 2000).

$\mathrm{Su}$ balance hídrico es positivo, gracias a altas tasas de nubosidad, neblina y precipitación horizontal (Young et al., 2011). El estudio preliminar efectuado por Crespo et al. (2014) en los páramos húmedos del sur de Ecuador sugiere que el movimiento del agua en el suelo se afecta por el pastoreo extensivo y la agricultura, que reduce su capacidad de regulación y amortiguación. Además, el rendimiento hídrico decrece y la infiltración vertical a través del suelo es dominante. Borja Ramón et al. (2008a) evaluaron la curva de retención de agua del suelo del páramo de Quimsacocha en la provincia de Cuenca y sostienen que en condiciones de alta humedad el principal proceso es la escorrentía superficial al permanecer casi inactivos los horizontes superiores a las variaciones del contenido de humedad, mientras que las capas más profundas del suelo permanecen activas, con una respuesta inmediata a los eventos de precipitación y contribuyen de forma positiva a los procesos hidrológicos en el páramo.

En el páramo, las especies muestran una baja tasa de migración y altos niveles de diversidad y de especiación in situ con gran número de endemismos, que pueden llegar al 60\% (Mena Vásconez \& Medina, 2001). Esto se debe principalmente a la historia evolutiva geológica y volcánica de los Andes en Ecuador; a los ciclos de glaciares durante el Plioceno y Pleistoceno que vinculados con las condiciones ecológicas resultan en diversas asociaciones de plantas; a la constancia en la humedad relativa del aire; al clima húmedo y frío que impera; a la alta irradiación solar; a factores biofísicos como el aislamiento geográfico de parches de vegetación, a la diversidad de hábitats y de suelo; a la orografía del país que destaca la disminución de su altitud hacia el sur que permite la influencia de las corrientes del litoral y de la Amazonía en la riqueza y composición de especies (Mena Vásconez \& Hofsted, 2006; Beltrán et al., 2009).

\section{Sur de Ecuador}

Entre los $2^{\circ} \mathrm{S}$ hasta los $3^{\circ} \mathrm{S}$ predominan los relieves tabulares, y desde los $3^{\circ} \mathrm{S}$ hasta los $4^{\circ} \mathrm{S}$ ambas cordilleras (Occidental y Oriental) quedan fusionadas en una unidad. La depresión de Cuenca-Girón
(Ecuador) y Huancabamba (Perú) son de los sectores más bajos de los Andes y constituye una zona de transición entre el páramo y la puna (Richter \& Moreira-Muñoz, 2005).

En el sector Catamayo-Alamor (541-66 Ma), que pertenece a la provincia de Loja, convergen en su estructura geológica rocas volcánicas y volcanoclásticas del Paleozoico, del arco volcánico continental del Cretácico-Paleógeno, y del antearco del Cretácico-Paleóceno tardío (Jaillard et al., 2008). Entre los depósitos más relevantes tenemos las tobas, conglomerados, brechas, areniscas, lutitas, y limolitas (Cretácico-Paleógeno); grauvacas y granidioritas (Cretácico; Pilatasig et al., 2005). Este sector presenta una amplia diversidad de suelos, encabezado por entisoles e inceptisoles, además de alfisoles, oxisoles, aridisoles y molisoles (Mapa 1:25000/SIG Tierras-IEE-CGSIN/2009-2015).

Desde Paute (Cuenca) hasta el norte de la provincia de Loja encontramos una gran variabilidad geomorfológica como conglomerados, areniscas y lutitas (Neógeno); tobas soldadas (Mioceno); tobas dacítico-rioltias, lava andesítica y rocas volcánicas sedimentarias (Eoceno-Oligoceno), esquistos verdes (Jurásico); ortogneis y paragneis (Paleozoico-Cenozoico); esquistos grafíticos, cuarcitas y metasamitas (Devónico), esquistos micáceos (Paleozoico) y granidioritas (Cenozoico, Pilatasig et al., 2005). Además del relieve irregular debido al entrecruzamiento intricado de montañas, estribaciones, nudos, portetes y mesetas, que junto a las cuencas hídricas favorecen la formación de hábitats y microhábitats (Aguirre-Mendoza et al., 2017).

La depresión geográfica de Huancabamba tuvo su origen en el Cretácico-Cenozoico (Espurt et al., 2017) y atraviesa de este a oeste a la Cordillera de los Andes en el norte de Perú e interrumpe su continuidad (Almeida \& Nogales, 2005). Aquí el río Marañón desvía su curso hacia el oriente amazónico y la Cordillera Occidental andina aminora su cota altitudinal en el Paso de Porculla, Perú (2145 $\mathrm{m})$. Esta deflexión estuvo influenciada por penetraciones esporádicas del Océano Pacífico desde el Eoceno hasta el Mioceno medio (56-23 Ma), separando la cordillera, y probablemente favoreció la especiación de organismos que habitaban en alta montaña a ambos lados de la depresión, al ser el océano una barrera a la dispersión, aunque existieron refugios de tierras bajas (Antonelli \& Sanmartín, 2011). Con el levantamiento de las Cordilleras 
Occidental y Oriental de los Andes y el fin de las irrupciones marinas desde el Mioceno nuevas rutas migratorias quedaron establecidas y la Cordillera Andina quedó interconectada (Antonelli \& Sanmartín, 2011). Prueba de ello son los bosques relictos o fragmentos de bosque con gran riqueza florística y de endemismos en la vertiente occidental del norte de Perú y del sur de Ecuador que en el pasado constituyó una unidad (Weigend et al., 2005).

Esta depresión sigue actuando como una barrera geográfica natural entre los Andes del Norte y los Centrales, que contribuye a la especiación al perderse la continuidad en la cobertura forestal (Weigend et al., 2005). Un ejemplo de ello es el valle árido del Río Santa en la zona Amotape-Huancabamba en Perú, fronteriza con Ecuador (Weigend et al., 2005). Este accidente geográfico constituye una zona de convergencia que permite la conexión biogeográfica entre las Regiones Litoral y Amazonía (Aguirre-Mendoza et al., 2017), ampliamente influenciada por las masas de aire provenientes del Pacífico cargadas de sales (Makowski et al., 2016). Además, la zona de divergencia al sur del Nudo de Loja, la depresión Girón-Cuenca y el sur de la provincia de Cuenca constituyen centros naturales de diversidad genética, con clima fragmentado que promueve la especiación adaptativa (Richter \& Moreira-Muñoz, 2005).

Lo antes expuesto justifica la riqueza en endemismos de plantas de provincia de Loja, que es megadiversa y consta de 22 ecosistemas con una diversidad florística de 3039 especies de plantas distribuida en diversos pisos altitudinales (AguirreMendoza et al., 2017).

\section{Región Litoral}

La región Litoral se localiza al oeste de la Cordillera Occidental y se formó por depósitos del PaleógenoCuaternario (66-0,01 Ma) con franjas que tuvieron su origen en la meseta oceánica y en el arco del Cretácico-Paleógeno (145-66 Ma, Jaillard et al., 2008). La franja litoral al sur de Ecuador y el sur de la provincia de El Oro están litológicamente formadas por granitoides, ortogneis y paragneis (Paleozoico-Cenozoico), esquistos, metagrauvacas, filitas y anfibolitas (Paleozoico; Pilatasig et al., 2005).

Sus suelos son principalmente del tipo inceptisol y molisol, seguidos en importancia por los suelos alfisoles, entisoles y aridisoles (Mapa 1:25000/
SIG Tierras-IEE-CGSIN/2009-2015). Los suelos son volcánicos y aluviales; ricos en arena, arcilla y limo, lo que proporciona una estructura franca a franca arcillosa, y son más evolucionados que los suelos del sector interandino (Zebrowski \& Sourdat, 1997; García Cruzatty \& Schlatter Vollmann, 2012; Novillo Espinoza et al., 2018).

Los endemismos de Asteraceae que habitan en los sectores Chocó [Elaphandra eggersii (Hieron) H. Rob., Hebeclinium obtusisquamosum (Hieron ex Sodiro) R. King \& H. Rob., Mikania palmata J. F. Pruski \& W. C. Holmes, M. psylobothrya Sodiro ex H. Rob. \& W. C. Holmes, Pentacalia carchiensis (Cuatrec.) Cuatrec., Verbesina minuticeps S. F. Blake], Cordillera Costera del Chocó (V. minuticeps) y Cordillera Costera del Pacífico Ecuatorial (Bidens simplicifolia C. H. Wright, M. psylobothrya, Pentacalia cazaletii H. Rob. \& Cuatrec., $V$. minuticeps) están estrechamente relacionados con sus homólogos que crecen en la Región Amazónica. Se enfatiza que el sector Chocó presenta valores análogos de temperaturas y precipitaciones medias anuales que la región Amazónica. Las especies pertenecientes a los géneros Mikania y Pentacalia son bejucos, hierbas o arbustos trepadores, mientras que E. eggersii es un arbusto trepador, hábito de crecimiento que comparten con los endemismos representados en la Amazonía.

Existe similitud estadística entre en la composición de endemismos que habitan en los sectores Jama-Zapotillo y Catamayo-Alamor al compartir los endemismos Elaphandra paucipunctata $\mathrm{H}$. Rob. y Verbesina pentantha S. F. Blake. Se destaca que el endemismo $V$. minuticeps está representado en todos los sectores de la región Litoral con adaptabilidad a diversos ecosistemas.

\section{Región Amazónica}

La región Amazónica se formó por depósitos del Paleógeno-Cuaternario (66-0,01 Ma, Jaillard et al., 2008). La base de las Cordilleras Amazónicas, zona subandina paralela a los Andes, se enclava en el Mesozoico, 252-66 Ma (Jaillard et al., 2008), considerada como una zona de "cabalgamiento y plegamiento tras-arco" tectónicamente vinculada a los Andes, que recibió diversidad de depósitos volcánicos durante el Cuaternario (Nieto, 1991). El arco de Loracachi separa los levantamientos de Napo por el norte y el de Cutucú por el sur, sobrecorrimiento 
y levantamiento que se produjo en el Neógeno (Nieto, 1991). En la zona del volcán Reventador (basaltos andesíticos, lahares y piroclastos), que corresponden al levantamiento de Napo, presenta fallas o fracturas con metamorfirmo de grado bajo (Nieto, 1991).

Las Cordilleras de Galeras (calizas del Cretácico) y Cutucú (pizarras y areniscas cuarcíticas del Silúrico-Devónico; calizas bioclásticas y dolomitas con lutitas y areniscas intercaladas del Carbonífero-Pérmico) forman parte de estas cordilleras (Pilatasig et al., 2005). Al igual que la Cordillera del Cóndor que está estructuralmente formada por rocas areniscas y calizas con instrucciones ígneas del Mesozoico-Cenozoico cuyos suelos derivados son altamente ácidos y muy pobres en nitrógeno, fósforo y otros nutrientes (Rodríguez-Rodríguez et al., 2013). Además de gneis (Pre-cámbrico); pizarras y areniscas cuarcíticas (Silúrico-Devónico); granidioritas, areniscas rojas, tobas y andesitas (Jurásico); rocas sedimentarias finogranulares silíceas, calizas, areniscas, arcillas y lavas (Paleógeno; Pilatasig et al., 2005).

Destacan los depósitos de lapillis y cenizas en el oriente de la zona costera y en el piedemonte amazónico (García Cruzatty \& Schlatter Vollmann, 2012). Hacia el este de la Región Amazónica se extiende una amplia llanura aluvial, que es tectónicamente más estable que zona subandina (Nieto, 1991). En esta región prevalecen los suelos del tipo inceptisol, y en orden decreciente de importancia están los ultisoles, alfisoles entisoles y oxisoles (Mapa 1:25.000/SIG Tierras-IEE-CGSIN/2009-2015).

La vegetación en la región Amazónica es exuberante y cerrada, donde dominan los árboles, hierbas, arbustos y epífitas (Jørgensen \& León-Yánez, 1999) y la familia Asteraceae requiere una exposición directa al sol para su desarrollo. Los endemismos amazónicos Elaphandra pastazensis $(\mathrm{H}$. Rob.) H. Rob., Mikania dodsonii H. Rob. \& W. C. Holmes, M. farsiliflora H. Rob. \& W. C. Holmes, M. harlingii R. M. King \& H. Rob., M. urcuensis H. Rob. \& W. C. Holmes, Pentacalia hurtadoi H. Rob. \& Cuatrec., P. luteynorum H. Rob. \& Cuatrec., P. moronensis H. Rob. \& Cuatrec., P. napoensis H. Rob. \& Cuatrec., Sampera cusalaguensis (Hieron.) V. A. Funk \& H. Rob., Sciadocephala asplundii R. M. King \& H. Rob., Stachycephalum asplundii H. Rob. \& Tangerini son bejucos, hierbas o arbustos trepadores que les permite alcanzar la parte superior de la cobertura vegetal y cubrir sus requerimientos de luz mientras que Hebeclinium palaciosii $\mathrm{H}$. Rob. e Ichthyothere pastazensis $\mathrm{H}$. Rob. son arbustos.

\section{Islas Galápagos}

El Archipiélago de Galápagos se originó producto de una intensa actividad volcánica hace aproximadamente 4 Ma (Niedbalai \& Schatz, 1996) y se localiza en la zona de contacto de las placas de Nazca y Cocos que se desplazan en dirección opuesta y en ángulo con el Centro de Expansión de Galápagos (Zurita, 1988; Andrus et al., 2009; Clausen, 2016) a razón de $70 \mathrm{~km} /$ millón de año, por tanto, desde sus orígenes el archipiélago ha migrado $200 \mathrm{~km}$ en dirección al continente (Lanteri, 2001). Las islas más antiguas (Española, Santa Fe y San Cristobal) se localizan hacia el sureste y las jóvenes (Fernandina e Isabela) no tienen más de $0,7 \mathrm{Ma}$ (Niedbalai \& Schatz, 1996). Los islotes Daphne Mayor, Champion y las cuatro Guy Fawkes tienen tan solo varios cientos de miles de años (Geist, 1997). Las islas Española y Santa Fe son fragmentos de escudos volcánicos subaéreos (Geist, 1997). Las islas más jóvenes ocupan la región occidental del archipiélago (Zurita, 1988) que coincide con un punto caliente o pluma de magma en el manto terrestre que se originó hace 80 a $90 \mathrm{Ma}$ en las profundidades del manto de la litósfera (Geist, 1997). La pluma de magma ha dado origen a todos los volcanes basálticos de estas islas, incluyendo los de la cordillera submarina de Carnegie, cuya lava tiene un bajo contenido de sílice que le proporciona una menor viscosidad (Clausen, 2016). Lo que indica que cada isla que conforma el archipiélago es un volcán, excepto Isabela que es producto de la fusión de seis volcanes mediante puentes de lava, evidencia de ello es el Istmo de Perry (Geist, 1997; Clausen, 2016).

Las especies de plantas que colonizaron el Archipiélago Galapaguense provenían de Ecuador, Colombia, Perú (Carvajal-Endara et al., 2017), Chile, América del Norte, América Central y el Caribe (Andrus et al., 2009) como resultado de un sistema de arcos de islas o fragmentos continentales de 90 Ma a 76 Ma de antigüedad que se desplazaron hacia el este hasta colicionar con América del Norte, Central y del Sur (Grehan, 2001). El éxito de estas colonizaciones estuvo marcado por la idoneidad 
del ambiente y del hábitat, al coincidir el nicho climático y el clima imperante en las islas, donde este último factor se asocia al tamaño de las islas para determinar la estructura filogenética de las comunidades de plantas que la habitan que a su vez está relacionada con la especiación "in situ", relegando al "aislamiento entre islas" y a las "limitaciones en la dispersión" a una posición secundaria en relación a la composición de especies (Carvajal-Endara et al., 2017). Estos autores también destacan que las islas con comunidades de plantas filogenéticamente similares y condiciones climáticas análogas no están cerca geográficamente.

Las especies que integran la familia Asteraceae son pioneras y heliófilas, adaptadas a invadir hábitats perturbados y son colonizadoras, con alta capacidad de bloqueo de las oportunidades ecológicas que ralentiza o inhibe la taza de colonización de otras especies (Takayama et al., 2018). El alto potencial de diversificación de las especies de Asteraceae en el Archipiélago de Galápagos y su elevado número de endemismos puede estar impulsado por la radiación adaptativa que es propiciada por la heterogeneidad del entorno y diversidad de hábitats existentes en las islas en un período de tiempo relativamente corto. Probablemente, las especies evolucionaron "in situ" en una isla, migren o irradien hacia las otras islas, en el caso de los endemismos de Asteraceae, a excepción hasta el presente de Chrysanthellum fagerlindii Eliass., Lecocarpus leptolobus, Scalesia atractyloides, S. divisa, y $S$. retroflexa, habitan en más de una isla del Archipiélago Galapaguense. Sin embargo, la mayoría de los táxones tienen áreas de distribución restringida, lo que indica que la dispersión entre islas es limitada. Las hipótesis de la "regla de dispersión" y de la "especiación corolario" están relacionadas con este fenómeno. La aplicación de la hipótesis de la "regla de dispersión" podría explicar este proceso, al sugerir que los miembros basales de una radiación archipiélago surgen en las islas más antiguas y colonizan las islas más jóvenes en función de su edad y de las condiciones ecológicas imperantes (Funk \& Wagner, 1995; Landis et al., 2018). La hipótesis de la "especiación corolario" plantea que en las islas jóvenes los clados menos especializados, con gran adaptabilidad, presentan una mayor tasa de especiación y diversificación, cubriendo los nichos disponibles, a la vez que se especializan (Wagner et al., 1995; Landis et al., 2018). Ambos procesos, cladogénesis y anagénesis contribuyen a la especiación en estas islas (Takayama et al., 2018).

Durante el Pleistoceno las islas tenían una mayor superficie a consecuencia del descenso de los océanos por los eventos de glaciación y una mayor aridez en comparación con la actualidad (Lanteri, 2001). Aquí las fluctuaciones del nivel del mar influyeron en la conectividad dinámica espaciotemporal entre las islas de este archipiélago. Una sucesión de islas de aproximadamente 90 Ma yacen sumergidas en las Cordilleras de Cocos y de Carnegie (Grehan, 2001) pudieron emerger de forma temporal y actuaron como puentes de conectividad entre islas y como refugios transitorios de biodiversidad, donde los procesos de fusión y separación de islas impulsaron la especiación dinámica y la conectividad redujo la tasa de extinción de especies (Andrus et al., 2009; Borregaard et al., 2017; Crawford \& Archibald, 2017). Ambas cordilleras probablemente estuvieron emergidas previo a la formación del Archipiélago Galapaguense, y no existe certeza que albergaran a especies ancestrales de Asteraceae que contribuyeran a formar las especies endémicas actuales presentes en el archipiélago (Andrus et al., 2009).

El modelo propuesto por Lenzner et al. (2016) muestra una correlación entre la riqueza de especies y la riqueza de endemismos con la edad de las islas, donde la familia Asteraceae presenta la mayor riqueza de especies y de endemismos. A escala general, la mayor riqueza de especies se alcanza entre 1,79 a 1,89 Ma, mientras que la mayor riqueza de endemismos en esta familia ocurre a los 3,6 Ma, en ambos casos a edades tempranas, cuando las islas son jóvenes, con una fuerte tendencia al decrecimiento en la medida que se incrementa la edad. La variación en el número de especies de Asteraceae entre las distintas islas que integran el archipiélago de Galápagos, no necesariamente significa una mayor tasa de diversificación, ni implica una direccionalidad en los procesos de dispersión. Además, el tiempo en el cual se produjo la divergencia de los endemismos isleños, no necesariamente tienen que coincidir con la edad de las islas, esto fue demostrado por Pillon \& Buerki (2017) para endemismos de Nueva Caledonia.

A nivel infraespecífico se reconocen dos variedades para Scalesia microcephala (microcephala y cordifolia) y $S$. atractyloides (atractyloides y darwinii), tres subspecies para S. affinis (affinis, 
brachyloba, gummifera) y Darwiniothamnus lancifolius (lancifolius, glabriusculus y glandulosus), dos subspecies para $S$. helleri (helleri y santacruzia$n a)$ y $S$. baurii (baurii y hopkinsii). Los patrones de variación interespecíficas no están claramente definidos a nivel morfológico y genético, excepto en $S$. affinis, y su estudio sería oportuno y ventajoso. El estudio molecular efectuado por Nielsen (2004) en S. affinis demuestra que los individuos se diferencian a escala de islas por su diversidad de alozimas y que la varianza molecular se distribuye de forma irregular entre las islas y dentro de ellas, donde las poblaciones de Isabela divergen de las poblaciones de Santa Cruz y Floreana y justifican tan solo dos subespecies circunscritas a este táxon S. affinis subsp. affinis y S. affinis subsp. gummifera (Hook. f.) Harling.

La interacción entre especiación-colonizaciónextinción determina los gradientes de biodiversidad espacial y la riqueza de especies en islas, que cambia a través del tiempo según el modelo de McArthur \& Wilson (1963). La separación de las islas a escala temporal es un factor importante que promueve la especiación alopátrica por la aparición de barreras geográficas que interrumpen el flujo génico (Lenzner et al., 2016), que se modula con la dinámica de la tectónica de placas, la formación de las islas, las fluctuaciones de las condiciones ambientales y su erosión geológica dentro de un marco espacio-temporal (Chalmandrier et al., 2018). Aquí la radiación adaptativa potencia la conquista acelerada de múltiples hábitats y el incremento de la productividad del ecosistema, donde las especies inmigrantes encuentran un espacio de nuevas oportunidades, con escasa competencias para el acceso a los recursos que incrementa la probabilidad de colonización exitosa y de especiación con una rápida fijación de las variaciones genéticas y morfológicas que induce a altas tasas de evolución. Se espera que el nivel de aislamiento genético generalmente sea resultado de una fuerte barrera postzigótica para que las variaciones acumuladas a lo largo del tiempo no puedan revertir por hibridación (Crawford \& Archibald, 2017).

Probablemente, la hibridación y la introgresión han tenido un rol destacado en la especiación y en la evolución de la flora de las Islas Galápagos; impacto que fue objeto de análisis por Caujapé-Castells et al. (2017) para la flora de las Islas Canarias. El género Scalesia despliega barreras reproductivas que no garantizan el completo aislamiento, existiendo flujo génico en el nivel interespecífico y que solo la distancia geográfica y las limitaciones en vectores de polinización son las que frenan la hibridación interespecífica en el género (Lindhardt et al., 2009). Las islas San Cristóbal y Santa Cruz son un entorno propicio para los procesos de hibridación interespecíficas que se evidencia entre $S$. divisa y S. incisa (isla San Cristóbal; Nielsen et al., 2003) y entre $S$. aspera, $S$. crockeri y $S$. pedunculata (isla Santa Cruz; Eliasson, 1974; Lindhardt et al., 2009).

Los ancestros de las especies endémicas de $\mathrm{As}$ teraceae de las Islas Galápagos debieron de caracterizarse por un "flexible" hábito de crecimiento, sistema de cruzamiento, de polinización y dispersión que le permitiera superar con éxito al efecto fundador y al cuello de botella en su fase inicial de colonización; quizás con un sistema de especiación homoploide alopátrica y parapátrica.

Los estudios moleculares demuestran que Darwiniothamnus es un género polifilético (Andrus et al., 2009). Darwiniothamnus lancifolius y D. tenuifolius son monofiléticas y hermanas del endemismo cubano herbáceo Erigeron bellidiastroides Griseb. (Andrus et al., 2009) que está filogenéticamente relacionado con los endemismos de las Antillas Mayores agrupados en Erigeron sec. Microcephalum (Nesom, 2008). Darwiniothamnus alternifolius se circunscribe a Erigeron sec. Meridionales (Nesom, 2008) transferencia efectuada por Tye (2010) al publicar la nueva combinación Erigeron alternifolius (Lawesson \& Andersen) N. Andrus \& Tye. La especie señalada es una planta herbácea perenne de base leñosa, que crece hasta $50 \mathrm{~cm}$ de altura y es hermana de los endemismos chilenos Erigeron fasciculatus Colla y E. luxurians (Skottsb.) Solbrig de la región Coquimbo-Valparaiso, con hábito de crecimiento análogo (Andrus et al., 2009). El presente trabajo declina la transferencia efectuada por Tye (2010) al estar incompleta la filogenia en la cual se basa, aunque Nesom (2000) circunscribe el género Darwiniothamnus en la sinonimia del género Erigeron.

Encelia Adans. (Fehlberg \& Ranker, 2007), Pectis (Hansen et al., 2016) y Scalesia (Blaschke \& Sanders, 2009) son monofiléticos. Encelia es hermano de Enceliopsis (A. Gray) A. Nelson y Geraea Torr. \& A. Gray, y forma dos grandes subclados con escasa diferenciación genética entre las especies circunscritas en cada uno de ellos (Fehlberg 
\& Ranker, 2007). Pectis es hermano del género Porophyllum Guett. (Hansen et al., 2016). Scalesia es hermano del género Pappobolus, endémico de los Andes y del clado Viguiera Kunth (Schilling et al., 1994; Blaschke \& Sanders, 2009) cuyo origen pudo producirse como resultado de una única introducción de un poliploide de Pappobolus desde el Ecuador continental hace 1,9 a 6,2 Ma (Schilling et al., 1994) que irradió y se dispersó a las ditintas islas. Acmella darwinii es hermana de A. sodiroi, cuyo ancestro pudo ser similar en morfología a esta especie, quizás proveniente de Ecuador o Perú y en su proceso de divergencia reduce el tamaño y el número de piezas florales de pentámeras a tetrámeras (Jansen, 1985).

Harling (1962) reeleva Lipochaeta laricifolia (Hook. f.) W. L. Wagner \& H. Rob. a escala genérica como Macraea laricifolia Hook. f., decisión que fue aceptado por Cronquist (1971), excluida por Gardner (1979) por ser un nombre dudoso y rechazada por Wagner \& Robinson (2001) al transferir L. lariciofolia del ilegítimo género Macraea Hook. f. a Trigonopterum Steetz ex N. J. Andersson. Basado en datos moleculares de Panero et al. (1999) esta especie es hermana del género Sphaneticola O. Hoffm. de la zona costera pantropical de Mesoamérica y del norte de América del Sur (Stuessy et al., 2014), probablemente su ancestro proceda de esta región de América Tropical (Panero et al., 1999).

Las filogenias moleculares realizadas por Blöch et al. (2009) y Stuessy et al. (2011) muestran que el género Lecocarpus está incluido dentro de la variación del género Melampodium L. (parafilético), cuyo origen pudo ocurrir a partir de la rápida divergencia de poblaciones ancestrales de Acanthospermum a consecuencia de las condiciones ambientales imperantes en las islas (Stuessy et al., 2014).

Los géneros Chrysanthellum Pers. ( $n=8$; Turner, 1988), Darwiniothamnus ( $n=9$; Crawford et al., 2009), Lecocarpus ( $2 n=2 x=22$; Blöch et al., 2009; Crawford et al., 2009; Stuessy et al., 2011), y Trigonopterum $(2 n=2 x=28$; Eliasson, $1984)$ son diploides, mientras que Scalesia $(n=34$; Ono, 1967; Crawford et al., 2009), Jaegeria gracilis Hook. f. $(2 n=4 x=36$; Torres, 1968), y Pectis subsquarrosa $(2 n=6 x=72$; Keil, 1977) son poliploides; probablemente deriven de especies ancestrales también poliploides. La especie Baccharis gnidiifolia Kunth $(n=9)$ es diploide (Sundberg et al., 1986).
Los endemismos de Asteraceae de las Islas Galápagos son en su mayoría perennes que permite la supervivencia de las especies en condiciones desfavorables y la estabilidad de las poblaciones no está condicionada a la germinación de las semillas en cada generación. Chrysanthellum fagerlindii, C. pusillum (Turner, 1988), Delilia inelegans (Hook. f.) Kuntze y D. repens (Delprete, 1995), Jaegeria gracilis (Torres, 1968; Chamorro et al., 2012), y Pectis subsquarrosa (Wiggins \& Porter, 1971) son hierbas anuales; Acmella darwinii (Ornduff, 1969; Jansen, 1985) y Pectis tenuifolia (Wiggins \& Porter, 1971) son hierbas perennes; $S$. pedunculata, $S$. cordata y $S$. microcephala son árboles (Itow, 1995); los endemismos de los géneros Baccharis, Darwiniothamnus, Encelia, Lecocarpus (Chamorro et al., 2012), Trigonopterum (Eliasson, 1984) y el resto de las especies de Scalesia (Itow, 1995) son arbustos leñosos.

En las especies arbóreas se distinguen características que responden a un hábito de crecimiento herbáceo: crecimiento rápido, madera blanda, médula bien desarrollada y floración rápida, al año después de haber germinado (Itow, 1995). El carácter xerofítico decrece de alto a moderado en los géneros Lecocarpus, Trigonopterum, y Darwiniothamnus (Carlquist \& Eckhart, 1982). Trigonopterum exhibe estructuras helicoidales en la pared de sus vasos y con las fibras más grandes en longitud que se ensancha en las zonas aledañas a la médula y son más delgadas hacia el exterior; en cambio el género Darwiniothamnus reúne bandas en su parénquima $\mathrm{y}$ al igual que Baccharis angustifolia Desf. ostenta dimorfismo en sus fibras, lo cual es incipiente en Lecocarpus que es notable por la punteaduras en la pared de sus vasos (Carlquist \& Eckhart, 1982).

La zona litoral es generalmente rocosa con arena gruesa. En la zona árida la vegetación es xerofítica y las especies habitan sobre suelos superficiales y están adaptadas a un sustrato rocoso y a escasa humedad. En cambio, en la zona de transición el sustrato es variable, desde suelos volcánicos poco profundos y permeables hasta bloques de lava y suelos degradados en el que se desarrolla una vegetación xerofítica y mesofítica. En la zona húmeda los suelos son profundos y ricos en humus que le proporcionan una coloración de marrón oscuro a rojo, en el que crecen hongos, briófitos, helechos, miconias, orquídeas y otras epífitas.

La vegetación húmeda, de reciente formación, está aislada en las laderas con exposición sur en 
los volcanes del archipiélago, rodeada por la vegetación de las tierras bajas secas. La vegetación de tierras altas ha sido sometida a intensas presiones evolutivas debido a la impetuosa influencia de las oscilaciones del nivel del mar en sus procesos de expansión y de contracción (Ali \& Aitchison, 2014). La formación de hábitats abiertos pudo estar influenciada por continuas perturbaciones, principalmente por una intensa actividad volcánica, deslizamientos de tierras, y condiciones climáticas variables que propiciaron la aparición de cambios genéticos y morfológicos a escala poblacional (Takayama et al., 2018). Los endemismos de $A s$ teraceae en la región insular muestran solapamiento de sus áreas de ditribución y sus hábitats están escasamente diferenciados, donde la frecuencia de especies se incrementa en relación a la superficie y edad geológica de las islas, principalmente en el género Scalesia que muestra una distribución alopátricas o parapátricas, excepto $S$. affinis que ocupa un amplio rango de hábitats y es simpátrica con otras especies del género (Blaschke \& Sanders, 2009). Se añade que a mayor elevación se produce un incremento del número de endemismos de esta familia en la zona húmeda.

Los representantes de la familia Asteraceae en las Islas Galápagos tienen inflorescencias solitarias en ramas terminales o axilares [Acmella, Chrysanthellum, Encelia, Jaegeria (1-3 capítulos largamente pedicelados/nudo), Trigonopterum, Pectis, Scalesia], en cimas (Pectis), cimas corimbiformes (Darwiniothamnus), compuestas de numerosas cabezuelas cortamente pediceladas y densamente agrupadas en el extremo de las ramas y en las axilas de las hojas (Delilia), corimbos (Encelia, $S$. cordata) y capítulos heterógamos, solitarios, que salen de las tricotomías de las ramas (Lecocarpus). En D. alternifolius las inflorescencias están situadas por encima de las hojas terminales, mientras que en las otras dos especies del género se localizan al mismo nivel que las hojas terminales (McMullen, 1999; Andrus et al., 2009). Los capítulos son en su mayoría bisexuados, raramente unisexuados, homógamos o heterógamos. Scalesia, Acmella darwinii y en ocasiones Jaegeria, presentan capítulos bisexuados homógamos con las flores flosculosas hermafroditas y fértiles (capítulos discoideos). Los capítulos radiados, bisexuados, y heterógamos con flores externas hemiliguladas y las internas flosculosas están presentes en Chrysanthellum,
Darwiniothamnus, Jaegeria y Pectis (las externas femeninas, las internas hermafroditas, ambas fértiles); Delilia (las externas femeninas y las internas funcionalmente masculinas con el ovario estéril); Encelia (las externas neutras al faltar el androceo y el gineceo, las internas hermafroditas y fértiles), y en Lecocarpus y Trigonopterum (las externas femeninas y las internas estaminadas). También encontramos capítulos unisexuados homógamos con todas las flores flosculosas blancas en Baccharis steetzii, especie dioca con inflorescencias en corimbos terminales o en cortas ramas axilares.

Scalesia presentan las flores blancas y algunas especies (S. affinis, S. baurii, S. retroflexa, S. inci$s a)$ pueden presentar flores liguladas blancas en la periferia del capítulo (McMullen, 1999), carácter que contribuye al incremento de las visitas florales por parte de los vectores de polinización y de dispersión; probablemente, la amplia distribución y la diversidad de hábitats que ocupa $S$. affinis esté correlacionada con esta característica morfológica (Blaschke \& Sanders, 2009). El género Darwiniothamnus presenta las flores liguladas blancas y las tubulosas amarillas. Acmella darwinii presenta las flores blancas con las anteras negras (Jansen, 1985). Los respresentantes de los géneros Jaegeria, Pectis y Chrysanthellum presentan las flores liguladas y tubulosas de color amarillo. Delilia repens presenta las flores liguladas bidentadas de color amarillo a blancas, las flores del disco son tubulosas, blancas de glabras a puberulentas (Delprete, 1995).

Los géneros Baccharis (Velásquez \& Rangel, 1995; Almeida Braga et al., 2012), Darwiniothamnus (Jaramillo \& Trigo, 2006a), Encelia (Saavedra, 2013), Jaegeria (Velásquez \& Rangel, 1995), y Scalesia (Jaramillo \& Trigo, 2006b) presentan granos de polen trizonocolporados, isopolares y radiosimétricos, con espinas cónicas y agudas. La diferenciación morfológica del polen de las especies de Scalesia se ha producido por apomorfías homoplásticas (Blaschke \& Sanders, 2009).

La familia Asteraceae en las Islas Galápagos es generalista en cuanto a sus requerimientos en vectores de polinización, autocompatible o parcialmente autocompatible y autógama (Acmella, Darwiniothamnus, Encelia, Jaegeria, Lecocarpus, Pectis y Scalesia), por lo que no depende estrictamente de los vectores de polinización para reproducirse, lo que constituye una ventaja que se fundamenta 
en la edad de las islas y en la escasez de polinizadores (Ornduff, 1969; Clark, 1988; McMullen \& Naranjo, 1994; Schilling et al., 1994; Philipp et al., 2004; Crawford et al., 2009; Chamorro et al., 2012; Takayama et al., 2018). Por lo expuesto, la dioecia de Baccharis gnidiifolia y B. steetzii no evolucionó en las Islas Galápagos (Sundberg et al., 1986; Chamorro et al., 2012). Los estudios efectuados en $S$. cordata (Philipp \& Nielsen, 2010), S. affinis (Nielsen et al., 2007) demuestran que es parcialmente autoincompatible. Se enfatiza que un alto nivel de autogamia presumiblemente reduce la diversidad genética de los individuos en las poblaciones, lo cual limita de forma ostensible la radiación, la diversificación y la especiación (Takayama et al., 2018).

El fruto de la familia Asteraceae está adaptado a la dispersión a larga distancia al presentar gran parte de los grupos vilano, ser de bajo peso, con pericarpo rugoso (Lenzner et al., 2016) y en algunos casos con glándulas viscosas. Las dos primeras características propician su dispersión anemófila y las tres últimas posibilitan su dispersión epizoocórica. Ambos procesos estimulan la conectividad poblacional de propágulos entre las islas y entre el continente y las islas. La eficacia de la dispersión epizoocórica estaría condicionada por los vientos, el flujo migratorio, fundamentalmente de aves, y por los vectores de dispersión nativos dentro de las islas o grupos de islas (Takayama et al., 2018). Nielsen (2004) demostró que el flujo génico a través de la dispersión del fruto de $S$. affinis era muy limitado dentro de las islas y entre las islas, siendo la tranferencia de polen lo que garantiza el flujo génico inter poblacional a ambas escalas.

Los endemismos de Asteraceae de estas islas presentan un sistema de dispersión variable con dominio de la epizoocoria. Las especies endémicas de los géneros Baccharis y Pectis son anemócoras (Vargas et al., 2012), un modo de dispersión que se fundamenta en los aquenios estrechamente fusiformes con un vilano de cerdas barbelladas o de pelos rectos, escabrosos y delgados de Baccharis steetzii (Andersson, 1855; Nesom, 2000), y en los aquenios ovado-oblongos, comprimido, con costillas redondeadas, multiestriado, puberulentos, con vilano de escamas, cerdas o aristas bien desarrolladas o reducidas a una corona de Pectis (Schutz, 1856). Encelia es estrictamente epizoocórico (Vargas et al., 2012) con cipselas fuertemente comprimidas de obovada a cuneadas, velloso-ciliadas, y generalmente sin vilano (Andersson, 1855; McMullen, 1999; Panero et al., 1999). Los géneros Chrysanthellum y Jaegeria revelan un sistema de dispersión no asistido (Vargas et al., 2012) que se apoya en los aquenios irregularmente papilados con vilano ausente de Chrysanthellum (Eliasson, 1967) y en los aquenios negros, glabros y sin vilano de Jaegeria (Wiggins \& Porter, 1971). En este último, los aquenios externos son aplanados o trígonos abrazados por una bráctea que presenta un delgado margen por todo su borde; los internos son comprimidos y envueltos por los pliegues traslúcidos de las brácteas internas (Wiggins \& Porter, 1971; Panero et al., 1999). Problemente Acmella darwinii presente un sistema de dispersión análogo al estar el vilano ausente en sus cipselas y ser glabras (Jansen, 1985).

Los géneros Darwiniothamnus (epizoocóricoanemócoro), Lecocarpus (epizoocórico-anemócoro) y Scalesia (epizoocórico-no asistido) muestran un sistema de dispersión mixto (Vargas et al., 2012). Darwiniothamnus presenta aquenios con un vilano de numerosas cerdas en el ápice (McMullen, 1999); con aquenios no dimórficos en D. alternifolius (Andrus et al., 2009). Lecocarpus está provisto de aquenios con espinas o anzuelos que respaldan su dispersión epizoocórica (McMullen, 1999; Sønderberg Brok \& Andersen, 2007), los aquenios de las flores liguladas son fértiles y están equipados de un ala delgada y peltada que le facilita la dispersión por el viento a distancias relativamente cortas (Carlquist, 1966; Philipp et al., 2004). Scalesia se surte de aquenios delgados (S. crockeri), con una o dos aristas cortas (S. microcephala, $S$. pedunculata, S. atractyloides, S. incisa, S. baurii, y $S$. cordata; Carlquist, 1966), con puntas o callos o sin vilano (S. gordilloi; McMullen, 1999, S. cordata; Carlquist, 1966) que ayudan a la dispersión epizoocórica mediante su adhesión a los agentes dispersantes y para ser liberados de las cabezuelas. Carlquist (1966) destaca que en los aquenios de $S$. pedunculata y $S$. microcephala la arista puede estar presente o ausente, ya sea a escala poblacional $(S$. pedunculata) o a escala de capítulo (S. microcephala). Trigonopterum está aprovisionada de aquenios obovado-cuneados, comprimidos, trígonos e híspidos, con vilano muy corto que McMullen (1999) lo describe como proyecciones semejantes a dientes y Carlquist (1966) los define como aquenios alados y coronados por un círculo de escamas; los externos 
más anchos y verrugosos, adaptados a un mecanismo de dispersión a corta distancia, aunque algunos presentan una o dos aristas. Existe la probabilidad de que su ancestro estuviese equipado de aristas para facilitar la dispersión epizoocórica, carácter que al parecer se perderá en la evolución de T. laricifolia (Hook. f.) W. L. Wagner \& H. Rob. Delilia exhibe aquenios ovoides y lateralmente comprimidos, estriados y sin vilano, con escasos pelos cortos en el ápice (Delprete, 1995), lo cual se contradice con lo expresado por Panero et al. (1999) que indica que vilano es en forma de arista como resultado de la prolongación del margen de la cipsela.

\section{Riesgo de extinción en Asteraceae}

Según los datos reportados por la IUCN, en la actualidad hay un total de 341 especies de Asteraceae de la Flora de Ecuador incluidas en la Lista Roja de Especies Amenazadas. Barriga et al. (2011) identificaron 11 especies de Asteraceae que probablemente estén extintas, las cuales se relacionan a continuación: Baccharis mollis Kunth (una única colección efectuada por A. Humboldt y A. Bonpland), Delilia inelegans (tres especímenes recolectados por C. Darwin, 1835), Elaphandra retroflexa (S. F. Blake) H. Rob. (2 poblaciones recolectadas, 1921), Hieracium debile (Fr.) F. W. Schultz \& Sch. Bip. (dos colecciones de localidad y fecha desconocidas efectuadas por W. Jameson; sinónimo de Pilosella debilis (Fr.) F. W. Schultz \& Sch. Bip.), Mikania iserniana Cuatrec. (una única colección, 1864), M. palmata (una única colección efectuada por Jativa y Epling, 1962), M. seemannii B. L. Rob. (una única colección realizada por Seemann, 1845-1851), M. stereolepis B. L. Rob. (una única colección, 1876), M. tafallana Kunth (una única colección previo a 1818), Viguiera media Blake [una única colección, 1849, sinónimo de $\mathrm{Al}$ dama media (S. F. Blake) E. E. Schill \& Panero], y Wedelia oxylepis S. F. Blake (una única colección, 1918).

Las principales causas del alto número de especies de Asteraceae con categoría de la IUCN se relacionan a continuación: (1) pérdida y fragmentación del hábitat natural de las especies por la intensa deforestación, la agricultura y ganadería intensiva, la expansión del área agrícola y ganadera, la colonización humana no organizada, la quema de la vegetación original, la construcción de nuevas carreteras y apertura de nuevas vías de comunicación en la región amazónica, la construcción del Oleoducto de Crudos Pesados, la intensificación de la actividad minera, la ampliación del área urbana, la expansión del área natural destinada a la implementación de centros turísticos y recreativos, e incremento del número de especies de plantas y herbívoros introducidos; (2) el cambio climático que favorece la propagación de especies invasoras; (3) las erupciones volcánicas; (4) falta de medidas efectivas gubernamentales y de leyes, así como su adecuada aplicación, para la protección de la flora y fauna ecuatoriana y de sus ecosistemas en las áreas preservadas o no tuteladas por el SNAP (Sistema Nacional de Áreas Protegidas); (5) escaso controly evaluación de áreas naturales para su protección y conservación; (6) falta de estrategias y limitados recursos destinados a investigar y conservar especies amenazadas a corto y largo plazo; (7) los estudios de impacto ambiental presentan escasos resultados a favor de los ecosistemas naturales y de las especies que contienen, sin incluir especies endémicas en los proyectos de reforestación.

Henderson et al. (1991) estimaron que el 90-95\% de los bosques andinos, incluyendo los que están en el páramo han desaparecido. Ecuador consta con 91 ecosistemas, 87 de los cuales están mapeados que cubren una superficie de 15.333 .562 ha $(59,80 \%$ del territorio nacional), de las cuales 7.620.780 ha están declaradas como áreas protegidas (MAE, 2015). Los cinco ecosistemas con mayor registro de especies de plantas inventariadas sin especificar la familia son (MAE, 2015): bosque siempre verde piemontano del norte de la Cordillera Oriental de los Andes (3725 especies), bosque siempre verde de tierras bajas del Napo-Curaray (3177), bosque siempre verde montano de la Cordillera Occidental de los Andes (3053), bosque siempre verde montano del sur de la Cordillera Oriental de los Andes (2859) y herbazal del páramo (2769).

Los ecosistemas con mayor número de endemismos de especies de plantas se listan en orden descendente sin especificar la familia (MAE, 2015): bosque siempre verde montano del sur de la Cordillera Oriental de los Andes (513 especies), herbazal del páramo (463), bosque siempre verde montano (420) y montano bajo (265) de la Cordillera Occidental de los Andes (420) y bosque siempre verde montano del norte de la Cordillera Oriental de los Andes (238). 
Destacan cinco ecosistemas con el mayor número de especies endémicas amenazadas (MAE, 2015): bosque siempre verde montano del sur de la Cordillera Oriental de los Andes (335 especies), herbazal del páramo (273), bosque siempre verde montano (235) y montano bajo (156) de la Cordillera Occidental de los Andes (235), y bosque siempre verde piemontano de la Cordillera Oriental de los Andes (143).

El carbono almacenado por estrato varió de 37 t/ha en el bosque seco pluvioestacional a $160,4 \mathrm{t} /$ ha en el bosque siempre verde de tierras bajas de la Amazonía. El 84,60\% del carbono se localiza en la biomasa viva y el $15,40 \%$ restante se almacena en la biomasa muerta (MAE, 2015).

Salazar et al. (2017) en el informe de Encuesta de Superficie y Producción Agropecuaria Continua en relación al uso del suelo en Ecuador muestra lo siguiente: (1) el $11,58 \%$ se destina a cultivos permanentes, (2) el $7,32 \%$ se emplea en cultivos transitorios y barbechos, (3) el 1,05\% se utiliza en concepto de descanso, (4) el 5,49\% y el $19,81 \%$ lo ocupan pastos cultivados y naturales respectivamente, (5) el 2,69\% y el 45,94\% lo aprovechan páramos, montes y bosques respectivamente, y (6) el $6,13 \%$ se dispone para otros usos. Las estadísticas muestran una tasa decreciente de $0,25 \%$ respecto al año 2016 en relación a la superficie total (Salazar et al., 2017). Los datos indican que menos del $50 \%$ del territorio nacional es destinado a vegetación nativa, de las cuales se desconoce su estado de conservación. La superficie ocupada por montes y bosques sufrió una reducción del 1,70\% (5,68 millones de hectáreas a escala nacional), la Región Amazónica es la que ocupa la mayor superficie $(50,67 \%)$ y en orden decreciente le siguen la Región Sierra (25,01\%), la Región Litoral $(24,21 \%)$ y las zonas no delimitadas $(0,11 \%)$. Los páramos han experimentado una contracción de su superficie del $12,01 \%(332,418$ hectáreas a escala nacional) en el año 2017 , donde el $98,37 \%$ se localizan en la Región Sierra, el 1,46\% ocupan la Región del Litoral y el $0,18 \%$ están representados en la Región Amazónica (Salazar et al., 2017). El descenso en la superficie total destinada a vegetación natural acelera la extinción de las especies y en consecuencias una pérdida de la biodiversidad afectando los servicios ecosistémicos (Ojeda-Luna et al., 2015).

El proceso de degradación de los páramos ecuatorianos es continuo y muestra un espectro variable
(Podwojewski, 1999), desde muy degradado (páramo de pajonal) hasta conservado (páramo de frailejones), con una tasa muy baja de recuperación. En el caso particular de Espeletia pycnophylla Cuatrec. la actividad antropogénica ha reducido el tamaño de las poblaciones de la Reserva Ecológica El Ángel en un 30\% en los últimos 10 años (Rodríguez et al., 2017). Se estima que más de las tres cuartas partes del área geográfica ocupada por los páramos presentan señales de actividad antropogénica y que las áreas que se encuentran en buen estado de conservación se localizan en la Región Amazónica de la Cordillera Oriental y en los extremos norte y sur del país (Hofstede et al., 2002).

La transformación del páramo está directamente vinculada a la actividad antropogénica desde las culturas Cañari, Puruhá, Caranqui, CaranquiCayambe, Palta, Quitu e Inca hasta la actualidad. Se destaca la ocupación inca del páramo, en el que establecieron fortificaciones militares, miradores, templos religiosos, observatorios astronómicos, centros de descanso para sus atletas que actuaban de correo; además de expandir la cota altitudinal destinada a la agricultura, la ganadería y la caza e introducir las llamas y las alpacas (Mena Vásconez, 2010; Hofstede et al., 2014).

La introducción de especies agrícolas, caballos y de ganado de pastoreo como ovino, bovino y caprino se intensifico durante la dominación española en toda la región andina, al igual que la implantación de las haciendas ganaderas, agrícolas o mixtas que condujeron a cambios drásticos en el ecosistema (Mena Vásconez, 2010; Hofstede et al., 2014).

Los páramos intervenidos presentan escasa vegetación natural que ha sido sustituida por pastos para el consumo del ganado, por plantaciones de Pinus spp. y Eucalyptus spp. o por cultivares. Los mismos muestran una menor capacidad de retención de agua, mayor porosidad, bajo contenido de materia orgánica y disminución de la conductividad que los páramos no intervenidos (Carúa et al., 2008; Camacho, 2014). Lo cual tiene un efecto negativo sobre erosión del suelo de las microcuencas al provocar deslizamientos y movimientos de masas (Damián Carrión et al., 2017).

En las Islas Galápagos a pesar de los grandes esfuerzos que se han desplegado el riesgo de extinción sigue siendo alto. La diversidad genética de las poblaciones ha mermado debido al intenso pastoreo de mamíferos introducidos y la explotación 
de la tierra, entre las especies más afectadas se encuentra $S$. affinis, en particular las poblaciones de Floreana y Santa Cruz (Nielsen, 2004).

\section{Deforestación, repoblación forestal y políticas pú-} blicas

La tasa anual de desforestación en Ecuador es muy alta y varió considerablemente entre 1990 al 2014. En el período 1990-2000 la deforestación neta fue de 92.742 ha/año, con un decrecimiento del 0,58\% en el período 2000-2008 en el que se deforestaron 77.748 ha/año (MAE, 2015). Durante el período 2008-2014 se observó un decremento del 0,37\% con 47.497 ha/año deforestadas (MAE, 2015), cifras que resaltan en las provincias de Morona Santiago (7925 ha), El Oro (6274 ha) y Esmeraldas (5476 ha). El 64,9\% de la superficie de bosque se transformó en pastizales para la ganadería, el $11,8 \%$ en mosaicos agropecuarios, el $3,7 \%$ en plantaciones de cacao, el 3,1\% en cultivos de maíz duro, el $3 \%$ en plantaciones de palma africana, el $2 \%$ en cafetales; el porcentaje restante se destinó a otras coberturas y a áreas urbanas (MAE, 2016).

En términos de miles de metros cúbicos, la tala de árboles relictos $(127$ a 170,1) y de árboles en formaciones pioneras $(33,38$ a 9,60$)$ se incrementó en el primero y se contrajo significativamente en el segundo del 2007 al 2009 (MAE, 2010).

En el 2013 se inventariaron 1639 parcelas forestales y un total de 102.647 árboles, destinados en su mayoría para la producción de madera $(50 \%)$, leña $(19 \%)$, y frutales $(7 \%)$; el $22 \%$ restante se empleó en otros usos (MAE, 2015).

Los factores que a continuación se relacionan inciden en la deforestación en Ecuador (MAE, 2016): (1) políticas públicas y leyes que favorecen la colonización y el desarrollo de los sectores minero, petrolero y agropecuario; (2) incentivos fiscales y monetarios para modificar prácticas y acciones determinadas; (3) prácticas agropecuarias y forestales poco sostenibles, generalmente ilegales, que no respetan las tasas de regeneración natural del bosque; (4) monocultivo extensivo, susceptible a plagas y enfermedades; (5) incentivos nacionales e internacionales para la comercialización de madera de especies endémicas y nativas que promueve la deforestación y 6) factores socio-económicos y ambientales como el crecimiento demográfico, la infraestructura vial, el empleo, y las fluctuaciones en el precio del petróleo y de los productos no manufacturados.

La repoblación forestal con especies exóticas de rápido crecimiento con Pinus radiata $\mathrm{D}$. Don, $P$. patula Seem., Eucalyptus globulus Labill., E. saligna Sm. en la Región Sierra y con Schizolobium parahybum (Vell.) S. F. Blake, Tectona grandis L., Eucalyptus spp. y Gmelina arborea en la Región Litoral (MAE, 2010) es un hecho perjudicial para la vegetación nativa, los suelos y las cuencas hídricas (Geoinformática y Sistemas Cia. Ltda., 2015). $\mathrm{Su}$ impacto sobre el paisaje es notable al proporcionar monotonía y homogenidad.

En el caso particular de las especies de los géneros Pinus y Eucalyptus demandan gran cantidad de agua que altera el régimen hídrico del suelo y produce su desecación, que a su vez acelera la descomposición de la materia orgánica con implicaciones negativas sobre la fertilidad del suelo (Crespo et al., 2014; Hofstede et al., 2014). El efecto de ambas especies sobre el sotobosque es negativo, la hojarasca de Pinus spp. es uniforme y resistente a la descomposición mediante actividad microbiana por lo que el suelo deja de recibir aporte de materia orgánica; la hojarasca de Eucalyptus spp. es rica en fenoles que inhibe el crecimiento de otras especies (Hofstede et al., 2014). En ambos casos, el desarrollo de la vegetación autóctona queda anulado (Hofstede, 2001).

Para la reforestación también se emplean especies nativas maderables como Cordia alliodora (Ruiz \& Pav.) Oken, Pollalesta discolor (Kunth) J. F. Pruski, Ochroma pyramidale (Cav.) Urban, Dacryodes peruviana (Loes.) H. J. Lam, Cedrelinga cateniformis (Ducke) Ducke, Humiriastrum diguense (Cuatrec.) Cuatrec., Cedrela P. Bowne spp. y Swietenia macrophylla G. King (MAE, 2010).

\section{Quema de la vegetación natural}

Durante el año 2017, con fecha de corte el 15.12.2017, se han producido 968 incendios y se han quemado 13.403,78 hectáreas de cobertura vegetal a escala nacional, con mayor incidencia en las provincias de Guayas (138 eventos), Loja (132), Santa Elena (120), Manabí (107) y Azuay (98); siendo las provincias de Pichincha (2250,6 ha quemadas), Loja (1762,6 ha); Azuay (1523,28 ha), Imbabura (1294,04 ha), Chimborazo $(1087,15 \mathrm{ha})$ y Santa Elena $(1055,06 \mathrm{ha})$ las 
más afectadas (Equipo Técnico de Dirección de Monitoreo de Eventos Adversos, 2017).

La quema extensiva es una actividad frecuente con el fin de eliminar la vegetación existente (GeoPlaDes, 2011), mayoritariamente la paja y el manto vegetal seco y muerto, que favorece el rebrote del pasto tierno para la alimentación del ganado; facilitar la caza al ahuyentar a las especies de animales silvestres a consecuencia del fuego, y promover la preparación de la tierra para la labranza (Hofstede, 2001). Su efecto sobre el suelo es indirecto porque desaparece la cobertura vegetal que actúa como capa aislante para amortiguar en la Región Sierra las bajas y las altas temperaturas nocturnas y diurnas, respectivamente (Camacho, 2014). Las altas temperaturas incrementan su descomposición y la pérdida de su humedad por evaporación. La quema reiterada impide que el ecosistema se recupere y la diversidad biológica de especies silvestres y su abundancia tienda a desaparecer (Camacho, 2014).

\section{Ganadería y la avicultura}

El sector pecuario tiene censadas en el ejercicio del 2017 a 4.190.611 cabezas de ganado vacuno; 1.115.473 de porcino; 390.120 de ovino, 49.727 de asnal, 209.990 de caballar, 80.111 de mular y 39.583 de caprino (Salazar et al., 2017). En relación al ejercicio del 2016, las estadísticas muestran un incremento del $1,53 \%$ para las cabezas de ganado vacuno censadas a escala nacional; $48,87 \%$ del total se localizan en la Región Sierra, mientras que el 42,32\% y el 8,77\% están censadas en las Regiones Litoral y Amazonía, respectivamente (Salazar et al., 2017).

El sector avícola tiene censadas a escala nacional, en el año 2017, a 3.344 .602 pollos, 3.847 .466 de pollitos, 483.969 patos y 41.913 pavos que se crían de forma libre en el campo (Salazar et al., 2017).

La ganadería y la avicultura tienen un doble efecto, la herbivoría y la compactación del suelo; a las cuales no está evolutivamente adaptada la vegetación paramera (Hofstede et al., 2014). El impacto de la ganadería está directamente correlacionado con el tipo animal, su carga, su manejo y si este último está aparejado con la quema de la vegetación, que potencia su efecto negativo (Geoinformática y Sistemas Cia. Ltda., 2015). La herbivoría intensifica la pérdida de la cobertura vegetal (Camacho, 2014), dañando de forma indirecta al suelo. El pisoteo compacta el suelo perdiendo capacidad de absorción, infiltración y retención; acelerando la escorrentía superficial y la erosión (Podwojewski, 1999; Hofstede et al., 2014). Este proceso daña el meristemo de las plantas, produce aperturas en la capa vegetal y deja zonas expuestas a la erosión por el viento (Podwojewski, 1999; Hofstede et al., 2014), en especial las reses, ovejas, cabras y aves. También cortan la vegetación desde la parte basal del tallo (Podwojewski, 1999), particularmente ovejas, cabras y aves. Además de apelmazar el suelo suave, lo que perjudica a la vegetación en almohadilla, en los que destacan los caballos (Hofstede, 2001).

\section{Expansión de la frontera agrícola}

En el año 2017 se destinan 1,43 millones de hectáreas a cultivos permanentes, con un decremento del $0,60 \%$ en relación al año anterior (Salazar et al., 2017), donde el $72,04 \%$ del total se localizan en la Región Litoral, y en orden descendentes les siguen la Región Sierra (17,11\%), la Región Amazónica $(10,18 \%)$ y las zonas no delimitadas $(0,67 \%)$. Los cultivos transitorios (0,90 millones de hectáreas) presentaron una tasa de crecimiento de $6,42 \%$ respecto al año anterior (Salazar et al., 2017), con mayor representación en la Región Litoral (65,72\%), seguidos por la Región Sierra $(30,42 \%)$ y la Región Amazónica (3,85\%).

Los pastos cultivados se extienden por 2,45 millones de hectáreas a escala nacional, con una tasa de crecimiento del 6,39\% en el año 2017, distribuidos en orden descendentes como sigue (Salazar et al., 2017): Región Litoral (53,18\%), Región Sierra (29,54\%), Región Amazónica (17,21\%) y zonas no delimitadas $(0,07 \%)$.

Los pastos naturales ocuparon 0,68 millones de hectáreas a escala nacional en el año 2017, cuya superficie se contrajo en un $15,31 \%$ respecto al año anterior; con una representatividad del 78,00\% en la Región Sierra, $12,02 \%$ en la Región Litoral, 9,91\% en la Región Amazónica y el 0,07\% en las zonas no delimitadas (Salazar et al., 2017).

La actividad agrícola implica la retirada de la vegetación original y mover las capas del suelo para la siembra de especies generalmente introducidas $(\mathrm{Ca}-$ macho, 2014). Esto causa una pérdida de su humedad lo que conlleva a una merma en el contenido de materia orgánica, y a su vez disminuye su capacidad 
de retención del agua (Podwojewski, 1999; Crespo et al., 2014; Hofstede et al., 2014). La remoción del suelo moviliza sus nutrientes que al ser liberados produce a corto plazo un decrecimiento de su fertilidad y se modifique su estructura y propiedades físicas (Hofstede, 2001). A esto se le suma el uso de abonos orgánicos e inorgánicos y de pesticidas e insecticidas, que intensifican la contaminación, y a su vez necesarios para mantener una producción agraria en correspondencia con las demandas de la población actual. La frontera agrícola tiende a desplazarse en altitud a causa del incremento de la población y por pérdida de la fertilidad del suelo a causa de la erosión o el sobreuso (Mena Vásconez, 2010; GeoPlaDes, 2011; Camacho, 2014).

\section{Turismo}

Las áreas naturales recibieron la visita de 2.060.698 turistas, de los cuales 1.625 .938 son nacionales y 434.760 son extranjeros (Riofrío et al., 2017). Las áreas naturales más visitadas durante el año 2016 fueron: Área de Recreación Isla Santay, Reserva Faunística Puntilla de Santa Elena, Parque Nacional Galápagos, Reserva Ecológica Cotacachi-Cayapas, y la Reserva Geobotánica Pululahua (Riofrío et al., 2017).

La actividad turística nacional y extranjera también muestra sus implicaciones sobre la biodiversidad en áreas vulnerables al contaminar el medio con desechos, provocar incendios, emplear material vegetal nativo como leña, compactar el suelo y pisar la vegetación por donde transita (Mena Vásconez, 2010; GeoPlaDes, 2011).

\section{Comercialización de plantas}

El estudio efectuado por Rivero-Guerra (inédito) en los mercados de plantas medicinales silvestres de varias provincias de Ecuador indica que la familia Asteraceae es una de las más utilizadas por la población ecuatoriana con fines terapéuticos. $\mathrm{La}$ recolección sistemática de especies silvestres repercute de forma regativa en el tamaño y número de poblaciones.

\section{Cambio climático y riesgo ambiental}

Se atribuyen al cambio climático el incremento general y gradual de la temperatura, la modificación en el régimen de precipitaciones, las fluctuaciones en la frecuencia e intensidad de eventos extremos, pérdida de humedad del suelo, reducción de los glaciares, pérdida de biodiversidad e integridad de los ecosistemas, principalmente en los trópicos y una mayor exposición a enfermedades tropicales (IPCC, 1995; Vergara et al., 2014).

La temperatura de los Andes Tropicales se acentuó en $0,34^{\circ} \mathrm{C} /$ década entre $1979-1998$ (Cuesta et al., 2012) y disminuye $0,6^{\circ} \mathrm{C}$ por cada 100 metros de ascenso (Yánez et al., 2011), con una tendencia al incremento de las precipitaciones en los Andes del Norte y de decrecimiento hacia el sur. La humedad atmosférica se ha intensificado en un 2,5\%/década en los últimos 45 años en los Andes (Cuesta et al., 2012). Esto produce una desglaciación progresiva, se modifica la dinámica de las nubes al cambiar la ubicación del banco de nubes y del punto de rocío, afectando principalmente al bosque nublado (Aguirre et al., 2011; Marengo et al., 2011).

En el período 2010-2016 acaecieron entre 802 a 2118 eventos naturales de relevancia en Ecuador (García Guerrero et al., 2017), entre los que destacan los deslizamientos de tierra (1107 eventos), inundaciones (398), sismos (284) y déficit hídrico (103). Echeverría et al. (2017) estimaron el ascenso en 1 grado centígrado de las temperaturas y un acrecentamiento de las precipitaciones durante el período 2015-2039 en el páramo de Igualata, provincia de Chimborazo; con un riesgo a escala local y global del cambio climático sobre el ecosistema alto, con un índice de vulnerabilidad del 62,5. Serrano Vincenti et al. $(2012,2017)$ señalan un patrón variable y desigual en el régimen de precipitaciones, tendencia a la disminución en la evaporación total y la humedad relativa, un ascenso lineal de las temperaturas máximas $\left(0,1^{\circ} \mathrm{C}-1,25^{\circ} \mathrm{C}\right)$ y mínimas $\left(0,30^{\circ} \mathrm{C}-0,67^{\circ} \mathrm{C}\right)$ por cada 10 años en tres estaciones meteorológicas del Distrito Metropolitano de Quito, y un aumento en 1 día/año con temperaturas superiores a $25^{\circ} \mathrm{C}$. La Región Litoral muestra tendencias análogas, la temperatura terrestre $\left(0,012^{\circ} \mathrm{C} /\right.$ año) y de la superficie marina $\left(0,011^{\circ} \mathrm{C} /\right.$ año $)$ registran una tasa de cambio alta; el nivel medio del mar y su oleaje exhiben un aumento del orden de 1,1 $\mathrm{mm} /$ año en el primero y de $1,46 \mathrm{~cm} /$ año en el segundo con una rotación de $0,29^{\circ}$ a $0,58^{\circ}$ dirección sur (Contreras López et al., 2014).

Las especies más vulnerables son las que presentan hábitats especializados (Tiessen, 2011) y 
ante el cambio climático, pueden desarrollar diversas estrategias (Neill, 1999b, c; Delgado \& Suárez-Duque, 2009); entre ellas puede incluir la tolerancia y la adaptabilidad a las nuevas condiciones, reducir su hábitat que aumenta notoriamente su riesgo de extinción, pueden emigrar, y en el peor de los casos no consiguen adaptarse y desaparecen. Lo cual trae implicaciones en la expansión o contracción de ecosistemas (Anderson et al., 2011) que modifica las interacciones bióticas y abióticas, transforman su estructura, cambian las perturbaciones, alteran los roles y varían los servicios ecosistémicos.

El calentamiento del planeta potencia la influencia humana en los páramos, principalmente por un acrecentamiento en la frecuencia de incendios antropogénicos. Se añade que el ascenso de la temperatura del planeta incrementa la evaporación de lagos y humedales reduciendo la disponibilidad de agua, su área y los niveles de oxígeno; además de elevar su salinidad, las emisiones de dióxido de carbono y el potencial de eutrofización. También producen cambios sobresalientes que alteran la intensidad y recurrencia de las precipitaciones en los Andes (Tiessen, 2011), causando alteraciones en la erosión, balance del carbono y en los deslizamientos de tierra (Bader et al., 2007); que a su vez tiende a incrementar la frecuencia de eventos extremos como las sequías o lluvias intensas, así como olas de calor y de frío agudas (Anderson et al., 2011). Además de disminuir la cobertura de los bosques, bosquetes y páramos (Yánez et al., 2011).

El incremento de la temperatura puede potenciar el desplazamiento de las especies hacia altitudes mayores las cuales tendrán que vencer el efecto fundador y el cuello de botella que se produce a causa de las limitaciones en el flujo de genes; además de una reducción de biodiversidad y cambios en la composición de especies, su fenología y tasas de crecimiento, la frecuencia y diversidad de los agentes polinizadores y dispersantes, se afecta la producción de polen, de néctar y su concentración, cambia el balance del carbono en los organismos y en el suelo, variando el mecanismo de sensibilidad al fotoperiodo (Aguirre et al., 2011). Cuestión que se patentiza en la Reserva Ecológica el Ángel y en el Bosque Protector Golondrinas en la provincia de El Carchi, lo que modificará la estructura de los ecosistemas naturales actuales (Delgado \& SuárezDuque, 2009).

\section{Sistema Nacional de Áreas Protegidas (SNAP)}

El SNAP cubre el $19 \%$ del territorio nacional y abarca a todas las provincias del país (Yánez et al., 2011), en el que avanza la desforestación y la extensión de las áreas destinadas al sector agropecuario. Yánez et al. (2011) resumieron la problemática del manejo del SNAP como sigue: (1) ecosistemas altamente vulnerables están excluidos; (2) las investigaciones realizadas no responden, ni contribuyen, a las necesidades de conservación, de manejo y a la toma de decisiones; (3) desactualización y mínima socialización de los planes estratégicos a corto, mediano y largo plazo; (4) exiguo reconocimiento social de la diversidad biológica como recurso esencial para el desarrollo sustentable, así como de los disímiles servicios ecosistémicos que brinda; (5) conflictos por la tenencia de la tierra dentro de las áreas protegidas; (6) moderada capacidad de gestión y control por parte de las autoridades gubernamentales; (7) finaciamiento restringido y escasa administración sostenible de los mismos; y (8) vulneración de las directrices vigente para el aprovechamiento de los recursos naturales, con baja participación social en su manejo y protección. Probablemente la iniciativa conservacionista privada podría tener cierta efectividad en beneficio de la naturaleza.

\section{CONCLUSIONES}

Las conclusiones para los endemismos de la familia Asteraceae en la Flora de Ecuador son las siguientes: (1) presencia de 310 endemismos (307 especies, 1 subespecies y 2 variedades) que pertenecen a 80 géneros, 15 tribus y 4 subfamilias las cuales son mayoritariamente arbustos e hierbas en Ecuador Continental; (2) presencia de 33 especies endémicas de Islas Galápagos que se agrupan en la sufamilia Asteroideae con 11 géneros y 5 tribus; (3) dominio de la subfamilia Asteroideae; (4) primacía de las tribus Senecioneae, Eupatorieae, Heliantheae, Astereae y Vernonieae en Ecuador continental; (5) los géneros Mikania, Pentacalia y Gynoxys agrupan la mayor frecuencia de especies endémicas en Ecuador continental; (6) predominan en la Cordillera Andina (270 especies, 1 subespecie, 1 variedad) y en las Islas Galápagos (33 especies), distribuidos desde los $0^{\circ} \mathrm{N}$ hasta los 
$4^{\circ} \mathrm{S}$ y de los $75^{\circ} \mathrm{W}$ hasta $\operatorname{los} 91^{\circ} \mathrm{W}$, con especial ocurrencia a $0^{\circ} \mathrm{S}$ entre $77^{\circ} \mathrm{W}$ y $79^{\circ} \mathrm{W}$; (7) endemismos de la tribu Tageteae están representados en las Islas Galápagos exclusivamente, sin aparente presencia de endemismos de esta tribu en Ecuador continental, (8) los géneros Baccharis y Acmella están representados en las Islas Galápagos y en Ecuador continental, (9) existe similitud estadística en relación a la frecuencia de tribus y la composición de especies respecto a los sectores biogeográficos en los que habitan en Ecuador continental; (10) dominan en las provincias de Pichincha, Loja, Azuay, y Chimborazo; (11) existe una correlación baja y significativa entre la superficie y la edad geológica de las Islas Galápagos respecto al número de especies endémicas que la habitan y a mayor elevación se produce un incremento del número de endemismos en la zona húmeda; (12) en su mayoría son vulnerables o están en peligro de extinción y exhiben un amplio espectro altitudinal desde cercano al nivel del mar hasta cotas superiores a los 5000 metros de altitud, con un máximo en el rango de 2900-3000 m; (13) en Ecuador continental crecen principalmente en una vegetación de bosque siempreverde o de bosque y arbustal, siempreverde o semideciduo, soportan un bioclima principalmente pluvial, ocupan mayoritariamente un ombrotipo húmedo a hiperhúmedo y termotipo infratropical inferior hasta el criorotropical atérmico, creciendo desde las tierras bajas hasta el nivel nival; (14) en las islas Galápagos habitan en bosque y arbustal húmedo (zona litoral), en vegetación de bosque y arbustal deciduo (zona árida), en bosque siempreverde estacional y en vegetación arbustiva (zona de transición), en bosque y arbustal siempreverde, y en herbazal húmedo (zona húmeda).

Del estudio de la variación de la temperatura y la pluviosidad en los sectores biogeográficos de Ecuador se concluye lo siguiente: (1) la Cordillera Oriental de los Andes, Chocó Ecuatorial y todos los sectores de la región Amazónica muestran los más altos niveles de pluviosidad anual; (2) los valles interandinos, Jama-Zapotillo, CatamayoAlamor y los páramos de la Cordillera Occidental de los Andes son los sectores más secos; (3) la intensidad pluviométrica es inferior en los páramos de la Cordillera Occidental respecto a los de la Cordillera Oriental de los Andes; (4) las temperaturas y precipitaciones medias anuales varían significativamente entre los sectores biogeográficos; (5) no existe una correlación significativa entre la pluviosidad y la altitud, lo inverso ocurre con la temperatura.

En general, el número de especies endémicas de Ecuador en la familia Asteraceae está altamente sobreestimado y en la medida que se avance en estudios taxonómicos y filogenéticos en la familia se contraerá aún más el presente listado, así como el número de especies nativas de Asteraceae representadas en la Flora de Ecuador (Rivero-Guerra, en preparación).

\section{AGRADECIMIENTOS}

Se agradece la colaboración prestada por el Herbario QCA y a los gestores de la base de datos TROPICOS: http://www.tropicos.org/home.aspx?langid=66. Se agradece, además, a los profesores C. Romero Zarco, M. A. Ortiz, J. Cebrino y A. Susanna por su colaboración en la búsqueda de literatura científica; a $\mathrm{O}$. M. Vargas Hernández, PhD., J. Pruski, y F. García Yanés, Msc. por su interés y atención telefónica/correo electrónico para responder a mis inquietudes; a los profesores D. G. Gutiérrez, G. Heiden, F. Luebert, K. Romoleroux y D. A. Minga Ochoa por enviar sus publicaciones en Asteraceae; a los dos revisores anónimos por proporcionar comentarios al manuscrito, y al comité editorial de Collectanea Botanica por su paciencia. El presente proyecto se financia con los fondos AST-BIO-2015 de la autora.

\section{REFERENCIAS BIBLIOGRÁFICAS}

Aguirre, L. F., Anderson, E. P., Brehm, G. et al. 2011. Phenology and Interspecific Ecological Interactions of Andean Biota in the Face of Climate Change. In: Herzog, S. K., Martínez, R., Jørgensen, P. M. \& Tiessen, H. (Eds.), Climate Change and Biodiversity in the Tropical Andes. Inter-American Institute for Global Change Research (IAI) and Scientific Committee on Problems of the Environment (SCOPE): 68-92.

Aguirre, N. \& Torres, J. 2013. Informe de la línea base del estado de degradación de los páramos de Jatunhuaycu: scenario de degradación y caracterización de sistemas de referencia. FONAG, Quito: 8-42.

Aguirre-Mendoza, Z., Aguirre, N., Merino, B. \& Ochoa, I. 2015. Los páramos del Parque Nacional Podocarpus: una aproximación a su diversidad ecosistémica y florística. In: Aguirre, N., Ojeda-Luna, T., Eguiguren, P. \& Aguirre-Mendoza, Z. (Eds.), Cambio climatico y biodiversidad: Estudio de caso de los páramos del Parque Nacional Podocarpus, Ecuador. Programa de biodiversidad y Servicios Ecosistémicos, Universidad Nacional de Loja: 65-76.

Aguirre-Mendoza, Z., Aguirre Mendoza, N. \& Muñoz Ch., J. 2017. Biodiversidad de la provincia de Loja, Ecuador. Arnaldoa 24: 523-542.

Akeroyd, J. \& Synge, H. 1992. Higher plant diversity. In: Groombridge, B. (Ed.), Global Biodiversity: Status of the 
Earth's Living Resources. Chapman \& Hall, Londres: 64 87. https://doi.org/10.1007/978-94-011-2282-5 8

Ali, J. R. \& Aitchison, J. C. 2014. Exploring the combined role of eustasy and oceanic island thermal subsidence in shaping biodiversity on the Galápagos. Journal of Biogeography 41: 1227-1241. https://doi.org/10.1111/ jbi.12313

Almeida, D. P. \& Nogales, F. B. 2005. Evaluación ecológica rápida de la herpetofauna de dos bosques secos al occidente de la provincia de Loja. In: Vázquez, M., Freile, J. F. \& Suárez, L. (Eds.), Biodiversidad en los bosques secos de la zona de Cerro Negro-Cazaderos, suroccidente de la provincia de Loja: Un reporte de las evaluaciones ecológicas y socioeconómicas rápidas. EcoCiencia, MAE y Proyecto Bosque Seco, Quito: 25-42.

Almeida Braga, J., Oliveira Sales, E., Soares Neto, J., Menezes Conde, M., Barth, O. M. \& Lorenzon, M. C. 2012. Floral sources to Tetragonisca angustula (Hymenoptera: Apidae) and their pollen morphology in a Southeastern Brazilian Atlantic Forest. Revista de Biología Tropical 60: 1491-1501. https://doi.org/10.15517/rbt.v60i4.2067

Adsersen, H. 1980. Revision of the Galapagos endemic genus Lecocarpus (Asteraceae). Botanisk Tidsskrift 65: 246-277.

Anderson, E. P., Marengo, J., Villalba, R. et al. 2011. Consequences of Climate Change for Ecosystems and Ecosystem Services in the Tropical Andes. In: Herzog, S. K., Martínez, R., Jørgensen, P. M. \& Tiessen, H. (Eds.), Climate Change and Biodiversity in the Tropical Andes. Inter-American Institute for Global Change Research (IAI) and Scientific Committee on Problems of the Environment (SCOPE): 1-18.

Andersson, N. J. 1855. Om Galapagos-öarnes vegetation. Kongliga Svenska Vetenskaps Academiens Handlingar, Ny Följd 1853: 61-256. https://doi.org/10.5962/bhl.title. 9019

Andrade, L. \& Ríos, C. 2014. Variabilidad climática y caudales mínimos en los Andes Ecuatorianos. Revista EPN 33: Retrieved December 30, 2018, from https://revistapolitecnica.epn.edu.ec/ojs2/index.php/revista_politecnica2/article/ view/89

Andrus, N., Tye, A., Nesom, G. et al. 2009. Phylogenetics of Darwiniothamnus (Asteraceae: Astereae) - molecular evidence for multiple origins in the endemic flora of the Galápagos Islands. Journal of Biogeography 36: 1055-1069. https://doi.org/10.1111/j.1365-2699.2008.02064.x

Anhalzer, J. \& Lozano, P. 2015. Flora y fauna de los páramos de Ecuador. Breve guía de la vida de la Altura. Mariscal, Puyo: $330 \mathrm{pp}$.

Antonelli, A. \& Sanmartín, I. 2011. Why are there so many plant species in the Neotropics? Taxon 60: 403-414. https:// doi.org/10.1002/tax.602010

Aranguren, A., Morillo, G. \& Fariñas, M. 2008. Distribución geográfica y clave de las especies del género Oritrophium (Kunth) Cuatrec. (Asteraceae). Acta Botanica Venezuelica 31: 81-106.

Arriagada, J. E. 2003. Revision of the genus Clibadium (Asteraceae, Heliantheae). Brittonia 55: 245-301. http://doi. org/10.1663/0007-196X(2003)055[0245:ROTGCA]2.0. $\mathrm{CO} ; 2$

Avila, F., Funk, V. A., Diazgranados, M., Díaz-Piedrahíta, S. \& Vargas, O. 2015. Asteraceae. In: Bernal, R., Gradstein, S. R. \& Celis, M. (Eds.), Catálogo de plantas y líquenes de Colombia. Instituto de Ciencias Naturales, Universidad
Nacional de Colombia, Bogotá. http://catalogoplantasdecolombia.unal.edu.co

Bader, M., van Geloof, I. \& Rietkerk, M. 2007. High solar radiation hinders tree regeneration above the alpine treeline in northern Ecuador. Plant Ecology 191: 33-45. http://doi. org/10.1007/s11258-006-9212-6

Barriga, P., Toasa, G., Montúfar, R. \& Tye, A. 2011. Asteraceae. In: León-Yánez, S., Valencia, R., Pitman, N., Endara, L., Ulloa Ulloa, C. \& Navarrete, H. (Eds.), Libro Rojo de las Plantas Endémicas del Ecuador. Pontificia Universidad Católica del Ecuador, Quito: 139-196.

Beltrán, K., Salgado, S., Cuesta, F., León-Yánez, S., Romoleroux, K., Ortiz, E., Cárdenas, A. \& Velástegui, A. 2009. Distribución Espacial, Sistemas Ecológicos y Caracterización Florística de los Páramos en el Ecuador. EcoCiencia, Proyecto Páramo Andino y Herbario QCA. Quito: 14-150.

Beltrán, H. 2016. Las Asteráceas (Compositae) del distrito de Laraos (Yauyos, Lima, Perú). Revista Peruana de Biología 23: 195-220. http://dx.doi.org/10.15381/rpb. v23i2.12439

Beltrán, H. 2017. Sinopsis del género Werneria (Asteraceae: Senecioneae) del Perú. Arnaldoa 24: 45-62.

Benítez de Rojas, C. E. 2011. Especies venezolanas del género Critonia (Asteraceae). Acta Botanica Venezuelica 34: 407-416.

Blaschke, J. D. \& Sanders, R. W. 2009. Preliminary insights into the phylogeny and speciation of Scalesia (Asteraceae), Galápagos Islands. Journal of the Botanical Research Institute of Texas 3: 177-191.

Blöch, C., Weiss-Schneeweiss, H., Schneeweiss, G. M., Barfuss, M. H. J., Rebernig, C. A., Villaseñor, J. L. \& Stuessy, T. F. 2009. Molecular phylogenetic analyses of nuclear and plastid DNA sequences support dysploid and polyploid chromosome number changes and reticulate evolution in the diversification of Melampodium (Millerieae, Asteraceae). Molecular Phylogenetic and Evolution 53: 220-233. https://doi.org/10.1016/j.ympev.2009.02.021

Borja Ramón, P., Iñiguez, V., Crespo, P., Cisneros, P., Cisneros, F. \& Feyen, J. 2008a. Caracterización hidráulica de Andosoles e Histosoles del Austro del Ecuador. XI Congreso Ecuatoriano de la Ciencia del Suelo, 29-31 de octubre de 2008, Quito: 1-10.

Borja Ramón, P., Iñiguez, V., Crespo, P., Cisneros, P. \& Cisneros, F. 2008b. Características físico - químicas de Histosoles y Andosoles de los páramos de Quimsacocha, Ecuador. XI Congreso Ecuatoriano de la Ciencia del Suelo, 29-31 de octubre de 2008, Quito: 1-11.

Borregaard, M. K., Amorim, I. R., Borges, P. A. V. et al. 2017. Oceanic island biogeography through the lens of the general dynamic model: assessment and prospect. Biological Reviews 92: 830-853. https://doi.org/10.1111/ brv. 12256

Brako, L. \& Zarucchi J. L. 1993. Catalogue of the flowering plants and gymnosperms of Peru. Monographs in Systematic Botany from the Missouri Botanical Garden 45: $1-1286$.

Bussmann, R. W. 2006. Andean floristic diversity and its importance for cultural diversity - examples from Northern Peru and Southern Ecuador. Lyonia 10: 19-36.

Cáceres, B., Francou, B., Favier, V. et al. 2006. El glaciar 15 del Antisana: investigaciones glaciológicas y su relación con el recurso hídrico. Climate Variability and 
Change-Hydrological Impacts. Proceedings of the Fifth FRIEND World Conference, Havana, Cuba, IAHS Publ.: 479-482.

Calvo, J. 2017. Neotypifications and new synonyms of the Ecuadorian Senecio (Compositae, Senecioneae) species described by F. W. Domke. Willdenowia 47: 77-80. https:// doi.org/10.3372/wi.47.47108

Calvo, J., Arnelas, I. \& Minga, D. 2019. Taxonomic novelties in Andean Senecioneae (Compositae). Phytotaxa 402: 145154. http://dx.doi.org/10.11646/phytotaxa.402.3.2

Calvo, J. \& Freire, E. 2016. A nomenclator of Senecio group Lasiocephalus (Compositae, Senecioneae): nomenclatural and taxonomic notes and new typifications. Phytotaxa 260: 116-130. http://dx.doi.org/10.11646/phytotaxa.260.2.2

Camacho, M. 2014. Los páramos ecuatorianos: caracterización y consideraciones para su conservación y aprovechamiento sostenible. Anales de la Universidad Central del Ecuador 372: 78-92. https://doi.org/10.29166/anales.v1i372.1241

Carlquist, S. 1966. The biota of long-distance dispersal. II. Loss of dispersibility in Pacific Compositae. Evolution 20: 30-48. https://doi.org/10.1111/j.1558-5646.1966. tb03341.x

Carlquist, S. \& Eckhart, V. M. 1982. Wood anatomy of Darwiniothamnus, Lecocarpus, and Macraea (Asteraceae). Aliso 10: 291-300. https://doi.org/10.5642/aliso.19821002.08

Carúa Cola, J., Proaño, M., Suárez, D. \& Podwojevski, P. 2008. Determinación de retención de agua en los suelos de los páramos: estudio de caso en la subcuenca del río San Pedro, cantón Mejía, Pichincha, Ecuador. In: Mena Vásconez, P. \& Ochoa, N. (Eds.), Páramo, Abya Yala \& EcoCiencia, Quito: 27-45.

Caranqui, J., Lozano, P. \& Reyes, J. 2016. Composición y diversidad florística de los páramos en la Reserva de Producción de Fauna Chimborazo, Ecuador. Enfoque UTE 7: 33-45. https://doi.org/10.29019/enfoqueute.v7n1.86

Cargua, F. E., Rodríguez, M. V., Recalde, C. G. \& Vinueza, L. M. 2014. Cuantificación del contenido de carbono en una plantación de Pino Insigne (Pinus radiata) y en estrato de páramo de Ozogoche Bajo, Parque Nacional Sangay, Ecuador. Información Tecnológica 25: 83-92. http://dx.doi. org/10.4067/S0718-07642014000300011

Carrasco, M., Padilla, A. \& Echeverría, M. 2016. Análisis del ecosistema páramo Igualata frente al cambio climático en base a los recursos naturales. Perfiles 15: 11-16.

Carvajal-Endara, S., Hendry, A. P., Emery, N. C. \& Davis, T. J. 2017. Habitat filtering not dispersal limitation shapes oceanic island floras: species assembly of the Galápagos archipelago. Ecology Letters 20: 495-504. https://doi. org/10.1111/ele. 12753

Caujapé-Castells, J., García-Verdugo, C., Marrero-Rodríguez, A., Fernández-Palacios, J. M., Crawford, D. J. \& Mort, M. E. 2017. Island ontogenies, syngameons, and the origins and evolution of genetic diversity in the Canarian endemic flora. Perspectives in Plant Ecology, Evolution and Systematics 27: 9-22. https://doi.org/10.1016/j. ppees.2017.03.003

Chalmandrier, L., Albouy, C., Descombes, P. et al. 2018. Comparing spatial diversification and meta-population models in the Indo-Australian Archipelago. Royal Society Open Science 5: 171366. https://doi.org/10.1098/rsos.171366

Chamorro, S., Heleno, R., Olesen, J. M., McMullen, C. K. \& Traveset, A. 2012. Pollination patterns and plant breeding systems in the Galápagos: a review. Annals of Botany 110: 1489-1501. https://doi.org/10.1093/aob/mcs132
Chen, J., Shen, C.-Z., Guo, Y.-P. \& Rao, G.-Y. 2018. Patterning the Asteraceae capitulum: duplications and differential expression of the flower symmetry CYC2-like genes. Frontiers in Plant Science 9: 551-552. https://doi.org/10.3389/ fpls.2018.00551

Cilia-López, G. V., Aguirre-Rivera, J. R., Espinosa-Reyes, G., Flores-Cano, J. A., Reyes-Agüero, J. A. \& Juárez-Flores, B. I. 2014. Distribución de Heliopsis longipes (Heliantheae: Asteraceae), un recurso endémico del centro de México. Revista Chapingo Serie Ciencias Forestales y del Ambiente 20: 47-54. http://dx.doi.org/10.5154/r.rchscfa.2013.05.015

Cisneros, P., Cajamarca, J. \& Pacheco, E. 2010. Estudios para establecer la línea base de los suelos inalterados en el páramo de Quimsacocha. XII Congreso Ecuatoriano de la Ciencia del Suelo, 17-19 de noviembre de 2010, Santo Domingo: 1-9. Retrieved December 30, 2018, from https:// docplayer.es/23479522-Xii-congreso-ecuatoriano-de-laciencia-del-suelo.html

Clapperton, C. 1993. Quaternary geology and geomorphology of South America. Elsevier Press, Amsterdam: 779 pp.

Clark, C. 1998. Phylogeny and adaptation in the Encelia alliance (Asteraceae: Heliantheae). Aliso 17: 89-98. https:// doi.org/10.1007/978-94-009-1207-6 9

Clausen, B. 2016. La geología de las Islas Galápagos. Ciencia de los Orígenes 89: 3-5.

Contreras López, M., Cevallos Zambrano, J., Erazo Cedeño, T., Alday González, M. \& Mizobe, C. E. 2014. Cambio y variabilidad climática contemporáneos en la costa de Manabí, Ecuador. Revista la Técnica 13: 90-99. https://doi. org/10.33936/la tecnica.v0i13.599

Crawford, D. J. \& Archibald, J. K. 2017. Island floras as model systems for studies of plant speciation: Prospects and challenges. Journal of Systematics and Evolution 55: 1-15. https://doi.org/10.1111/jse.12234

Crawford, D. J., Lowrey, T. K., Anderson, G. J., Bernardello, G., Santos-Guerra, A. \& Stuessy, T. F. 2009. Genetic diversity in Asteraceae endemic to oceanic islands: Baker's Law and polyploidy. In: Funk, V. A., Susanna, A., Stuessy, T. F. \& Bayer, R. (Eds.), Systematics, Evolution, and Biogeography of the Compositae. International Association of Plant Taxonomy, Vienna: 101-113.

Crespo, P., Célleri, R., Buytaert, W. et al. 2014. Impactos del cambio de uso de la tierra sobre la hidrología de los páramos húmedos andinos. In: Cuesta, F., Sevink, J., Llambí, L. D., Bièvre, B. de \& Posner, J. (Eds.), Avances en investigación para la conservación de los páramos andinos. CONDESAN, Quito: 288-304.

Cromwell, T., Montgomery, R. B. \& Stroup, E. D. 1954. Equatorial undercurrent in Pacific Ocean revealed by new methods. Science 119: 648-649. https://doi.org/10.1126/ science.119.3097.648

Cronquist, A. 1971. Compositae. In: Wiggins, I. L. \& Porter, D. M. (Eds.), Flora of the Galapagos Islands. Stanford University Press, Stanford: 353-361.

Cuesta, F., Muriel, P., Beck, S. et al. (Eds.) 2012. Biodiversidad y cambio climático en los Andes Tropicales - Conformación de una red de investigación para monitorear sus impactos y delinear acciones de adaptación. Red Gloria-Andes, LimaQuito: 14-28.

Cunalata, C., Inga, C., Álvarez, G., Recalde, C. \& Echeverría, M. 2013. Determinación de carbono orgánico total presente en el suelo y la biomasa de los páramos de las comunidades de Chimborazo y Shobol Llinllin en Ecuador. Boletín del Grupo Español del Carbón 27: 10-13. 
Damián Carrión, D. A., Márquez, C. O., García, V. J., Recalde Moreno, C. G., Rodríguez Llerena, M. V. \& Ayala, J. E. 2017. Priorización de microcuencas en los Andes ecuatoriano usando parámetros morfométricos, WSA y GIS. Revista Geográfica Venezolana 58: 38-61.

Del Vitto, L. A. \& Petenatti, E. M. 2009. Asteráceas de importancia económica y ambiental. Primera Parte. Sinopsis morfológica y taxonómica, importancia ecológica y plantas de interés industrial. Multequina 18: 87-115.

Delgado, T. \& Suárez-Duque, D. 2009. Efectos del cambio climático en la diversidad vegetal del corredor de conservación comunitaria Reserva Ecológica El Ángel - bosque protector golondrinas en el norte del Ecuador. Ecología Aplicada 8: 27-36. http://dx.doi.org/10.21704/rea.v8i12.379

Delprete, P. G. 1995. Systematic study of the genus Delilia (Asteraceae, Heliantheae). Plant Systematics and Evolution 194: 111-122. https://doi.org/10.1007/BF00983220

Diazgranados, M. 2012. A nomenclator for the frailejones (Espeletiinae Cuatrec., Asteraceae). PhytoKeys 16: 1-52. https://doi.org/10.3897/phytokeys.16.3186

Diazgranados, M. \& Barber, J. C. 2017. Geography shapes the phylogeny of frailejones (Espeletiinae Cuatrec., Asteraceae): a remarkable example of recent rapid radiation in sky islands. PeerJ 5: e2968. https://doi.org/10.7717/peerj.2968

Dillon, M. O. \& Sagástegui Alva, A. 2001. Tribal classification and diversity in the Asteraceae of Peru. Arnaldoa 8: 25-44.

Duškova, E., Kolař, F., Sklenař, P. et al. 2010. Genome size correlates with growth form, habitat and phylogeny in the Andean genus Lasiocephalus (Asteraceae). Preslia 82: 127-148.

Dytham, C. 2003. Choosing and using statistics. A biologist's guide (3th ed.). Blackwell, Oxford: 298 pp.

Echeverría, M., Rosero, C. \& Bravo, L. 2017. Vulnerabilidad a nivel de ecosistema de Páramo frente al cambio climático en la zona de Igualata, parroquia San Isidro, cantón Guano, provincia de Chimborazo. Revista del Instituto de Investigación, FIGMMG-UNMSM 20: 137-148.

Eguiguren, P., Ojeda-Luna, T. \& Aguirre, N. 2015a. Patrones de diversidad florística a lo largo de la gradiente altitudinal del páramo del Parque Nacional Podocarpus. In: Aguirre, N., Ojeda-Luna, T., Eguiguren, P. \& Aguirre-Mendoza, Z. (Eds.), Cambio climático y biodiversidad: Estudio de caso de los páramos del Parque Nacional Podocarpus, Ecuador. Programa de biodiversidad y Servicios Ecosistémicos, Universidad Nacional de Loja: 145-169.

Eguiguren, P., Santín, A., Vidal, E. \& Aguirre, N. 2015b. Reservorios de carbono en los páramos del Parque Nacional Podocarpus. In: Aguirre, N., Ojeda-Luna, T., Eguiguren, P. \& Aguirre-Mendoza, Z. (Eds.), Cambio climático y biodiversidad: Estudio de caso de los páramos del Parque $\mathrm{Na}$ cional Podocarpus, Ecuador. Programa de biodiversidad y Servicios Ecosistémicos, Universidad Nacional de Loja: 211-225.

Eliasson, U. H. 1967. Studies in Galápagos plants IV. The genus Chrysanthellum Pers. Svensk Botanisk Tidskrift 61: $88-92$.

Eliasson, U. H. 1974. Studies in Galápagos plants. XIV. The genus Scalesia Arn. Opera Botanica 36: 117 pp.

Eliasson, U. H. 1984. Chromosome number of Macraea laricifolia Hooker fil. (Compositae) and its bearing on the taxonomic affinity of the genus. Botanical Journal of the Linnean Society 88: 253-256. https://doi. org/10.1111/j.1095-8339.1984.tb01574.x
Equipo Técnico de Dirección de Monitoreo de Eventos Adversos. 2017. Informe de Situación - Incendios Forestales. Dirección de Monitoreo de Eventos Adversos (DMEVA), Secretaría de Gestión de Riesgos, Quito: 1-7.

Espurt, N., Brusset, S., Baby, P. et al. 2017. Deciphering the late Cretaceous-Cenozoic structural evolution of north peruvian forearc system. Tectonics 37: 251-282. https://doi. org/10.1002/2017TC004536

Fehlberg, S. D. \& Ranker, T. A. 2007. Phylogeny and biogeography of Encelia (Asteraceae) in the Sonoran and Peninsular Deserts based on multiple DNA sequences. Systematic Botany 32: 692-699. https://doi. org/10.1600/036364407782250689

Freire, S. E., Chemisquy, M. A., Anderberg, A. A., Beck, S. G., Meneses, R. I., Loeuille, B. \& Urtubey, E. 2015. The Lucilia group (Asteraceae, Gnaphalieae): phylogenetic and taxonomic considerations based on molecular and morphological evidence. Plant Systematics and Evolution 301: 1227-1248. http://dx.doi.org/10.1007/s00606-014$1147-0$

Freire, S. E., Monti, C., Bayón, N. D. \& Migoya, M. A. 2018. Taxonomic Studies in Pseudognaphalium Kirp. (Asteraceae, Gnaphalieae) from Peru. Systematics Botany 43: 325-343. https://doi.org/10.1600/036364418X696914

Funk, V. A., Kelloff, C. \& Chan, R. 2012. Phylogeny and biogeography of the tribe Liabeae (Compositae subfamily Cichorioideae). Taxon 61: 437-455. http://dx.doi. org/10.1002/tax.612013

Funk, V. A., Randall, J. B., Keeley, S. C. et al. 2005. Everywhere but Antarctica: Using a supertree to understand the diversity and distribution of the Compositae. Biologiske Skrifter 55: $343-373$.

Funk, V. A. \& Robinson, H. 2001. A bully new genus from the Andes (Compositae: Liabeae). Systematic Botany 26: 216-225.

Funk, V. A. \& Robinson, H. 2009. Sampera, a new genus of Liabeae (Compositae or Asteraceae) from the northern Andes. Proceedings of the Biological Society of Washington 122: 155-161. https://doi.org/10.2988/08-31.1

Funk, V. A., Robinson, H., Mckee, G. S. \& Pruski, J. F. 1995. Neotropical montane Compositae with an emphasis on the Andes. In: Churchill, S. P., Balslev, E., Forero, E. \& Luteyn, J. L. (Eds.), Biodiversity and Conservation of Neotropical Montane Forests. The New York Botanical Garden, New York: 451-471.

Funk, V. A., Susanna, A., Stuessy, T. F. \& Robinson, H. E. 2009. Classification of Compositae. In: Funk, V. A., Susanna, A., Stuessy, T. F. \& Bayer, R. J. (Eds.), Systematics, evolution, and biogeography of Compositae. International Association for Plant Taxonomy (IAPT), Viena: 171-189.

Funk, V. A. \& Wagner, W. L. 1995. Biogeographic patterns in the hawaiian islands. In: Funk, V. A. \& Wagner, W. L. (Eds.), Hawaiian biogeography: evolution on a hot spot archipelago. Smithsonian Institution Press, Washington DC: 379-419. https://doi.org/10.5962/bhl.title.129909

García Cruzatty, L. C. \& Schlatter Vollmann, J. E. 2012. Caracterización de suelos a lo largo de un gradiente altitudinal en Ecuador. Revista Brasileira de Ciencias Agrárias 7: 456-464. http://dx.doi.org/10.5039/agraria.v7i3a1736

García, M., Parra, D. \& Mena, P. 2014. El país de la biodiversidad: Ecuador. Fundación Botánica de los Andes, Ministerio del Ambiente y Fundación EcoFondo, Quito: $28-79$. 
García Guerrero, J., Castillo Añazco, R., Naranjo Orozco, L. et al. 2017. Compendio estadístico 2016. Instituto Nacional de Estadísticas y Censos, Quito: 21-411.

Gardner, R. C. 1979. Revision of Lipochaeta (Compositae: Heliantheae) of the Hawaiian Islands. Rhodora 81: 291-343.

Geist, D. 1997. Sobre el surgimiento y hundimiento de las Islas Galápagos. Noticias de Galápagos 56-57: 54-60.

Geoinformática y Sistemas Cia. Ltda. 2015. Estudio del Estado Actual del Ecosistema Páramo en Tungurahua. Honorable Gobierno Provincial de Tungurahua (HGPT), Ambato: 14-239.

GeoPlaDes, 2011. Elaboración de los componentes: recursos naturales, zonificación y cartografía del plan de manejo del área del bosque y páramo del cantón Bolivar. Gobierno Provincial del Carchi, Tulcán: 1-102.

Germeraad, J. H., Hopping, C. A. \& Muller, J. 1968. Palynology of Tertiary sediments from tropical areas. Review of Palaeobotany and Palynology 6: 189-348. https://doi. org/10.1016/0034-6667(68)90051-1

Gonzáles, P., Navarro, E., Trinidad, H., Cueva, M., Cano, A., Al-Shehbaz, I. \& Ramírez, D. W. 2016. Doce nuevos registros de plantas vasculares para los Andes de Perú. Arnaldoa 23: $159-170$.

Grafen, A. \& Hails, R. 2002. Modern statistics for the life sciences. Oxford University Press, Oxford: $351 \mathrm{pp}$.

Gregory-Wodzicki, K. 2000. Uplift history of the Central and Northern Andes: A review. Geological Society of America Bulletin 112: 1091-1105. https://doi.org/10.1130/00167606(2000)112<1091:UHOTCA >2.0.CO;2

Grehan, J. R. 2001. Islas Galápagos: Biogeografía, tectónica y evolución en un Archipélago oceánico. In: Llorente Bousquets, J. \& Morrone J. J. (Eds.), Introducción a la Biogeografia en Latinoamérica: teorías, conceptos, métodos $y$ aplicaciones. Las prensas de Ciencias, Facultad de Ciencias, Universidad Nacional Autónoma de México, Ciudad de México: 153-160.

Gutiérrez, D. G. \& Katinas, L. 2015. Systematics of Liabum Adanson (Asteraceae, Liabeae). Systematics Botany Monographs 97: 1-121.

Hansen, D. R., Jansen, R. K., Sage, R. F., Villaseñor, J. L. \& Simpson, B. B. 2016. Molecular phylogeny of Pectis (Tageteae, Asteraceae), a $\mathrm{C}_{4}$ genus of the neotropics, and its sister genus Porophyllum. Lundellia 19: 6-38. https://doi. org/10.25224/1097-993X-19.1.6

Harling, G. 1962. On some Compositae endemic to the Galápagos Islands. Acta Horti Bergiani 20: 63-120. https:// doi.org/10.3417/2008081

Harling, G. 1991. Compositae-Mutisieae. In: Harling, G. W. \& Sparre, B. B. (Eds.), Flora of Ecuador 42. University of Göteborg \& Swedish Museum of Natural History, Göteborg \& Stockholm: 1-105.

Haro-Carrión, X. \& Robinson, H. 2008. A review of the genus Critoniopsis in Ecuador (Vernonieae: Asteraceae). Proceeding of the Biological Society of Washington 121: 1-18. https://doi.org/10.2988/07-18.1

Hassler, M. 2019. World Plants: Synonymic checklists of the vascular plants of the world (version Nov 2018). In: Roskov, Y., Ower, G., Orrell, T., Nicolson, D., Bailly, N., Kirk, P. M., Bourgoin, T. et al. (Eds.), Species 2000 \& ITIS Catalogue of Life, 2019 Annual Checklist, Leiden. Retrieved December 30, 2018, from www.catalogueoflife.org/annual-checklist/2019

Henderson, A., Churchill, S. P. \& Luteyn, J. L. 1991. Neotropical plant diversity: Are the northern Andes richer than the Amazon Basin? Nature 351: 21-22. https://doi. org/10.1038/351021e0
Hind, D. J. N. \& Jeffrey, C. 2001. A checklist of the Compositae of Vol. IV of Humboldt, Bonpland \& Kunth's Nova Genera et Species Plantarum. Compositae Newsletter 37 : $1-84$.

Hofstede, R. 2001. El Impacto de las actividades humanas en el páramo. In: Mena, P., Medina, G. \& Hofstede, R. (Eds.), Los Páramos del Ecuador. Particularidades, Problemas y Perspectivas. Abya Yala/Proyecto Páramo, Quito: $161-185$.

Hofstede, R., Calles, J., López, V. et al. 2014. Los Páramos Andinos ¿Qué sabemos? Estado de conocimiento sobre el impacto del cambio climático en el ecosistema páramo. UICN, Quito: 8-154.

Hofstede, R., Coppus, R., Mena Vásconez, P., Segarra, P., Wolf, J. \& Sevink, J. 2002. El estado de conservación de los páramos de pajonal en el Ecuador. Ecotropicos 15: 3-18.

Holmes, W. C. 2015. Mikania parviflora (Asteraceae: Eupatorieae) and near relatives. Phytoneuron 3: 1-26.

Hoorn, C., Wesselingh, F. P., Ter Steege, H. et al. 2010. Amazonia through time: Andean uplift, climate change, landscape evolution, and biodiversity. Science 330: 927-931. https://doi.org/10.1126/science.1194585

INIGEMM 2017. Atlas geológico minero de Ecuador. Instituto Nacional de Investigación Geológico Minero Metalúrgico de Ecuador, Quito: 27 pp.

IPCC 1995. Climate change 1995, the science of climate change. Cambridge University Press, Cambridge: 133-192. https://doi.org/10.1002/qj.49712454921

Itow, S. 1995. Phytogeography and ecology of Scalesia (Compositae) endemic to the Galápagos Islands. Plant Science 49: 17-30.

Izco, J., Pulgar, I., Aguirre, Z. \& Santin, F. 2007. Estudio florístico de los páramos de pajonal meridionales de Ecuador. Revista Peruana de Biología 14: 237-246. http://dx.doi. org/10.15381/rpb.v14i2.1783

Jaillard, E., Bengtson, P., Ordóñez, M., Vaca, W., Dhondt, A., Suárez, J. \& Toro, J. 2008. Sedimentary record of terminal Cretaceous accretions in Ecuador: the Yunguilla group in the Cuenca area. Journal of South American Earth Sciences 25: 133-144. https://doi.org/10.1016/j.jsames.2007.08.002

Jansen, R. K. 1985. The systematics of Acmella (AsteraceaeHeliantheae). Systematic Botany Monographs 8: 1-115. https://doi.org/10.2307/25027614

Jaramillo, P. \& Trigo, M. M. 2006a. Palynological study of the Galapagos endemic genus Darwiniothamnus (Asteraceae). Abstracts XV A.P.L.E. Symposium 16: 39-40.

Jaramillo, P. \& Trigo, M. M. 2006b. Pollen morphology of the galapagos endemic genus Scalesia (Asteraceae). Galapagos Research 64: 26-64.

Jiménez, L., Gusmán, J., Capa-Mora, D., Quichimbo, P. Mezquida, E., Benito, M. \& Rubio, A. 2017. Riqueza y diversidad vegetal en un bosque siempreverde piemontano en los Andes del sur del Ecuador. Bosques Latitud Cero 7: 17-29.

Jørgensen, P. \& León-Yánez, S. (Eds.). 1999. Catalogue of the Vascular Plants of Ecuador. Missouri Botanical Garden, St. Louis: $1181 \mathrm{pp}$.

Jørgensen, P., Ulloa, C. \& Maldonado, C. 2006. Riqueza de plantas vasculares. In: Moraes, M., Øllgaard, B., Kvist, L. P., Borchsenius, F. \& Balslev, H. (Eds.), Botánica Económica de los Andes Centrales. Universidad Mayor de San Andrés, La Paz: 37-50.

Jost, L. 2011. Endemismos en los flancos de los Andes: los bosques andinos. In: León-Yánez, S., Valencia, R., Pitman, 
N., Endara, L., Ulloa Ulloa, C. \& Navarrete, H. (Eds.), Libro Rojo de las Plantas Endémicas del Ecuador. Pontificia Universidad Católica del Ecuador, Quito: 29-33.

Katinas, L., Gutiérrez, D. G., Grossi, M. A. \& Crisci, J. V. 2007. Panorama de la familia Asteraceae (Compositae) en la República Argentina. Boletín de la Sociedad Argentina de Botánica 42: 113-129.

Katinas, L., Morrone, J. J. \& Crisci, J. V. 1999. Track analysis reveals the composite nature of the Andean biota. Australian Journal of Botany 47: 111-130. https://doi. org/10.1071/BT97049

Katinas, L., Pruski, J., Sancho, G. \& Tellería, M. C. 2008. The subfamily Mutisioideae (Asteraceae). Botanical Review 74: 469-716. https://doi.org/10.1007/s12229-008-9016-6

Keil, D. J. 1977. Chromosome studies in North and Central American species of Pectis L. (Compositae: Tageteae). Rhodora 79: 79-94.

Kessler, M., Grytnes, J.-A., Halloy, S. R. P. et al. 2011. Gradients of plant diversity: Local patterns and processes. In: Herzog, S. K., Martínez, R., Jørgensen, P. M. \& Tiessen, H. (Eds.), Climate Change and Biodiversity in the Tropical Andes. Inter-American Institute for Global Change Research (IAI) and Scientific Committee on Problems of the Environment (SCOPE): 205-219.

Kim, H.-G., Funk, V. A., Vlasak, A. \& Zimmer, E. A. 2003. A phylogeny of the Munnoziinae (Asteraceae, Liabeae): circumscription of Munnozia and a new placement of $M$. perfoliata. Plant Systematics and Evolution 239: 171-185. https://doi.org/10.1007/s00606-003-0003-4

King, R. M. \& Robinson, H. 1974. Studies in the Eupatorieae (Asteraceae). CXXVII. Additions to the American and Pacific Adenostemmatinae: Adenostemma, Gymnocoronis, and Sciadocephala. Phytologia 29: 1-20. https://doi. org/10.5962/bhl.part.13095

King, R. M. \& Robinson, H. 1975. Studies in the Eupatorieae (Asteraceae). CXXXIX. A new genus, Aristeguietia. Phytologia 30: 217-220.

King, R. M. \& Robinson, H. 1981. Studies in the Eupatorieae (Astereae). CCVII. Additional new combinations. Phytologia 49: 3-6.

Kruckeberg, A. R. 2002. Geology and plant life. The effects of landforms and rock types on plants. University of Washington, Seattle: 362 pp.

Landis, M. J., Freyman, W. A. \& Baldwin, B. G. 2018. Retracing the Hawaiian silversword radiation despite phylogenetic, biogeographic, and paleogeographic uncertainty. Evolution 72: 2343-2359. https://doi.org/10.1101/301887.

Lanteri, A. A. 2001. Biogeografía de las Islas Galápagos: principales aportes de los estudios filogenéticos. In: Llorente Bousquets, J. \& Morrone, J. J. (Eds.), Introducción a la Biogeografía en Latinoamérica: teorías, conceptos, métodos y aplicaciones. Las prensas de Ciencias, Facultad de Ciencias, Universidad Nacional Autónoma de México, Ciudad de México: 141-151.

Larsen, T. H., Brehm, G., Navarrete, H. et al. 2011. Range shi$\mathrm{fts}$ and extinctions driven by climate change in the Tropical Andes: Synthesis and directions. In: Herzog, S. K., Martínez, R., Jørgensen, P. M. \& Tiessen, H. (Eds.), Climate change and biodiversity in the Tropical Andes. Inter-American Institute for Global Change Research (IAI) and Scientific Committee on Problems of the Environment (SCOPE): $47-67$.

Lenzner, B., Weigelt, P., Kreft, H., Beierkuhnlein, C. \& Steinbauer, M. J. 2016. The general dynamic model of island biogeography revisited at the level of major flowering plant families. Journal of Biogeography 44: 1029-1040. https:// doi.org/10.1111/jbi.12906

León Yánez, S. 2011. Patrones taxonómicos de las plantas endémicas del Ecuador. In: León-Yánez., S., Valencia, R., Pitman, N., Endara, L., Ulloa-Ulloa., C. \& Navarrete, H. (Eds.), Libro rojo de las plantas endémicas del Ecuador. Pontificia Universidad Católica del Ecuador, Quito: $19-25$.

Lindhardt, M. S., Philipp, M., Tye, A. \& Nielsen, L. R. 2009. Molecular, morphological, and experimental evidence for hybridization between threatened species of the Galapagos endemic genus Scalesia (Asteraceae). International Journal of Plant Sciences 170: 1019-1030. http://dx.doi. org/10.1086/605113

Loockerman, D. J., Turner, B. L. \& Jansen, R. K. 2003. Phylogenetic relationships within the Tageteae (Asteraceae) based on nuclear ribosomal ITS and chloroplast $n d h F$ gene sequences. Systematic Botany 28: 191-207.

López Ramos, E. 2001. Evolución tectónica de América Central, del Sur y el Caribe, desde el Jurásico hasta el reciente. In: Llorente Bousquets, J. \& Morrone, J. J. (Eds.), Introducción a la Biogeografía en Latinoamérica: teorías, conceptos, métodos y aplicaciones. Las prensas de Ciencias, Facultad de Ciencias, Universidad Nacional Autónoma de México, Ciudad de México: 15-22.

Lozano, P., Armas, A. \& Machado, V. 2016. Estrategias para la conservación del ecosistema del páramo en Pulingupí San Pablo y Chorrera Mirador, Ecuador. Enfoque UTE: 7: 55-70. https://doi.org/10.29019/enfoqueute.v7n4.114

Lozano, P., Bussmann, R. W. \& Küppers, M. 2007. Diversidad florística del bosque montano en el Occidente del Parque Nacional Podocarpus, sur de Ecuador y su influencia en la flora pionera en deslizamientos naturales. Revista UDO Agrícola 7: 42-159.

Lozano, P., Cleef, A., Yangora, J., Torres, B., Carrión, J. \& Abril, R. 2013. Páramos aislados del volcán Sumaco, Amazonía del Ecuador. Universidad Estatal Amazónica, Puyo: $120 \mathrm{pp}$.

Lozano, P., Duque, J., Balslev, H. et al. 2015. Flora paramuna de la base del cono del volcán Sangay - Amazonía de Ecuador. Universidad Estatal Amazónica, Puyo: 156 pp.

Luna-Romero, A. E., Ramírez Morales, I., Sánchez Mendieta, C., Conde Solano, J., Agurto Rodriguez, L. \& Villaseñor Ortiz, D. 2018. Distribución espacio-temporal de la precipitación en la cuenca del río Jubones, Ecuador: 1975-2013. Scientia Agropecuaria 9: 63-70. http://dx.doi. org/10.17268/sci.agropecu.2018.01.07

Luteyn, J. 1999. Páramos: A checklist of plant diversity, geographical distribution, and botanical literature. Memoirs of the New York Botanical Garden 84. New York Botanical Garden, New York: 278 pp. https://doi. org/10.2307/4113659

Makowski, S. G, Trachte, K., Rollenbeck, R., Lehnert, L., Fuchs, J. \& Bendix, J. 2016. Atmospheric salt deposition in a tropical mountain rainforest at the eastern Andean slopes of south Ecuador - Pacific or Atlantic origin? Atmospheric Chemestry Physics 16: 10241-10261. https://doi. org/10.5194/acp-16-10241-2016

Marengo, J. A., Pabón, J. D., Díaz, A. et al. 2011. Climate change: evidence and future scenarios for the Andean Region. In: Herzog, S. K., Martínez, R., Jørgensen, P. M. \& Tiessen, H. (Eds.), Climate change and biodiversity in the Tropical Andes. Inter-American Institute for Global Change 
Research (IAI) and Scientific Committee on Problems of the Environment (SCOPE): 110-127.

Marhold, K. \& Sklenáŕ, P. 2013. Senecio imbaburensis, proposed name for Lasiocephalus sodiroi in the genus Senecio (Asteraceae). Phytotaxa 152: 59-60. http://dx.doi. org/10.11646/phytotaxa.152.1.8

Martínez, R., Ruiz, D., Andrade, M. et al. 2011. Synthesis of the climate of the Tropical Andes. In: Herzog, S. K., Martínez, R., Jørgensen, P. M. \& Tiessen, H. (Eds.), Climate change and biodiversity in the Tropical Andes. Inter-American Institute for Global Change Research (IAI) and Scientific Committee on Problems of the Environment (SCOPE): 97-109.

McArthur, R. H. \& Wilson, E. O. 1963. An equilibrium theory of insular zoogeography. Evolution 17: 373-387. https:// doi.org/10.1111/j.1558-5646.1963.tb03295.x

McMullen, C. K. 1999. Flowering plants of the Galápagos. Comstock Publishing Associates \& Cornell University Press, Ithaca and London: 384pp.

McMullen, C. K. \& Naranjo, S. J. 1994. Pollination of Scalesia baurii ssp. hopkinsii (Asteraceae) on Pinta Island. Noticias de Galápagos 53: 25-28.

MECN - INB. 2015. Plantas de los páramos del Distrito Metropolitano de Quito, Ecuador. Serie de Publicaciones del Museo Ecuatoriano de Ciencias Naturales del Instituto Nacional de Biodiversidad. Publicación Patrimonio Natural del Ecuador Nro. 2, Quito: 14-116.

Mena Vásconez, P. 2010. Los páramos ecuatorianos: Paisajes diversos, frágiles y estratégicos. AFESE 54: 97-120.

Mena Vásconez, P. \& Hofstede, R. 2006. Los páramos ecuatorianos. In: Moraes, M., Øllgaard, B., Kvist, L. P., Borchsenius, F. \& Balslev, H. (Eds.), Botánica Económica de los Andes Centrales. Universidad Mayor de San Andrés, La Paz: 91-109.

Mena Vásconez, P. \& Medina, G. 2001. La biodiversidad de los páramos del Ecuador. In: Mena, P., Medina, G. \& Hofstede, R. G. M. (Eds.), Los Páramos del Ecuador. Proyecto Páramo y Abya Yala, Quito: 23-48.

MAE [Ministerio del Ambiente del Ecuador] 2010. Aprovechamiento de los Recursos Forestales 2007 - 2009. Ministerio del Ambiente del Ecuador, Quito: 1-9.

MAE [Ministerio del Ambiente del Ecuador] 2013. Sistema de clasificación de los ecosistemas del Ecuador Continental. Subsecretaría del Patrimonio Natural, Quito: 9-206.

MAE [Ministerio del Ambiente del Ecuador] 2015. Estadisticas del patrimonio natural. Unidad de Procesamiento de Información y Geomática Sistema Nacional de Monitoreo de Patrimonio Natural, Ministerio del Ambiente, Subsecretaría de Patrimonio Natural, Sistema Único de Información Ambiental, Quito: 1-18.

MAE [Ministerio del Ambiente del Ecuador] 2016. Bosques para el Buen Vivir - Plan de Acción REDD+ Ecuador (2016-2025). Ministerio del Ambiente del Ecuador, Quito: 10-221.

Mittermeier, R. A. 1988. Primate diversity and the tropical forest. In: Wilson, E. O. \& Peter, F. M. (Eds.), Biodiversity. National Academic Press, Washington DC: 145-154.

Morillo, G. \& Briceño, B. 2000. Distribución de Asteraceae de los páramos venezolanos. Acta Botanica Venezuelica 23: 47-67.

Muller, J. 1970. Palynological evidence on early differentiation of angiosperms. Biological Reviews 45: 417-450. https://doi.org/10.1111/j.1469-185X.1970.tb01649.x
Muriel, P. M. 2008. La diversidad de ecosistemas en el Ecuador. In: Torre, L. de la, Naverrete, H., Muriel, P. M., Macía, M. J. \& Balslev, H. (Eds.), Enciclopedia de las plantas útiles del Ecuador. Herbario QCA \& Hernario AAU, Quito \& Aarhua: 28-38.

Myers, N., Mittermeier, R., Mittermeier, C., da Fonseca, G. \& Kent, J. 2000. Biodiversity hotspots for conservation priorities. Nature 403: 853-858. https://doi. org/10.1038/35002501

Neill, D. A. 1999a. Geología. In: Jørgensen, P. \& León-Yánez, S. (Eds.), Catalogue of the Vascular Plants of Ecuador. Missouri Botanical Garden. St. Louis. Retrieved December 30, 2018, from http://www.mobot.org/mobot/research/ ecuador/geologysp.shtml

Neill, D. A. 1999b. Geografía. In: Jørgensen, P. \& León-Yánez, S. (Eds.), Catalogue of the Vascular Plants of Ecuador. Missouri Botanical Garden. St. Louis.

Neill, D. A. 1999c. Paleoclimas. In: Jørgensen, P. \& León-Yánez, S. (Eds.), Catalogue of the Vascular Plants of Ecuador. Missouri Botanical Garden. St. Louis. Retrieved December 30, 2018, from http://www.mobot.org/mobot/research/ ecuador/paleoclimatessp.shtml

Neill, D. A. 2012 ¿Cuántas especies nativas de plantas vasculares hay en Ecuador? Revista Amazónica Ciencia y Tecnología 1: 70-83.

Neill, D. A. \& Ulloa Ulloa, C. 2011. Adiciones a la Flora de Ecuador: segundo suplemento, 2005-2010. Fundación Jatun Sacha. RG Grafitas, Quito: 39-41.

Nesom, G. L. 2000. Generic conspectus of the Tribe Astereae (Asteraceae) in North America and Central America, the Antilles, and Hawai (Sida, Botanical Miscellany 20). Botanical Research Institute of Texas: $100 \mathrm{pp}$.

Nesom, G. L. 2008. Classification of subtribe Conyzinae (Asteraceae: Astereae). Lundellia 11: 8-38. https://doi. org/10.25224/1097-993X-1.11.8

Niedbalai, W. \& Schatz, H. 1996. Euptyctimous mites from the Galapagos Islands, Cocos Island, and Central America (Acari: Oribatida). Genus 7: 239-317.

Nielsen, L. R. 2004. Molecular differentiation within and among island populations of the endemic plant Scalesia affinis (Asteraceae) from the Galápagos Islands. Heredity 93: 434-442. https://doi.org/10.1038/sj.hdy.6800520

Nielsen, L. R., Cowan, R. S., Siegismund, H. R., Adsersen, H., Philipp, M. \& Fay, M. F. 2003. Morphometric, AFLP and plastid microsatellite variation in populations of Scalesia divisa and S. incisa (Asteraceae) from the Galápagos Islands. Botanical Journal of the Linnean Society 143: 243 254. https://doi.org/10.1046/j.1095-8339.2003.00221.x

Nielsen, L. R., Siegismund, H. R. \& Hansen, T. 2007. Inbreeding depression in the partially self-incompatible endemic plant species Scalesia affinis (Asteraceae) from Galápagos Islands. Evolutionary Ecology 21: 1-12. https://doi. org/10.1007/s10682-006-9128-6

Nieto, A. S. 1991. Geología general del Nororiente Ecuatoriano. In: Hall, M. L. (Ed.), Los terremotos del Ecuador del 5 de marzo de 1987 (Colección "Estudios de Geografía", 9). Corporación Editora Nacional, Quito: 19-25.

Nouvelot, J. F., Goulven, P. L., Alemán, M. \& Pourrut, P. 1993. Análisis estadístico y regionalización de las precipitaciones en el Ecuador. In: Ribadeneira, H., Aleman, M., Ruf, T., Goulven, P., Sabatier, J. L., Nuñez, P. \& Nouvelot, J. F. (Eds.), Funcionamiento del riego particular en los Andes ecuatorianos: recomendaciones para el Plan Nacional de Riego: artículos publicados sobre el riego tradicional en 
los Andes del Ecuador: periodo 1987-1992. Quito (ECU); Quito: INERHI; ORSTOM: 167-204.

Novillo Espinoza, I. D., Carrillo Zenteno, M. D., Cargua Chavez, J. E., Nabel Moreira, V., Albán Solarte, K. E. \& Morales Intriago, F. L. 2018. Propiedades físicas del suelo en diferentes sistemas agrícolas en la provincia de Los Ríos, Ecuador. Temas Agrarios 23: 177-187. https://doi. org/10.21897/rta.v23i2.1301

Ojeda-Luna, T., Eguiguren, P. \& Aguirre, N. 2015. El cambio climático y la conservación de la biodiversidad en el Ecuador. In: Aguirre, N., Ojeda-Luna, T., Eguiguren, P. \& Aguirre-Mendoza, Z. (Eds.), Cambio climático y biodiversidad: Estudio de caso de los páramos del Parque Nacional Podocarpus, Ecuador. Programa de biodiversidad y Servicios Ecosistémicos, Universidad Nacional de Loja, Loja: 19-42.

Oliveira Amorim, V. \& Pousada Bautista, H. 2016. Asteraceae da Ecorregião Raso da Catarina, Bahia, Brasil. Rodriguésia 67: 785-794. http://dx.doi.org/10.1590/21757860201667317.

Ono, M. 1967. Chromosome number of Scalesia (Compositae), an endemic genus of the Galapagos Islands. Journal of Japanese Botany 42: 353-360.

Ornduff, R. 1969. Neotropical Nymphoides (Menyanthaceae): Meso-American and West Indian Species. Brittonia 21: 346-352. https://doi.org/10.2307/2805761

Pacurucu Reyes, A., Chiluiza Ramos, P., Abdo López, S. \& Huilcapi López, I. 2015. Estudio de la diversidad florística del páramo de la comunidad de Guangopud, provincial de Chimborazo, Ecuador. Perspectiva 16: 75-82.

Panero, J. L. \& Crozier, B. S. 2016. Macroevolutionary dynamics in the early diversification of Asteraceae. Molecular Phylogenetics and Evolution 99: 116-132. https://doi. org/10.1016/j.ympev.2016.03.007

Panero, J. L., Freire, S. E., Ariza Espinar, L., Crozier, B. S., Barboza, G. E. \& Cantero, J. L. 2014. Resolution of deep nodes yields an improved backbone phylogeny and a new basal lineage to study early evolution of Asteraceae. Molecular Phylogenetics and Evolution 80: 43-53. https://doi. org/10.1016/j.ympev.2014.07.012

Panero, J. L. \& Funk, V. A. 2008. The value of sampling anomalous taxa in phylogenetic studies: major clades of the Asteraceae revealed. Molecular Phylogenetics and Evolution 47: 757-782. https://doi.org/10.1016/j.ympev.2008.02.011

Panero, J. L., Jansen, R. K. \& Clevinger, J. A. 1999. Phylogenetic relationships of subtribe Ecliptinae (Asteraceae: Heliantheae) based on chloroplast DNA restriction site data. American Journal of Botany 86: 413-427. https://doi. org/10.2307/2656762

Pasini, E., Funk, V. A., de Souza-Chies, T. T. \& Miotto, S. T. S. 2016. New insights into the phylogeny and biogeography of the Gerbera-Complex (Asteraceae: Mutisieae). Taxon 65: 547-562. https://doi.org/10.12705/653.7

Pelser, P. B., Kennedy, A. H., Tepe, E. J., Shidler, J. B., Nordenstam, B., Kadereit, J. W. \& Watson, L. E. 2010. Patterns and causes of incongruence between plastid and nuclear Senecioneae (Asteraceae) phylogenies. American Journal of Botany 97: 856-873. http://dx.doi.org/10.3732/ ajb.0900287

Pelser, P. B., Nordenstam, B., Kadereit, J. W. \& Watson, L. E. 2007. An ITS phylogeny of tribe Senecioneae (Asteraceae) and a new delimitation of Senecio L. Taxon 56: 1077-1104. https://doi.org/10.2307/25065905

Pennington, T. \& Lavin, M. 2017. Dispersal, isolation and diversification with continued gene flow in an Andean tropical dry forest. Molecular Ecology 26: 3327-3329. https://doi. org $/ 10.1111 / \mathrm{mec} .14182$

Peralta, J., Delgado, E. \& Sosa, I. 2016. Análisis y evaluación de la información meteorológica disponible para la prospección del recurso eólico en el perfil costero Ecuatoriano. XXI Congreso Nacional de Ingeniería Mecánica, Asociación Española de Ingeniería Mecánica: 1647-1654.

Philipp, M., Hansen, L. B., Adsersen, H. \& Siegismund, H. R. 2004. Reproductive ecology of the endemic Lecocarpus pinnatifidus (Asteraceae) in an isolated population in the Galápagos Islands. Botantical Journal of the Linnean Society 146: 171-180. https://doi.org/10.1111/j.1095-8339.2004.00323.x

Philipp, M. \& Nielsen, L. R. 2010. Reproductive ecology of Scalesia cordata (Asteraceae), an endangered species from the Galápagos Islands. Botanical Journal of the Linnean Society 162: 496-503. https://doi.org/10.1111/j.10958339.2010.01034.x

Pilatasig, L., Gordon, D., Palacios, O. \& Sánchez, J. 2005. Geología de Ecuador y Perú entre $3^{\circ} \mathrm{S}$ y $6^{\circ} \mathrm{S}$. Proyecto multinacional andino: geociencias para las comunidades andinas Ecuador-Perú-Canadá. DINAGE-INGEMMET, Ecuador: 1-78.

Pillon, Y. \& Buerki, S. 2017. How old are island endemics? Biological Journal of the Linnean Society 121: 469-474. https://doi.org/10.1093/biolinnean/blx005

Podwojewski, P. 1999. Los suelos de las altas tierras andinas: los páramos del Ecuador. Sociedad Ecuatoriana de la Ciencia del Suelo 18: 9-14.

Podwojewski, P. \& Poulenard, J. 2000. Los suelos de los páramos del Ecuador. In: Mena, P. A., Josse, C. \& Medina G. (Eds.), Los suelos del páramo (Serie Páramo, 5). GTP/ Abya Yala, Quito: 5-22.

Pourrut, P. 1986. Algunas consideraciones acerca de los fenómenos climáticos extremos observados en el Ecuador. Actas del coloquio "Ecuador 1986". Cultura: Revista del Banco Central de Ecuador 8: 257-272.

Pourrut, P., Gómez, G., Bermeo, A. \& Segovia, A. 1995. Factores condicionantes de los regímens climáticos e hidrológicos. In: Pourrut, P. (Eds.), El agua en el Ecuador: clima, precipitaciones, escorrentía. Corporación Editora Nacional, Colegio de Geógrafos del Ecuador. ORSTOM 7: 7-12.

Prance, G. T. 1994. A comparison of the efficacy of higher taxa and species numbers in the assessment of biodiversity in the neotropics. Philosophical Transactions of the Royal Society B. 345: 89-99. https://doi.org/10.1098/rstb.1994.0090

Pressey, R. L., Humphries, C. J., Margules, C. R., Vane-Wright, R. I. \& Williams, P. H. 1993. Beyond opportunism: key principles for systematic reserve selection. Trends in Ecology and Evolution 8: 124-128. https://doi.org/10.1016/01695347(93)90023-I

Pruski, J. F. 2005. Studies of neotropical compositae-i. Novelties in Calea, Clibadium, Conyza, Llerasia, and Pluchea. SIDA 21: 2023-2037.

Pruski, J. F. 2010. Flora del Río Cenepa, Amazonas, Perú: Asteraceae Bercht. \& J. Presl (Compositae Giseke, nom. alt. et cons.) (Monographs in Systematic Botany from the Missouri Botanical Garden, 114). Missouri Botanical Garden, St. Louis: 339-420, f. 84-90.

Pruski, J. F. \& Robinson, H. 2018. Asteraceae. 5(2): i-xix, 1-608. In: Davidse, G., Sousa Sánchez, M., Knapp, S. \& Chiang Cabrera, F. (Eds.), Flora Mesoamericana. Missouri Botanical Garden, St. Louis.

Ramírez-Padilla, B. R., Macías-Pinto, D. J. \& Varona-Balcazar, G. 2015. Lista comentada de plantas vasculares del 
valle seco del río Patía, suroccidente de Colombia. Biota Colombiana 16: 1-50.

Ramsay, P. \& Oxley, P. 1997. The growth form composition of plant communities in the Ecuadorian paramos. Plant Ecology 131: 173-192. https://doi. org/10.1023/A:1009796224479

Richter, M. \& Moreira-Muñoz, A. 2005. Heterogeneidad climática y diversidad vegetacional en el sur de Ecuador: un método de fitoindicación. Revista Peruana de Biología 12: 217-238. https://doi.org/10.15381/rpb.v12i2.2395

Riofrío, D., Alvaracín, M., Soria, A. \& Benavides, K. 2017. Boletín de estadísticas turísticas 2012-2016. Ministerio de Turismo del Ecuador, Quito: 3-178.

Rivero-Guerra, A. O. 2008. Cytogenetics, biogeography and biology of Santolina ageratifolia Barnades ex Asso (Asteraceae: Anthemideae). Botanical Journal of the Linnean Society 157: 797-807. https://doi.org/10.1111/j.10958339.2008.00821.x

Rivero-Guerra, A. O. 2009. Cytogenetics, geographical distribution, pollen stainability and fecundity of five taxa of Santolina rosmarinifolia L. aggregate (Asteraceae: Anthemideae). Plant Systematics and Evolution 281: 17-34. https:// doi.org/10.1007/s00606-009-0180-x

Rivero-Guerra, A. O. \& Laurin, M. 2012. Phylogenetic analysis of the Santolina rosmarinifolia L. aggregate (Asteraceae: Anthemideae: Santolininae) based on morphological characteristics. Nordic Journal of Botany 30: 533-545. https://doi.org/10.1111/j.1756-1051.2011.01382.x

Robinson, B. L. 1907. New or otherwise noteworthy spermatophytes chiefly from Mexico. Proceedings of the American Academy of Arts and Sciences 43: 21-48. https://doi. org/10.2307/20022300

Robinson, H. 1999. Generic and subtribal classification of American Vernonieae. Smithsonian Contributions to Botany 89: i-iii, 1-116. https://doi.org/10.5962/bhl.title.103697

Robinson, H. 2002. Three new species of Piptocarpha (Asteraceae: Vernonieae) from Ecuador and Peru. Novon 12: 393-398. https://doi.org/10.2307/3393087

Robinson, H. \& Cuatrecasas, J. 1993. New species of Pentacalia (Senecioneae: Asteraceae) from Ecuador, Peru, and Bolivia. Novon 3: 284-301. http://dx.doi.org/10.2307/3391473

Robinson, H. \& Funk, V. A. 2012. Cuatrecasanthus (Vernonieae, Compositae): A revision of a north-central Andean genus. PhytoKeys 14: 23-41. https://doi.org/10.3897/ phytokeys. 14.2520

Rodríguez, E. F., Vásquez, R., Rojas, R., Calatayud, G., León, B. \& Campos, J. 2006. Nuevas adiciones de angiospermas a la flora del Perú. Revista Peruana de Biología 13: 129-138. https://doi.org/10.15381/rpb.v13i1.1776

Rodríguez, R., Tigmasa, N., García, K., Pazmiño, R. \& Renzo, C. 2017. Espeletia pycnophylla subsp. angelensis, el ángel del norte. Bionatura 2: 273-276.

Rodríguez-Peces, M. J. \& Gordón-Pérez, D. 2015. Análisis automático de la susceptibilidad de las inestabilidades de laderas provocadas por terremotos en un sector de la Cordillera de los Andes, Ecuador. Revista de la Sociedad Geológica de España 28: 91-104.

Rodríguez-Rodríguez, E. F., David Neill, D., Alvítez-Izquierdo, E., Arroyo Alfaro, S. J. \& Núñez-Zapata, J. A. 2013. Estado actual de los estudios de la flora en la Cordillera del Cóndor y áreas adyacentes en el Perú, 2006. Sagasteguiana 1: $101-120$

Roque, N., de Oliveira, E. C., Moura, L. et al. 2016. Asteraceae no Município de Mucugê, Chapada Diamantina,
Bahia, Brasil. Rodriguésia 67: 125-202. http://dx.doi. org/10.1590/2175-7860201667109.

Royo-Márquez, M. H., Melgoza-Castillo, A. \& Quintana-Martínez, G. 2013. Especies vegetales en peligro, su distribución y estatus de conservación de los ecosistemas donde se presentan. Revista Mexicana de Ciencias Forestales 5: 86-103. https://doi.org/10.29298/rmcf.v5i22.352

Rull, V. 2011. Origins of biodiversity. Science 331: 398-399. https://doi.org/10.1371/journal.pbio.2000724

Rzedowski, J. 1991. Diversidad y orígenes de la flora fanerogámica de México. Acta Botanica Mexicana 14: 3-21. https://doi.org/10.21829/abm14.1991.611

Saavedra, K. I., Rojas, C. \& Delgado, G. E. 2013. Características polínicas y composición química del polen apícola colectado en Cayaltí (Lambayeque - Perú). Revista Chilena de Nutrición 40: 71-78. http://dx.doi.org/10.4067/S071775182013000100011

Salazar, D., Cuichán, M., Ballesteros, C., Márquez, J. \& Orbe, D. 2017. Encuesta de Superficie y Producción Agropecuaria Continua 2017. Unidad de estadísticas agropecuarias ESAG. Instituto Nacional de Estadísticas y Censos, Quito: $1-22$.

Salgado-Labouriau, M. L. 1982. Pollen morphology of the Compositae of the Northern Andes. Pollen and Spores 24: 397-452.

Salomón, L., Sklenáŕ, P. \& Freire, S. E. 2018. Synopsis of Senecio series Culcitium (Asteraceae: Senecioneae, Senecioninae) in the Andean region of South America. Phytotaxa 340: 1-47. http://dx.doi.org/10.11646/phytotaxa.340.1.1

Samaniego-Rojas, N., Eguiguren, P., Maita, J. \& Aguirre, N. 2015. Clima de la Región Sur de Ecuador: historia y tendencias. In: Aguirre, N., Ojeda Luna, T., Eguiguren, P. \& Aguirre Mendoza, Z. (Eds.), Cambio climático y biodiversidad: estudio de caso de los páramos del Parque Nacional Podocarpus, Ecuador. Programa de Biodiversidad y Servicios Ecosistémicos, Universidad Nacional de Loja, Loja: 43-63.

Sánchez-Chávez, E., Rodríguez, A., Castro-Castro, A., PérezFarrerad, M. A. \& Sosa, V. 2019. Spatio-temporal evolution of climbing habit in the Dahlia-Hidalgoa group (Coreopsidae, Asteraceae). Molecular Phylogenetics and Evolution 135: 166-176. https://doi.org/10.1016/j.ympev.2019.03.012

Schiavinato, D. J., Gutiérrez, D. G. \& Bartoli, A. 2017. Typifications and nomenclatural clarifications in South American Tagetes (Asteraceae, Tageteae). Phytotaxa 326: 175-188. http://dx.doi.org/10.11646/phytotaxa.326.3.2

Schilling, E. E. \& Panero, J. L. 2002. A revised classification of subtribe Helianthinae (Asteraceae: Heliantheae). I. Basal lineages. Botanical Journal of the Linnean Society 140: 65-76. https://doi.org/10.1046/j.1095-8339.2002.00079.x

Schilling, E. E. \& Panero, J. L. 2011. A revised classification of subtribe Helianthinae (Asteraceae: Heliantheae) II. Derived lineages. Botanical Journal of the Linnean Society 167: 311-331. https://doi.org/10.1111/j.10958339.2011.01172x

Schilling, E. E., Panero, J. L. \& Eliasson, U. H. 1994. Evidence from chloroplast DNA restriction site analysis on the relationships of Scalesia (Asteraceae: Heliantheae). American Journal of Botany 81: 148-254. https://doi. org $/ 10.2307 / 2445640$

Schutz, C. H. 1856. Flora of North-Western Mexico. In: Seemann, B. (Eds.), The Botany of the voyage of H. M. S. Herald. Lovell Reeve, London: 309. 
Serrano Giné, D. \& Galárraga Sánchez, R. 2015. El páramo andino: características territoriales y estado ambiental. Aportes interdisciplinarios para su conocimiento. Estudios Geográficos LXXV: 369-393. https://doi.org/10.3989/estgeogr.201513

Serrano Vicenti, S., Ruiz, J. C. \& Bersosa, F. 2017. Heavy rainfall and temperature proyections in a climate change scenario over Quito, Ecuador. La Granja, Revista de Ciencias de la Vida 25:16-32. https://doi.org/10.17163/lgr.n25.2017.02

Serrano Vincenti, S., Zuleta, D., Moscoso, V., Jácome, P., Palacios, E. \& Villacís, M. 2012. Análisis estadístico de datos meteorológicos mensuales y diarios para la determinación de variabilidad climática y cambio climático en el Distrito Metropolitano de Quito. La Granja, Revista de Ciencias de la Vida 16: 23-47. https://doi.org/10.17163/lgr.n16.2012.03

Sklenáŕ, P. \& Robinson, H. 2000. Two new species in Oritrophium and Floscaldasia (Asteraceae: Astereae) from the High Andes of Ecuador. Novon 10: 144-148. http://dx.doi. org/10.2307/3393015

Smith, A. \& Young, T. 1987. Tropical Alpine Plant Ecology. Annual Review of Ecology and Systematics 18: 137-158. https://doi.org/10.1146/annurev.es.18.110187.001033

Snell, H. L., Snell, H. M., Stone, P. A., Altamirano, M., Mauchamp, M. A. \& Aldáz, I. 1995. La diversidad biológica de las Islas Galápagos. I. Análisis de la flora. USAID, Quito: $1-10$.

Sønderberg Brok, C. \& Andersen, H. 2007. Morphological variation among populations of Lecocarpus (Asteraceae) on the Galápagos Islands. Botanical Journal of the Linnean Society 154: 523-544. https://doi.org/10.1111/j.10958339.2007.00677.x

Stuessy, T. F., Blöch, C., Villaseñor, J. L., Rebernig, C. A. \& Weiss-Schneeweiss, H. 2011. Phylogenetic analyses of DNA sequences with chromosomal and morphological data confirm and refine sectional and series classification within Melampodium (Asteraceae, Millerieae). Taxon 60: 436-449. https://doi.org/10.1002/tax.602013

Stuessy, T. F., König, C. \& López Sepúlveda, P. 2014. Paraphyly and endemic genera of oceanic islands: implications for conservation. Annals of Missouri Botanical Garden 100: 50-78. https://doi.org/10.3417/2012087

Stuessy, T. F., Sang, T. \& DeVore, M. L. 1996. Phylogeny and biogeography of the subfamily Barnadesioideae with implications for early evolution of the Compositae. In: Hind, D. J. N. \& Beentje, H. J. (Eds.), Compositae: Systematics. Proceedings of the International Compositae Conference, Kew, 1994, 1: 463-490.

Suárez Duque, D., Acurio, C., Chimbolema, S. \& Aguirre, X. 2016. Análisis del carbono secuestrado en humedales altoandinos de dos áreas protegidas del ecuador. Ecología Aplicada 15: 171-177. http://dx.doi.org/10.21704/rea. v15i2.756

Suárez-Mota, M. E. \& Villaseñor, J. L. 2011. Las compuestas endémicas de Oaxaca, México: diversidad y distribución. Boletín de la Sociedad Botánica de México 88: 55-66. http://dx.doi.org/10.17129/botsci.308

Sundberg, S., Cowan, C. P. \& Turner, B. L. 1986. Chromosome counts of Latin American Compositae. American Journal of Botany 73: 33-38. http://dx.doi.org/10.2307/2442300

Takayama, K., Crawford, D. J., López-Sepúlveda, P., Greimler, J. \& Stuessy, T. F. 2018. Factors driving adaptive radiation in plants of oceanic islands: a case study from the Juan Fernández Archipelago. Journal of Plant Research 131: 469-485. https://doi.org/10.1007/s10265-018-1023-z
Tiessen, H. 2011. Introduction. In: Herzog, S. K., Martínez, R., Jørgensen, P. M. \& Tiessen, H. (Eds.), Climate Change and Biodiversity in the Tropical Andes. Inter-American Institute for Global Change Research (IAI) and Scientific Committee on Problems of the Environment (SCOPE): 9-11.

Torres, A. M. 1968. Revision of Jaegeria (Compositae-Heliantheae). Brittonia 20: 53-73. https://doi. org/10.2307/2805461

Turetsky, M. R., Manning, S. W. \& Wieder, K. 2004. Dating recent peat deposits. Wetlands 24: 324-356. https://doi. org/10.1672/0277-5212(2004)024[0324:DRPD]2.0.CO;2

Turner, B. L. 1988. Taxonomic study of Chrysanthellum (Asteraceae) Coreopsideae. Phytologia 64: 410-444. https://doi. org/10.5962/bhl.part.29749

Tye, A. 2010. The Galápagos endemic Darwiniothamnus alternifolius (Asteraceae, Astereae) transferred to Erigeron. Novon 20: 111-112. https://doi.org/10.3417/2008081

Ulloa Ulloa, C. \& Neill, D. A. 2005. Cinco años de adiciones a la Flora de Ecuador 1999-2004. Missouri Botanical Garden, Universidad Técnica Particular de Loja y Funbotánica, Loja: 11-13.

Ulloa Ulloa, C., Zarucchi, J. L. \& León, B. 2004. Diez años de adiciones a la Flora del Perú: 1993-2003. Arnaldoa Edición Especial Noviembre: 1-242. https://doi.org/10.5962/bhl. title. 63538

Ulloa Ulloa, C., Acevedo-Rodríguez, P., Beck, S., Belgrano, M. J., Bernal, R., Berry, P. E., Brako, L. et al. 2017. An integrated assessment of the vascular plant species of the Americas. Science 358: 1614-1617. https://doi.org/10.1126/ science.aao0398

Urdiales, D. \& Célleri, R. 2018. Pronóstico de la ocurrencia de precipitación diaria en un gradiente altitudinal en el Sur del Ecuador, mediante un generador climático. Enfoque UTE 9: 29-41. https://doi.org/10.29019/enfoqueute. v9n3.209

Urtubey, E. 1999. Revisión del género Barnadesia (Asteraceae: Barnadesioideae, Barnadesieae). Annals of the Missouri Botanical Garden 86: 57-117. https://doi. org $/ 10.2307 / 2666218$

Urtubey, E., López, A., Chemisquy, M. A. et al. 2016. New circumscription of the genus Gamochaeta (Asteraceae, Gnaphalieae) inferred from nuclear and plastid DNA sequences. Plant Systematics and Evolution 302:1047-1066. https://doi.org/10.1007/s00606-016-1316-4

Vallejo, C., Winkler, W., Spikings, R. \& Luzieux, L. 2009. Evolución geodinámica de la Cordillera Occidental (Cretácico tardío-Paleógeno). Revista Politécnica 30: 112-130.

Van der Hammen, T. 1974. The Pleistocene changes of vegetation and climate in tropical South America. Journal of Biogeography 1: 3-26. https://doi.org/10.2307/3038066

Vargas, O. M. 2011. A nomenclator of Diplostephium (Asteraceae: Astereae): a list of species with their synonyms and distribution by country. Lundellia 14: 32-51. https://doi. org/10.25224/1097-993X-14.1.32

Vargas, O. M. 2018. Reinstatement of the genus Piofontia: A Pphylogenomic-based study reveals the biphyletic nature of Diplostephium (Asteraceae: Astereae). Systematic Botany 43: 485-496. https://doi. org/10.1600/036364418X697210

Vargas, O. M., Ortiz, E. M. \& Simpson, B. B. 2017. Conflicting phylogenomic signals reveal a pattern of reticulate evolution in a recent high-Andean diversification (Asteraceae: Astereae: Diplostephium). New Phytologist 214: 1736-1750. https://doi.org/10.1111/nph.14530 
Vargas, P., Heleno, R., Traveset, A. \& Nogales, M. 2012. Colonization of the Galápagos Islands by plants with no specific syndromes for long-distance dispersal: a new perspective. Ecography 35: 33-43. https://doi.org/10.1111/j.16000587.2011.06980.x

Velásquez, C. A. \& Rangel, J. O. 1995. Atlas palinológico de la flora vascular del páramo I. Las familias más ricas en especies. Caldasia 17: 509-568. https://doi.org/10.15446/caldasia

Vera, R. 2004. Perfiles por país del recurso pastura/forraje: Ecuador. FAO, Roma: 8-9.

Vergara, W., Ríos, A. R., Galindo, L. M., Gutman, P., Isbell, P., Suding, P. H. \& Samaniego, J. L. 2014. El desafío climático y desarrollo en América Latina y el Caribe. Opciones para un desarrollo resiliente al clima y bajo en carbono. Banco Interamericano de Desarrollo, Nigeria: 19-37.

Villaseñor J. L. \& Ortiz, E. 2007. La familia Asteraceae. In: Luna, I., Morrone, J. J. \& Espinosa, D. (Eds.), Biodiversidad de la Faja Volcánica Transmexicana. Universidad Nacional Autónoma de México, Ciudad de México: 289-310.

Villaseñor, J. L. \& Ortiz, E. 2012. La familia Asteraceae en la Flora del Bajío y de regiones adyacentes. Acta Botanica Mexicana 100: 259-291. https://doi.org/10.21829/ abm 100.2012 .37

Wagner, W. L. \& Robinson, H. 2001. Lipochaeta and Melanthera (Asteraceae: Heliantheae subtribe Ecliptinae): establishing their natural limits and a synopsis. Brittonia 53: 539-561. https://doi.org/10.1007/BF02809655

Wagner, W. L., Weller, S. \& Sakai, A. 1995. Phylogeny and biogeography in Schiedea and Alsinidendron (Caryophyllaceae). In: Funk, V. A. \& Wagner, W. L. (Eds.), Hawaiian biogeography: evolution on a hot spot archipelago. Smithsonian Institution Press, Washington DC: 221-258.

Weigend, M., Rodríguez, E. F. \& Arana, C. 2005. The relict forests of Northwest Peru and Southwest Ecuador. Revista Peruana de Biología 12: 185-194. https://doi.org/10.15381/ rpb.v12i2.2390

Wiggins, L. \& Porter, D. M. 1971. Flora of the Galápagos Islands. Stanford Univeristy Press, Stanford, California: 1020 pp. https://doi.org/10.2307/1219253
Xu, X., Zheng, W., Funk, V. A. \& Wen, J. 2018. Home at Last II: Gerbera hieracioides (Kunth) Zardini (Mutisieae, Asteraceae) is really a Chaptalia. PhytoKeys 95: 93-106. https://doi.org/10.3897/phytokeys.95.22916

Yánez, M. P, Núñez, M., Carrera, F. \& Martínez, C. 2011. Posibles efectos del cambio climático global en zonas silvestres protegidas de la zona andina de Ecuador. LA GRANJA. Revista de Ciencias de la Vida 14: 24-44. https://doi. org/10.17163/lgr.n14.2011.03

Young, K. 2011. Introduction to Andean geographies. In: Herzog, S. K., Martínez, R., Jørgensen, P. M. \& Tiessen, H. (Eds.), Climate Change and Biodiversity in the Tropical Andes. Inter-American Institute for Global Change Research (IAI) and Scientific Committee on Problems of the Environment (SCOPE): 128-140.

Zebrowski, C. \& Sourdatl, M. 1997. Los factores de la pedogénesis y los suelos en Ecuador. In: Winckell, A., Marocco, R., Winter, T., Huttel, C., Pourrut, P., Zebrowski, C. \& Sourdat, M. (Eds.), Los paisajes naturales del Ecuador, 4. Condiciones generales del medio natural. Centro Ecuatoriano de Investigaciones Geográficas (CEDIG)-IPGH (Sección Ecuador) - ORSTOM (Francia) - IGM, Quito, Ecuador: 97-129.

Zunino, M. \& Zullini A. 2003. Biogeografia: La dimensión especial de la evolución. Fondo de Cultura Económica, México: 359 pp.

Zurita, F. 1988. Origin and geological setting of the Galápagos Islands. In: Gaines, A. G. \& Moreno Andrade, J. (Eds.), Scientific Research and the Galápagos Marine Resources Reserve. Woods Hole Oceanographic Institution: 46-53. http://dx.doi.org/10.1575/1912/961

\section{APÉNDICES}

Los Apéndices 1 al 6, debido a su tamaño, están disponibles para descarga online en la versión HTML del artículo. 